CONDIÇÕES EDÁFICAS QUE AFETAM O MICOTROFISMO DE Stylosanthes guianensis (AUBL.) SW.

\title{
MARCIO RODRIGUES LAMBAIS
}

Engenheiro Agrônomo

Orientadora: Profa Drä. Elke J.B.N.Cardoso

Dissertação apresentada à Escola Superior de Agricultura "Luiz de Queiroz" da Universidade de São Paulo, para obtenção do título de Mestre em Agronomia. Área de Concentração: Microbiologia Agrí cola.

\author{
PIRACICABA \\ Estado de São Paulo - Brasil \\ Novembro, 1987
}


À Sandra, por seu estímulo e sua compreensão.

Ao meu filho Guilherme.

A minha avó e minha mãe pelas oportunidades criadas.

DEDICO. 


\section{AGRADECIMENTOS}

À Profa Dra Elke J.B.N. Cardoso, por sua orientação e sua grande amizade;

Ao Departamento de Solos, Geologia e Fertilizantes e seus docentes pelos ensinamentos;

Ao Conselho Nacional de Desenvolvimento Científico e Tecnológico pela cessão da bolsa;

Aos colegas do Curso de Pós-graduação em Microbiologia Agricola pela colaboração e sugestões;

Ao Dr. Paulo Bardauil, do Instituto de Zootecnia, pelas sementes;

Ao Dr. Francisco Krug, da Seção de Radioquímica do CENA, pela análise química das plantas;

Ao Dr. Antonio Roque Dechen e Dr. Quirino A. de C. Car mello do Departamento de Química da ESALQ pela análise de micronutrientes do solo;

Ao Dr. Paulo Sodero Martins pela discussão;

Ao Dr. J.M. Barea pelas sugestões e discussão;

À Dra Tsai S.M. Saito, da Seção de Microbiologia do So 10 do CENA, pela cessão do microcomputador;

A todos aqueles que de alguma maneira contribuiram para a realização deste trabalho. 
LISTA DE TABELAS $\ldots \ldots \ldots \ldots \ldots \ldots \ldots \ldots \ldots \ldots$

LISTA DE FIGURAS $\ldots \ldots \ldots \ldots \ldots \ldots \ldots \ldots \ldots \ldots \ldots$

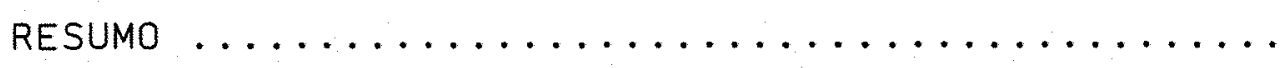

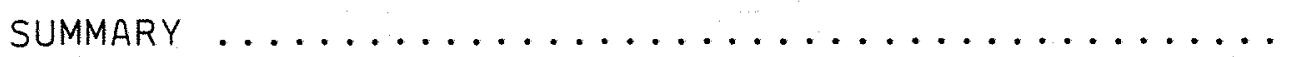

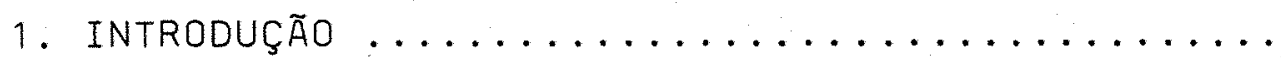

2. Revisão de literatura $\ldots \ldots \ldots \ldots \ldots \ldots \ldots \ldots \ldots$

2.1. Definição e conceito de micorrizas ....... 3

2.2. As micorrizas vesiculo-arbusculares: forma ção e desenvolvimento ............... 4

2.3. Fatores que afetam as micorrizas vesículo-

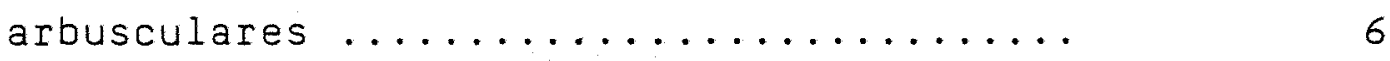

2.3 .1 . Fatores quimicos $\ldots \ldots \ldots \ldots \ldots \ldots \ldots$

$2.3 .1 .1 . \mathrm{pH} \ldots \ldots \ldots \ldots \ldots \ldots \ldots \ldots, 6$

2.3.1.2. Disponibilidade de fósforo e nitrogênio ............

2.3.1.3. Disponibilidade de outros nutrientes ..............

2.3 .1 .4 . Disponibilidade de alumi nio ............... 15

2.3.2. Fatores fisicos ............. 17

2.3.3. Fatores biológicos ............ 18

2.4. O efeito das MVA na absorção de nutrientes 18

2.5. Micorrizas vesiculo-arbusculares em Stylosanthes ..................... 21

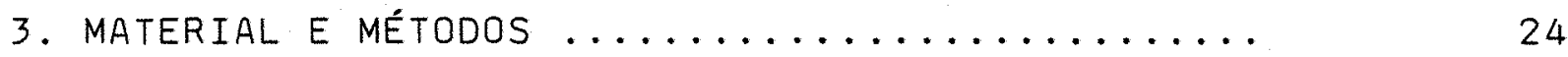

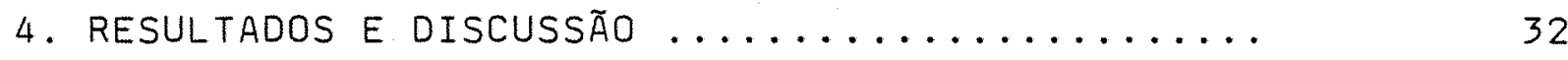

4.1. Experimento 1-Efeito da calagem em um solo ácido na germinação de esporos de fungos micorrízicos vesículo-arbusculares ... 
4.2. Experimento 2 - Efeito da calagem em um solo ácido no desenvolvimento de micorrizas vesiculo-arbusculares em Stylosanthes guia-

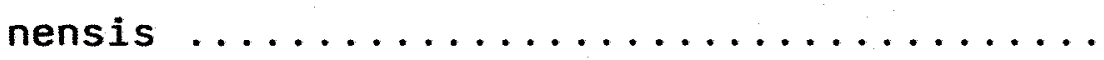

4.2.1. Desenvolvimento da colonização micor

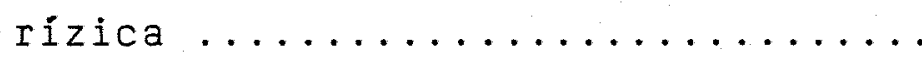

4.2.2. Desenvolvimento vegetativo de S.guia

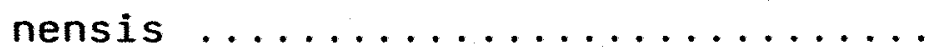

4.2.2.1. Desenvolvimento da parte aé

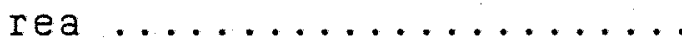

4.2.2.2. Desenvolvimento do sistema

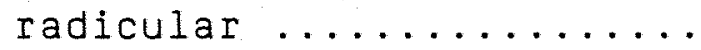

4.2.2.3. Relação entre parte aérea e sistema radicular .........

4.2.3. Absorção de nutrientes .......... 72

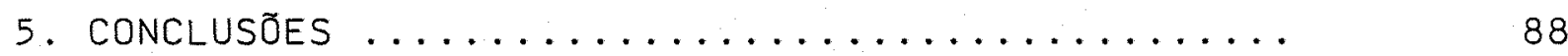

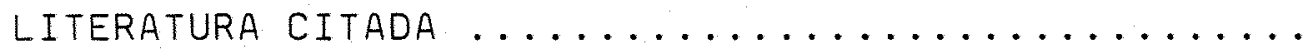


LISTA DE TABELAS

Página

1 - Análise química do solo utilizado nos experimentos, após correção da fertilidade ............

2 - Efeito da calagem em um solo ácido na germinação de esporos de fungos micorrizicos vesículo-arbus

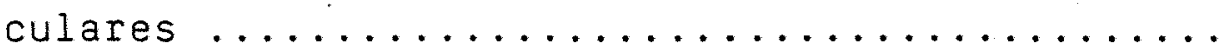

3 - Valores de $F$ obtidos na análise de variância da percentagem de germinação de esporos ..........

4 - Efeito de diferentes niveis de fósforo e de calcá rio na germinação de esporos de fungos micorrizi

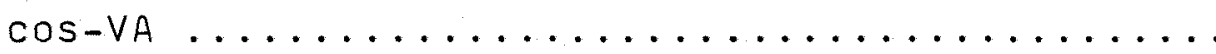

5 - Coeficientes de correlação linear entre percenta gem de germinação de esporos de fungos micorrizí cos-VA e propriedades químicas do solo ........

6 - Efeito da calagem e do nivel de fósforo no solo na colonização micorrízica de Stylosanthes guia-

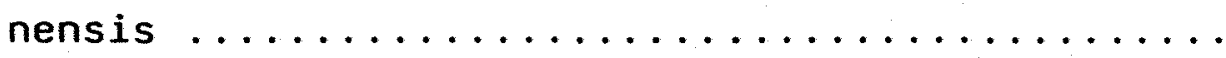

7 - Valores f obtidos na análise de variância de al-

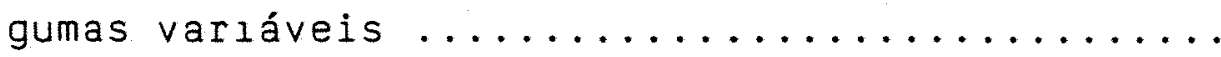

8 - Efeitos de diferentes associações micorrízicas vesiculo-arbusculares sobre algumas variáveis ana

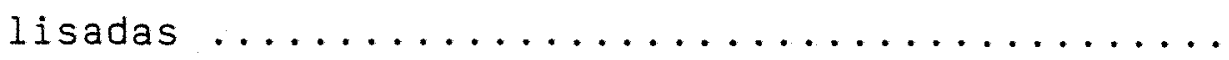


9 - Efeitos da calagem em um solo ácido sobre algu-

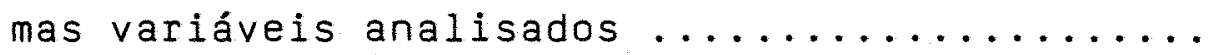

10 - Efeito da calagem em um solo ácido na colonização de raízes de $S$. guianensis por diferentes fungos micorrizicos- VA ................

11 - Efeitos do nivel de fósforo no solo sobre algu-

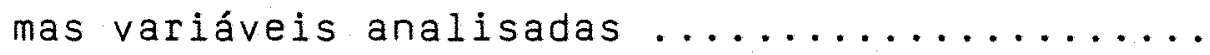

12 - Efeito do nivel de fósforo de um solo ácido sobre a colonização micorrízica em $\mathrm{S}$. guianensis.

13 - Variação percentual da colonização das raizes e da germinação dos esporos no solo com diferen tes níveis de calcário, em relação ao solo sem

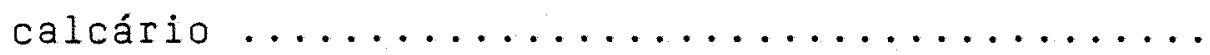

14 - Coeficientes de correlação entre a percentagem de germinação dos esporos e a percentagem de co

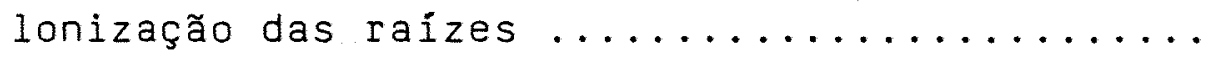

15 - Coeficientes de correlação linear entre percentagem de colonização das raizes aos 40 e 80 dias e as propriedades químicas do solo ...........

16 - Variação da produção de matéria seca da parte aé rea de 5. guianensis em um solo ácido com diferentes niveis de calcário e de $P$, diferentes associações MVA, e em diferentes épocas de colhei

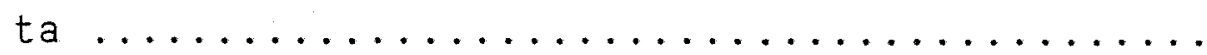


17 - Variação percentual média $(\Delta \%)$ da produção de matéria seca da parte aérea por $S$. guianensis, em relação ao controle não inoculado de cada

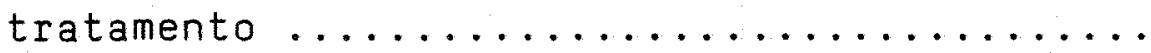

18 - Variação da matéria fresca do sistema radicular de S. guianensis en um solo ácido com diferentes niveis de calcário e de $P$, diferentes associações MVA, e em diferentes épocas de co

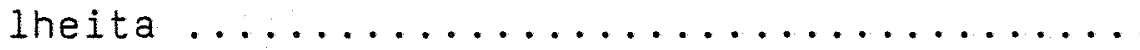

19 - Efeito da calagem em um solo ácido no desen volvimento do sistema radicular de $S$. guianen sis associado a diferentes fungos micorrizi -

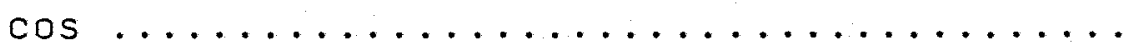

20 - Efeitos da calagem, doses de fósforo e inocu lação com fungos MVA na absorção de nutrien-

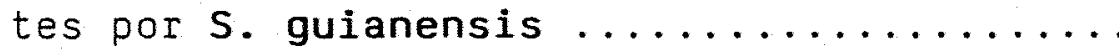

21 - Valores de $F$ obtidos na análise de variância da concentração e quantidade total de nutrientes na parte aérea de $S$. guianensis, nos

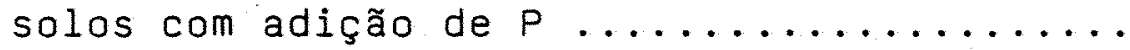

22 - Médias da concentração e quantidade total de nutrientes na parte aérea de $S$. guianensis para o fator FUNGo, nos solos sem adição de

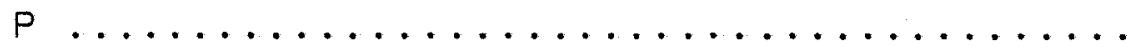


23 - Médias da concentração e quantidade total de nutrientes na parte aérea de $\mathrm{S}$. guianensis para o fator FUNGO, nos solos com adição de $P$..

24 - Variação percentual da concentração e quantida de total de nutrientes na parte aérea de $S$. guianensis com diferentes associações MVA, em relação ao controle não inoculado, nos solos

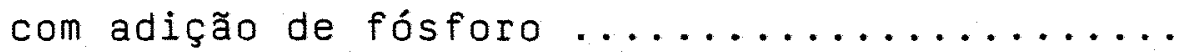

25 - Relação entre a concentração de nutrientes na

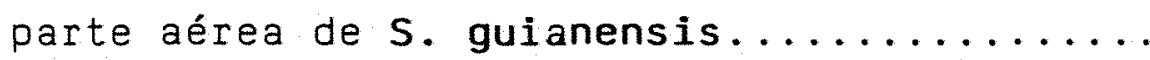


1 - Variação da percentagem de germinação de esporos para diferentes espécies de fungos micor-

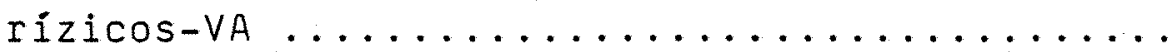

2 - Variação da percentagem de germinação de esporos de fungos micorrízicos VA em um solo ácido com diferentes niveis de calcário ..........

3 - Efeito de diferentes níveis de fósforo na germinação de esporos de Glomus macrocarpum, Acau lospora scrobiculata e Gigaspora margarita...

4 - Efeito de diferentes niveis de calcário na germinação de esporos de Glomus macrocarpum, Acau lospora scrobiculata e Gigaspora margarita....

5 - Desenvolvimento da colonização micorrízica em S. guianensis crescendo em solo ácido ........

6 - Correlação entre percentagem de colonização das raizes por fungos MVA e produção de matéria se ca da parte aérea por $S$. guianensis em solos ácidos com e sein adição de fósforo...........

7 - Efeito de diferentes niveis de calcário na produção de matéria seca da parte aérea de $S$. guianensis associado a diferentes fungos MVA.. 
Página

8 - Efeitos de diferentes niveis de fósforo e diferentes associações micorrizicas na produção de matéria seca da parte aérea de 5 . guianensis ..

9 - Efeito de associações micorrizicas na produção de matéria seca da parte aérea de $\mathrm{S}$. guianensis em diferentes épocas de colheita ............ 


\section{CONDIÇÕES EDÁFICAS QUE AFETAM O MICOTROFISMO DE \\ Stylosanthes guianensis (AUBL.) SW.}

Candidato: MARCIO RODRIGUES LAMBAIS Orientadora: Elke J.B.N. Cardoso

RESUMO

Com o objetivo de se estudar o micotrofismo de Stylosanthes guianensis e o comportamento de três associações micorrizicas vesiculo-arbusculares em diferentes condições edá ficas, foram feitas estudos de laboratório e casa-de-vegetação.

Em laboratório foram avaliados os efeitos da ca lagem em um solo ácido e da adubação fosfatada na germinação de esporos de Gigaspora margarita, Glomus macrocarpum e Acaulospo ra scrobiculata.

Os efeitos da calagem e da adubação fosfatada no desenvolvimento das micorrizas e das plantas, aos 40,60 e 80 dias após o plantio das sementes, foram avaliados em casa-de vegetação.

De uma maneira geral, o S. guianensis, que ocor re naturalmente en solos muito pobres em $P$, mostrou uma grande dependência da adubação fosfatada e/ou da micorriza. 0 micotrofismo do $S$. guianensis aumenta em solos ácidos com baixos niveis de $P$.

Os processos de germinação dos esporas dos fungos MVA e de colonização das raizes são afetados pelas diferen 
xii.

tes condições edáficas, dependendo da adaptabilidade dos fungos e/ou das micorrizas a tais condições.

Possiveis mecanismos que aumentam a tolerânciado S. guianensis a niveis tóxicos de $A l$ e $M n$ são discutidos. 
Stylosanthes guianensis (AUBL.) SW. AS AFFECTED BY EDAPHIC CONDITIONS.

\section{Candidate: MARCIO RODRIGUES LAMBAIS} Adviser: Elke J.B.N. Cardoso

\section{SUMMARY}

Greenhouse and laboratory experiments were carried out in order study the Stylosanthes guianensis mycotrophy and the behavior of three MVA associations under different eda phic conditions.

The effects of liming and phosphate fertiliza tion on spore germination of Gigaspora margarita, Glomus macro carpum and Acaulospora scrobiculata were evaluated under laboratory conditions. The same effects on plant growth and mycor rhizal development were also evaluated at 40,60 and 80 days after planting under greenhouse conditions.

It was found that $\mathbf{S}$. guianensis, wich grows generally under low $P$ level conditions, presented a great dependency on phosphate fertilization and/or on MVA association. At low $\mathrm{P}$ levels and low soil $\mathrm{pH}$, the $\mathrm{S}$. guianensis mycotrophy was even greater.

Spore germination and root colonization were affected by different edaphic conditions according to the fungal or to the mycorrhizal adaptability to such conditions. 
xiv.

Some mechanisms which may contribute to increase $S$. guianensis tolerance to $A l$ and $M n$ toxic levels are also discussed. 


\section{INTRODUÇÃo}

A ocorrência de fungos micorrizicos vesiculo-arbusculares (MVA) nos mais diferentes ecossistemas esua importância ecológica tern sido amplamente estudadas (St. JOHN e COLEMAN, $1981)$.

Em condições edáficas que dificultam o desenvolvimento do sistema radicular, as micorrizas tornam-se particu larmente importantes, aumentando o volume de șolo explorado e o acesso a nutrientes que podem limitar o desenvolvimento vegetal.

Plantas com um sistema radicular com poucos pêlos absorventes tendem a ser micotróficas, isto é, dependem de fungos micorrizicos para a absorção de nutrientes e crescimento (BAYLIS, 1975).

- Stylosanthes guianensis tem se mostrado muito dependente da associação com fungos micorrízicos-VA, não só para o crescimento como também para a nodulação (MOSSE, 1981; JEH NE, 1984; CORDEIRO et alii, 1986; MOSQUIM et alii, 1986).

Mesmo sendo relativamente exigente em fósforo 5. guianensis é encontrada naturalmente em solos muito pobres nesse nutriente, e com niveis altos de alumínio. 
As variações das condições edáficas podem alterar tanto o desenvolvimento quanto a eficiência da micorriza, dependendo da interação fungo-planta-solo (ABBOTT e ROBSON, 1984).

$A$ acidez do solo e a concentração de $A I^{+3}$ têm um grande efeito sobre os fungos MVA, bem como sobre as micorrizas formadas, em maior ou menor grau, dependendo da adaptabi lidade dos fungos e/ou das micorrizas envolvidas (MOSSE, 1981; SIQUEIRA et alii, 1982; WANG et alii, 1986; COLOZZI FILHO et alii, 1986).

Existem trabalhos que sugerem a possivel participação das micorrizas no aumento da tolerância das plantas a niveis tóxicos de AI e Mn no solo (CARDOSO, 1984; MALUF et alii, 1987), sendo um fato muito importante a ser considerado em estudos de ecologia de plantas.

A utilização de $S$. guianensis como forrageirano Brasil tem como objetivo principal o aproveitamento dos solos de baixa fertilidade e com altos níveis de AI (THOMAS, 1984), dai a importância do estudo das MVA nesse gênero.

- estudo do desenvolvimento das diferentes micorrizas em solos ácidos também é de grande interesse, principalmente para a otimização dessas associações, visando uma futura aplicação prática.

Este trabalho pretende justamente estudar o micotrofismo de $\mathrm{S}$. guianensis em diferentes condições edáficas e - desenvolvimento de suas micorrizas, para melhor compreensão dos fatores que determinam a maior ou menor eficiência de absorção de nutrientes em condições limitantes para a planta. 


\section{REVISÃO DA LITERATURA}

\subsection{Definição e conceito de micorrizas}

De acordo com WILCOX (1983), as associações sim bióticas entre fungos e raizes são bastante diversificadas, ha vendo uma transição gradual entre o parasistismo e o mutualismo.

Durante o processo evolutivo, os fungos saprofí ticos adquiriram mecanismos de infecção e patogênese, além de uma especialização nutricional, que atingem o máximo no biotro fismo obrigatório. Nesse estágio da evolução, existe uma perda da patogenicidade e o fungo torna-se mutualistico e verda deiramente micorrízico.

SIQUEIRA (1986) propõe definir micorriza como uma "simbiose endofitica, biotrófica mutualistica prevalente na maioria das plantas vasculares nativas e cultivadas espalhadas por toda a terra, sendo caracterizada pelo contato intimo e perfeita integração morfológica entre o fungo e a planta, pela regulação funcional e troca de metabólitos ajustada a trazer beneficios mútuos". 
No entanto, havendo algum desbalanceamento do sistema solo-planta-fungo, a simbiose mutualistica pode tornar-se parasitica, de forma reversivel ou irreversivel, depen dendo do tipo de desbalanceamento.

A presença de plantas micorrizadas em condições edafo-climáticas bastante adversas sugere que os endófitos, bem como os hospedeiros, passaram por um processo de coevolução, atingindo altos graus de interdependência.

2.2. As micorrizas vesiculo-arbusculares: formação e desenvolvimento

As micorrizas vesículo-arbusculares (MVA) são formadas basicamente por três componentes: as raizes do hospedeiro, as hifas do fungo no interior das raizes e as hifas externas que se estendem além da rizosfera.

Formadas por fungos da familia Endogonaceae, as MVA ocorrem em aproximadamente $90 \%$ das plantas vasculares, com exceção das Cruciferae e Chenopodiaceae.

Podem ser diferenciadas pela ausência de alterações morfológicas nas raizes, pela penetração inter e intra celular com formação de estruturas típicas (vesiculas, arbúsculos e esporos) nas raizes e/ou rizosfera.

A infecção tell início no contato de uma hifa, emitida por um propágulo (esporo, vesicula ou pedaço de raiz infectada), com a raiz de um hospedeiro adequado.

Em se tratando de colonização via esporo, os processos de germinação e crescimento do tubo germinado, bem como os fatores que interferem nesses processos são de grande importância. 
A emissão do tubo germinativo pode se dar de formas diferentes dependendo da espécie do fungo, podendo o tubo germinativo emergir diretamente da parede do esporo (SWARD, 1981; DANIELS e TRAPPE, 1980), através da hifa de sus tentação (DANIELS e TRAPPE, 1980; HEPPER e SMITH, 1976) ou através de compartimentos periféricos formados no esporo (SWARD et alii, 1978; HALL, 1977; GERDEMANN e TRAPPE, 1974 ; OLD et alii, 1973; MOSSE, 1970).

SIQUEIRA (1987) discute os mecanismos bioquimi cos que acompanham a germinação dos esporos e o crescimento do tubo germinativo.

Quando uma hifa infectante entra em contato com a raiz, há formação de um apressório, e a penetração tem lugar. As hifas intra-radiculares colonizam o córtex tanto inter quanto intracelularmente.

A hifa crescendo no interior de uma célula cor tical individual pode ramificar-se dicotomicamente inúmeras vezes, formando ramos de aproximadamente $1 \mu \mathrm{m}$. Essas estrutu ras altamente ramificadas, semelhantes a haustórios, são chamadas arbúsculos, e constituem os pontos de troca de metabóli tos entre o fungo e a planta.

As hifas intra-radiculares podem frequentemente se dilatar em sua porção terminal ou intercalar e acumular go tículas de óleo, formando as vesiculas, que podem funcionar como estruturas de reserva (HOLLEY e PETERSON, 1979) e/ou de propagação (GERDEMANN, 1968).

Uma vez estabelecida a associação, o fungo absorve nutrientes da solução do solo, translocando-os até os arbúsculos onde ocorrem as trocas por metabólitos originários 
da fotossintese (CABALA-ROSAND e DIAS, 1986). o balanço desses dois processos é que controla a natureza da simbiose, que pode variar de mutualística a antagônica (HARLEY e SMITH,1983).

A diferenciação das hifas pode dar origem aos esporos, que têm processos de formação diferentes, dependendo da espécie, podendo ser tanto inter quanto intra-radiculares (OLIVEIRA, 1986).

Os fatores que determinam o inicio da esporulação são desconhecidos, mas sabe-se que muitos fatores podem in terferir nesse processo (MENGE, 1978; KRUCKELMANN, 1975; SAIF et alii, 1975; SCHENCK e SCHRODER, 1974).

Os esporos formados, pedaços de raizes infectadas e hifas externas podem persistir no solo e emitir novas hi fas, que podem reiniciar o processo de colonização.

\subsection{Fatores que afetam as micorrizas vesiculo-arbusculares}

A formação, o funcionamento e a multiplicação das MVA são afetados por vários fatores quimicos, físicos e biológicos, que podem atuar separada ou interrelacionadamente, direta ou indiretamente.

2.3.1. Fatores químicos

$$
2 \cdot 3 \cdot 1 \cdot 1 \cdot \mathrm{pH}
$$

O efeito do pH do solo sobre as MVA é dificil de ser avaliado isoladamente, uma vez que as propriedades quimicas do solo variam em função do mesmo. Normalmente, nos ensaios que visam estudar o comportamento das MVA em diferentes valores de $\mathrm{pH}$ utiliza-se a calagem do solo como forma de se atingir os valores desejados. 
As MVA têm sido encontradas em solos com $\mathrm{pH}$ variando de 2,7 a 9,2 (BOWEN, 1980; DAFT e EL-GIAHMI, 1975).

Segundo MOSSE (1981), algumas espécies de fungos MVA são dependentes do pH. Geralmente, Glomus mosseae não coloniza solos com pH abaixo de 5,6 , enquanto Acaulospora laevis não é encontrada em solos neutros ou alcalinos. Espécies do gênero Gigaspora normalmente são mais abundantes em solos com $\mathrm{pH}$ baixo, sendo muito comuns em solos tropicais.

Glomus tenuis foi encontrado como predominante em solos extremamente ácidos de áreas de mineração (LAMBERT e COLE JI., 1980; DAFT e NICOLSON, 1974).

Em levantamentos feitos por COLOZZI FILHO et alii (1986) em ecossistemas naturaise agroecussistemas do estado de Minas Gerais foi verificado que o pH do solo afetou a compo sição da população de fungos MVA nativa. Em solos com pH menor que 5, 0 foram encontradas 7 espécies; $\mathrm{pH} 5,0$ a $6,0,13$ espécies; $\mathrm{pH}$ maior que 6,0, 4 espécies. As espécies Acaulospora scrobiculata e Acaulospora morrowae predominaram em solos com pH 6,0, enquanto Acaulospora spinosa, Scutellospora pellucida e Gigaspora sp-1 predominaram em $\mathrm{pH} 5,0$.

Em cafezais do sul de Minas Gerais foi verifica do que a ocorrência do gênero Acaulospora se dava em faixas mais amplas de $\mathrm{pH}$, enquanto Gigaspora e Scutellospora ocorriam em faixas mais estreitas (FERNANDES et alii, 1987).

WANG et alii (1986) observaram que aveia (Avena sativa) e batata (Solanum tuberosum), crescendo em solos naturais com $\mathrm{pH}$ baixo, eram colonizadas exclusivamente por Glomus tenuis, e em solos com pH alto por Glomus caledonium. Os mes- 
mos autores verificaram também que fungos extraidos de solo ácido colonizavam eficientemente plantas em vários niveis de $\mathrm{pH}$ do solo, enquanto os fungos micorrizicos adaptados a solos alcalinos infectavam muito pobremente as raizes quando em solo ácido.

A colonização micorrízica aumenta com o aumento do $\mathrm{pH}$ do solo, sendo que Gigaspora gigantea é capaz de colonizar raízes de trevo tanto em $\mathrm{pH} \mathrm{4,5}$ quanto em $\mathrm{pH} 6,5$, ao passo que Glomus musseae só responde em $\mathrm{pH}$ 6,5, mesmo assim num nivel inferior, em relação a G. gigantea e aos fungos isola dos de solos ácidos (LAMBERT e COLE Jr., 1980).

Glomus leptotichum, em solo com pH 5,0, mostrou maior efeito no desenvolvimento de Leucaena leucocephala do que Glomus macrocarpum e inóculo de fungos nativos (MALUF et alii, 1987).

MOSSE (1972), trabalhando com solos brasilei ros, verificou que com o aumento do $\mathrm{pH}$, de 4,8 para 5,8, atra vés de calagem, as plantas inoculadas com Glomus fasciculatum cresceram 2 vezes mais, enquanto aquelas colonizadas por fungos indigenas cresciam 5,6 vezes mais.

Assim, a calagem de solos ácidos, além de aumentar a capacidade de troca de cátions e diminuir a fixação de fosfatos adicionados, por uma diminuição de cargas positivas dos colóides, pode alterar a composição de endófitos indi genas, podendo favorecer populações mais eficientes.

o pH do solo pode alterar a solubilidade e con sequente disponibilidade de uma série de elementos, principal mente o $\mathrm{P}$, incluindo também $\mathrm{Fe}, \mathrm{Zn}, \mathrm{Cu}, \mathrm{Co}, \mathrm{Mn}, \mathrm{Al}$ e Mo. 
SIQUEIRA et alii (1982) sugerem que o mecanismo de ação do $\mathrm{pH}$ sobre os fungos MVA talvez seja através de alterações na permeabilidade da membrana citoplasmática, aumentando ou diminuindo a absorção de determinados nutrientes.

A influência do $\mathrm{pH}$ na germinação e crescimento do tubo germinativo é muito variável, dependendo principalmen te da espécie do fungo MVA. Existem interações do nivel de $\mathrm{pH}$ com a temperatura e a concentração de nutrientes ininerais e orgânicos disponiveis no meio, o que torna muito dificil seu estudo isoladamente (SIQUEIRA et alii, 1982).

Geralmente, o nivel de pH ótimo para germina ção em meios artificiais é bem próximo ao pH do solo onde a espécie ocorre naturalmente.

Gigaspora spp. parece ter uma faixa mais ampla de $\mathrm{pH}$ onde ocorre germinação, enquanto que para Glomus spp.es sa faixa é mais estreita (GREEN et alii, 1976).

Os esporos de Scutellospora coralloidea apresentam uma germinação máxima em pH 5,0, caindo rapidamente em pH aci ma de 6,0. (GREEN et alii, 1976).

Gigaspora margarita apresenta $\mathrm{pH}$ ótimo para germinação em torno de 6,0 a $28^{\circ} \mathrm{C}$, variando com a composição do meio (SIQUEIRA et alii, 1982). O mesmo valor foi encontra do para Scutellospora heterogama, incubada a $34^{\circ} \mathrm{C}$ (GREEN et alii, 1976).

NAVARRO et alii (1987) obtiveram germinação de G. margarita e S. heterogama em niveis de $\mathrm{pH}$ variando de 4,5 a 6,5 , sendo que não houve resposta significativa a essa variação. 
Esporos de G.mosseae germinam melhor em $\mathrm{pH} \mathrm{7,0,}$ quando incubados a $25^{\circ} \mathrm{C}$, ou $\mathrm{pH} 8,0$, quando incubados a $15^{\circ} \mathrm{C}$ (GREEN et alii, 1976). Para esporos de Glomus epigaeum $0 \mathrm{pH}$ ótimo está entre 7,0 e 7,4 , a $25^{\circ} \mathrm{C}$ (DANIELS e TRAPPE, 1980). G. macrocarpum responde prontamente à calagem de solos ácidos, germinando melhor em niveis de $\mathrm{pH}$ mais altos [NAVARRo et alii, 1987; LAMBAIS e CARDOSO, 1985 (dados não publicados)].

Segundo SIQUEIRA et alii (1982), o pH do meio afeta mais a germinação dos esporos do que o crescimento do tubo germinativo.

2.3.1.2. Disponibilidade de fósforo e nitrogênio

Certos nutrientes, especialmente o $P$ e o N, têm grande influência sobre as associações micorrizicas, princi palmente no grau de colonização das raízes (MOSSE, 1973), podendo afetar também a germinação dos esporos e o crescimento do tubo germinativo (SIQUEIRA et alii, 1985; SIQUEIRA et alii, 1982; DANIELS E TRAPPE, 1980).

O efeito da concentração de $P$ na solução do so lo sobre as MVA ainda é um aspecto bastante controvertido.

Quando aplicado em doses elevadas, o P,além de reduzir a colonização das raízes, pode reduzir também a produ Ção de esporos e micélio externo (SIQUEIRA et alii, 1984; MEN GE, 1978).

Já, outros autores verificaram que a adição de fosfato pode não intérferir no nivel de colonização das rai zes ou até mesmo aumentá-1o (SILVEIRA e CARDOSO, 1987; COOPER, 1975), dependendo da demanda de $P$ pela simbiose. Além do que 
a produção de esporos pode aumentar (SILVEIRA e CARDOSO, 1987; ROSS E HARPER, 1970).

Diferentes formas de $P$ adicionadas ao solo,tais como fosfato-de-rocha, superfosfato ou fosfato orgânico afetam diferentemente as MVA, provavelmente devido as diferenças na solubilidade de cada fonte (HAYMAN, 1982).

Não se conhece o mecanismo exato pelo qual o $P$ interfere na colonização das raizes, mas há indicações de que esse efeito seja indireto, ou seja, a concentração de $P$ na planta é que controlaria a colonização das raizes (GRAHAM et alii, 1981; HOWELER, 1981; MENGE et alii, 1978; SANDERS, 1975; MOSSE, 1973).

Existem três hipóteses para explicar esse efeito:

- lectinas nas raizes, que impedem a penetra ção do fungo, reagiriam com fosfatases produzidas em grandes quantidades em plantas com deficiência de $P$, formando dimeros que não mais bloqueariam a penetração do fungo (WOOLHOUSE, 1975),

- o P controla o grau de colonização das raizes interferindo na permeabilidade das membranas, através de seu efeito na produção de fosfolipideos. Em condições de baixa concentração de $P$, a sintese de fosfolipideos é menor, aumen tando a permeabilidade das membranas e consequente exsudação de substâncias orgânicas que estimulariam a atividade dos propágu los na rizosfera (RATNAYAKE et alii, 1978),

- a maior concentração de $P$ no solo aumenta a concentração de açúcares nas células corticais, criando condições desfavoráveis para a penetração e crescimento do fungo (AZCON e OCAMPO, 1981). 
Os efeitos do P na germinação dos esporos foram estudados por vários autores, e os resultados são variáveis, dependendo das condições do ensaio (SIQUEIRA et alii, 1982; KOSKE, 1981; DANIELS e TRAPPE, 1980).

KOSKE (1981) não observou diferença significativa na germinação de esporos de G. margarita com a adição de até $500 \mathrm{ppm} P$ na forma de $\mathrm{K}_{2} \mathrm{HPO}_{4}$ e $\mathrm{KH}_{2} \mathrm{PO}_{4}$. No geral, a germina ção de esporos de fungos MVA é máxima numa determinada concen tração de $P$, diminuindo em concentrações supraótimas (SIQUEIRA et alii, 1982; DANIELS e TRAPPE, 1980).

SIQUEIRA et alii (1982) observaram também que a concentração ótima de $P$ para a germinação dos esporos depen de das concentrações de $\mathrm{N}$ e $\mathrm{K}$.

$0 \mathrm{~N}$, assim como $\mathrm{O} P$, em altos niveis também po de reduzir a colonização das raizes (CHAMBERS et alii, 1980 ; HAYMAN, 1970; MOSSE, 1962).

A maior ou menor inibição de colonização é dependente da forma de $\mathrm{N}$ aplicada ao solo, sendo o $\mathrm{NH}_{4}^{+}$mais in bitório do que o $\mathrm{NO}_{3}^{-}$(CHAMBERS et alii, 1980).

A associação de fungos MVA e bactérias fixadoras de nitrogênio atmosférico tem se mostrado muito benéfica no aumento de produção em leguminosas, não sendo observados efeitos negativos do $\mathrm{N}_{2}$ fixado sobre as MVA. (SILVEIRA e CARDO SO, 1987; MOSQUIM et alii, 1986; OLIVEIRA e CARDOSO, 1986; AZZ CON et alii, 1986; CARDOSO, 1985; AZCON-AGUILAR et alii, 1982).

Efeitos específicos de fatores edáficos devem ser demonstrados claramente por várias vezes em condições experimentais perfeitamente definidas, por ser muito dificil es 
tabelecer correlações entre MVA e fatores edáficos em diferen tes locais, uma vez que as propriedades fisicas, químicas e biológicas dos solos são bastante variáveis de local para local, dependendo da temperatura, umidade, formação geológica, agentes intemperizadores predominantes, etc.

No entanto, de uma maneira geral pode-se dizer que alta fertilidade do solo determina baixo grau de colonização das raizes, podendo ser encontrados também solos muito férteis com alto grau de colonização, porém com menor frequência (HAYMAN, 1982).

DANIELS e TRAPPE (1980) não obtiveram efeitos significativos na germinação de esporos de G. epigaeum com a adição de até $900 \mathrm{ppm}$ de $\mathrm{N}$ total, na forma de $\mathrm{NH}_{4} \mathrm{NO}_{3}$, ou de até $152 \mathrm{ppm}$ de $\mathrm{K}$ trocável, na forma de $\mathrm{K}_{2} \mathrm{SO}_{4}$.

SIQUEIRA et alii (1982) observaram um efeito negativo do $\mathrm{N}$, na forma de $\mathrm{NH}_{4} \mathrm{NO}_{3}$ (24 ppm), no crescimento do tubo germinativo, desaparecendo com a adição de $P$ e $K$ ao meio, - que mostra que há necessidade de um balanceamento das con centrações de $N$, $P$ e $K$, interrelacionadamence, e em função do $\mathrm{pH}$.

2.3.1.3. Disponibilidade de outros nutrientes

Estudos mais acurados do efeito de micronu trientes sobre os fungos MVA, e o desenvolvimento dessas micorrizas, são difíceis de serem realizados, principalmente pe la dificuldade em se cultivar o fungo ou as micorrizas in vitro, onde o controle da composição do meio seria maior, e pelo grande número de interrelações entre nutrientes. 
No entanto, SIQUEIRA et alii (1984) mostraram que existe uma correlação negativa entre a percentagem de colonização de raízes de milho por G.mosseae e a concentração de Zn no solo, além de existir uma correlação negativa entre a concentração de Al e Cu no solo e a germinação dos esporos, bem como com o crescimento do tubo germinativo. Nos tratamen tos com G. margarita não houve nenhum tipo de correlação significativa.

Experimentos realizados em areia como substrato mostraram que $0 \mathrm{AI}^{+3}$ e $0 \mathrm{Mn}^{+2}$, em concentrações semelhan tes às da solução do solo, geralmente inibem a infecção micor rizica, sendo o $\mathrm{Al}^{+3} 5$ vezes mais inibidor do que o $\mathrm{Mn}^{+2}$ (WANG et alii, 1986).

ojala et alii (1978), citados por LAMBERT et alii (1980), observaram que a formação de MVA é maior em solos com baixas concentrações de $\mathrm{Zn}, \mathrm{Cu}$, Fe e $\mathrm{Mn}$.

A germinação de esporos de G. caledonium diminui em concentrações de $C u$ maiores que $0,3 \mathrm{ppm}$, e é inibida to talmente a concentrações acima de 1,0 ppm (HEPPER, 1979).

Em ágar-água, o Mn em concentrações de 0,136 ppm inibe a germinação de esporos de G.mosseae e G. caledonium, da mesma forma que $0,70 \mathrm{ppm}$ de $\mathrm{Zn}$ (HEPPER, 1979; HEPPER e SMITH, 1976).

Os efeitos do Mn, Cu e Zn na germinação dos esporos não são permanentes, uma vez que a germinação é normal quando os esporos são transferidos para ágar-água, sugerindo um efeito fungistático, o que poderia reduzir a colonização das raizes (HEPPER, 1979). 
o efeito dos micronutrientes, de uma maneira ge ral, na germinação dos esporos e no grau de colonização das raizes vai depender principalmente da origem do fungo. A dife rença na sensibilidade a certos metais entre -diversos isolados de esporos pode refletir uma adaptação a diferentes condições do solo, num determinado período de tempo (HEPPER e SMITH, 1976).

\subsubsection{Disponibilidade de alumínio}

o aluminio é um dos principais elementos

que pode limitar o crescimento das plantas em muitos solos ácidos, principalmente quando atinge niveis tóxicos.

No Brasil, aproximadamente 1,42 milhões de $\mathrm{km}^{2}$, no mínimo, apresentam solos com niveis tóxicos de $\mathrm{Al}$ para a maio ria das plantas cultivadas (LOPES, 1983).

o problema é particularmente sério em subsolos fortemente ácidos, dificeis de serem neutralizados pela cala gein.

Subsolos ácidos, com Al trocável em niveis tóxi cos, podem reduzir a penetração das raizes, aumentando a proba bilidade de injúrias causadas pela seca, principalmente durante os veranicos.

A disponibilidade do Al e o grau de toxidez para as plantas são afetados por muitos fatores do solo, incluin do $\mathrm{pH}$, tipo predominante de minerais de argila, concentração de outros cátions, concentração total de sais e teor de matéria or gânica. 
Geralmente, a toxidez de Al para as plantas não ocorre em solos com pH acima de 5,5, sendo bastante comum em valores mais baixos, principalmente abaixo de $\mathrm{pH} 5,0$, quando então a solubilidade do Al aumenta rapidamente.

Além de causar alterações morfo-fisiológicas nas raizes, altos niveis de Al no solo podem afetar também o desen volvimento de associações micorrízicas, que se tornam particularmente importantes para a nutrição mineral das plantas em si tuações onde as condições edáficas dificultam o desenvolvimento do sistema radicular.

Boutros-Mikhail (1976), citado por MOSSE (1981), observou em 3 solos de clima temperado que o beneficio das MVA decrescia com o aumento da concentração de Al no solo.

Stylosanthes guianensis, Centrosema pubescens e mandioca desenvolvem-se muito bem em solos com altos niveis de Al trocável, e são extremamente dependentes de associações micorrizicas (MOSSE, 1981), sugerindo que de alguma forma as micorrizas aumentam a tolerância das plantas ao Al.

MALUF et alii (1987) demonstraram que um cultivar de Leucaena leucocephala Al-intolerante é mais dependente da micorriza do que um cultivar Al-tolerante.

Para Stylosanthes guianensis e Stylosanthes macrocephala associadas a fungos MVA, CORDEIRO et alii (1986) ob servaram que o aumento da concentração de Al no solo era prejú dicial, e que o S. guianensis, menos tolerante ao Al, era mais dependente de MVA do que S. macrocephala.

A nodulação de $S$. guianensis em solos ricos em Al também é extremamente dependente da presença de micorriza 
(MOSQUIM et alii, 1986), uma vez que o alumino em solução causa uma grande redução da nodulação em espécies de Stylosanthes (CARVALHO et alii, 1982; CARVALHO et alii, 1981).

\subsubsection{Fatores físicos}

Muitos são os fatores físicos que afetam as MVA, desde a germinação dos esporos, até a penetração e colonização das raizes do hospedeiro.

A colonização das raizes é aparentemente mais rápida quando a umidade do solo é menor do que sua capacidade máxima de retenção de água (SAIF, 1981; REID e BOWEN, 1979), hạ vendo uma maior produção de esporos (SAIF et alii, 1975). Máxima germinação de esporos foi observada en solos com níveis de umidade acima da capacidade de campo (DANIELS e TRAPE, 1980).

SAIF (1981) verificou que a infecção micorrizica é influenciada quantitativa e qualitativamente por diferentes concentrações de $\mathrm{O}_{2}$ na atmosfera do solo.

- efeito da temperatura é muito variável, depen dendo principalmente da espécie do fungo e da combinação fungo-hospedeiro (DANIELS e TRAPPE, 1980; GREEN et alii, 1976 ; SCHENCK et alii, 1975; HAYMAN, 1974; SCHENCK e SCHRODER, 9174 ; FURLAN E FORTIN, 1973).

A luminosidade pode afetar as MVA indiretamente, através de seus efeitos na fotossintese, crescimento e metabolismo do hospedeiro (WANG et alii, 1986), e diretamente, afetando a germinação de esporos (SCHENCK et alii, 1975).

Tanto a textura quanto a resistência que o solo oferece a penetração das raizes podem afetar o desenvolvimento 
daS MVA (SAFIR E DUNIWAY, 1982; KRUCKELMAN, 1975; SAIF

et alii, 1975).

\subsubsection{Fatores biológicos}

Tanto a microbiota do solo quanto a macro e mi crofauna podem interagir com os fungos MVA, resultando em efeitos benéficos ou não. No entanto, a interação mais impor tante talvez seja com a microbiota do solo, sendo este assunto abordado mais detalhadamente por CARDOSO (1986) e BAREA e AZCON-AGUILAR (1982).

2.4. O efeito das MVA na absorção de nutrientes

Já está bell estabelecido que as MVA podem aumentar a eficiência de absorção de uma série de nutrientes, principalmente os menos móveis no solo, aumentando ein conse quência o desenvolvimento das plantas en solos onde a disponi bilidade de nutrientes é restrita.

o efeito primário das micorrizas é o aumento da absorção de nutrientes pela diminuição da distância de difusão até as raízes.

RHODES e GERDEMANN (1975) observaram que a zona de depleção para o $P$ ao redor das raizes de cebola micorrizadas era duas vezes maior do que ao redor das raizes não micorrizadas.

Existem evidências de que as hifas externas se estendem além da zona de depleção em torno das raizes, aumentando o volume de solo explorado. 
Em estudos de cinética de absorção de $P$, verifi cou-se que as MVA afetam tanto os valores de $\mathrm{Km}$ quanto de Vmax (FAQUIN et alii. 1987; SILVEIRA et alii, 1987; HARLEY e SMITH, 1983).

Diferenças na concentração de $\mathrm{N}, \mathrm{P}, \mathrm{K}, \mathrm{Ca}, \mathrm{Mg}$, $\mathrm{Na}, \mathrm{Fe}, \mathrm{Cu}, \mathrm{Zn}$, B e Al entre plantas micorrizadas e não micorcorrizadas já foram relatadas por vários autores (CARDOSO, 1984; MOSSE, 1973).

Associações micorrízicas em leguminosa aumentam significativamente a absorção de $N$, P e K (SILVEIRA e CARDOSO, 1987; CARDOSO, 1985).

Em plantas citricas, CARDOSO et alii (1986) observaram incrementos de até $5070 \%$ no $P$ absorvido e acumulado na parte aérea e de até $2680 \%$ no $\mathrm{K}$.

MOSSE (1957) observou que plântulas de macieira micorrizadas continham maiores concentrações de $K$, Fe e Cu e me nores concentrações de $M n$, em relação às plântulas não micorrizadas. Existem também relatos do aumento da absorção de $\mathrm{Zn}$ (GILMORE, 1971) e de CU (TIMMER e LEYDEN, 1978), em pessegueiro e plantas citricas micorrizadas, respectivamente.

GERDEMANN (1964) verificou que plantas de milho micorrizadas apresentavam maiores concentrações de $P$, e menores concentrações de $\mathrm{K}, \mathrm{Mg}, \mathrm{B}$ e $\mathrm{Mn}$, em relação às não micorrizadas.

Videiras micorrizadas apresentaram duas vezes mais $P$ e $K$ do que as não micorrizadas, mas os niveis de $\mathrm{Ca}, \mathrm{Mg}$, $\mathrm{Na}, \mathrm{Fe}, \mathrm{Cu}, \mathrm{Zn}$, B e Al eram menores (DEAL et alii, 1972).

PACKOVSKY (1986) estudou a assimilação e alocação de $\mathrm{Fe}, \mathrm{Mn}, \mathrm{Zn}$ e Cu en soja micorrizada ou com adubação fos- 
fatada, constatando aumentos de absorção de $C u$ e $Z n$ pelas plan tas micorrizadas, enquanto o $\mathrm{Fe} e \mathrm{Mn}$ diminuiam, em relação às plantas adubadas.

Como se pode observar, os dados da literatura são muito variáveis, principalmente com relação a absorção de micronutrientes.

Tais variações podem ser atribuidas a uma série de fatores, tais como: variabilidade genética das plantas e fungos usados nos experimentos, tipos de solo, balanço de nutrientes no solo, umi dade do solo e condições climáticas, dentre outros.

No entanto, o que se tem com maior frequência, especialmente em relação ao Al e Mn, é que plantas micorriza das apresentam menores concentrações desses elementos, sugerin do um possivel mecanismo de defesa para a planta en solos com altas concentrações de Al e $M n$.

As MVA poderiam também ajudar a manter uma rela ção $\mathrm{Mn} / \mathrm{Fe}$ pequena na parte aérea da planta, tornando-as mais tolerantes a altos niveis de $M n$ no solo, através de uma maior absorção de $\mathrm{Fe}$.

Como a toxidez de Al tem sido relacionada com a redução da absorção de alguns nutrientes essenciais para as plantas, principalmente o $\mathrm{P}$ e $\mathrm{Ca}$, as MVA poderiam aumentar a tolerância ao $A l$ aumentando a absorção desses nutrientes, mantendo um equilibrio nutricional nas plantas. 


\subsection{Micorrizas vesículo-arbusculares em Stylosanthes}

A utilização de Stylosanthes como forrageira no Brasil tem sido estudada, visando principalmente a utilização dos solos de baixa fertilidade, com baixos niveis de $P$ e altos niveis de Al, sem a aplicação de corretivos ou fertilizan tes (THOMAS, 1984).

o Stylosanthes é geralmente considerado tolerante a solos ácidos e distróficos, e apresenta boa tolerân cia ao Al. Nos solos brasileiros sob vegetação de cerrado,S. guianensis var. guianensis, S. capitata, S. macrocephala S. scabra e $S$. viscosa têm mostrado excelente adaptação a solos com pH 4,6 e saturação de alumínio maior do que $80 \%$ (CIAT, 1980).

A variabilidade dentro do gênero Stylosanthes é bastante pronunciada, bem como a variabilidade interespecifica, havendo a possibilidade de se obter genótipos adaptados às mais variadas condições edafo-climáticas.

BURNQUIST (1984) estudou 25 populações de S. guianensis e pode discriminar as populações mais tolerantes ao Al das menos tolerantes.

- Stylosanthes por ser uma planta com sistema radicular pivotante e com poucos pêlos absorventes é extremamente dependente da formação de micorrízas, principalmente pa ra a nodulação e fixação do nitrogênio pelo Rhizobium (MOSSE, 1981).

Poucos trabalhos têm sido feitos para se estudar mais detalhadamente o efeito das MVA no desenvolvimento do Stylosanthes principalmente no que se refere à tolerância a 
baixos niveis de $P$ e altos niveis de $A l$ (CORDEIRO et alii, 1986; MOSQUIM et alii, 1986).

MOSSE (1977) verificou um incremento máximo na produção vegetativa de $S$. guianensis em tratamentos que combi vam fungo micorrizico e fosfato-de-rocha, respostas semelhantes foram obtidas por WAIDYANATHA et alii (1979).

Stylosanthes hamata cv verano inoculado com fungos micorrízicos mostrou respostas no crescimento e absorção de nutrientes em solos distróficos muitas vezes semelhantes aquelas obtidas em niveis moderados de adubação fosfatada (JEHNE, 1984).

Segundo Jone e Jehne, citados por JEHNE (1984), a maioria dos solos do norte da Austrália possuem fungos micorrizicos capazes de colonizar raizes de $\mathrm{S}$. humulis e $\mathrm{S}$. hamata cv verano, e que aproximadamente $20 \%$ desses solos contém fungos micorrízicos eficientes para $S$. hamata $c v$ verano.

Muitas vezes a introdução de leguminosas em no vos habitats requer a inoculação de fungos micorrizicos eficientes, dependendo do tipo de solo, e da população de fungos nativos (AZCON-AGUILAR et alii, 1982).

BAREA et alii (1987), em trabalho enviado a New Phytologist, mostraram que gramíneas crescendo em pastagens con sorciadas com leguminosas altamente micotróficas possuem um grau de colonização das raízes praticamente duas vezes maior do que quando crescendo sozinhas. Além disso, as gramineas consorciadas produzem mais matéria seca e acumulam mais $N$ na parte aérea. 
De acordo com BAREA, 1987 (comunicação pessoal), em solos sell fungos micorrizicos, as leguminosas em pastagens consorciadas com gramíneas tendem a desaparecer com o tempo, de vido à grande competição, principalmente por nutrientes.REEVES et alii (1979) estudaram a sucessão de espécies em solos que sofreram distúrbios, e verificaram que a composição da população é afetada pela presença de fungos micorrizicos. TRAPPE (1981) reviu vários aspectos da influência das MVA na produtividade de pastagens em regiões áridas e semi-áridas.

Em pastagens consorciadas, uma mesma hifa de fungo micorrizico poderia colonizar tanto as raízes da leguminosa quanto da gramínea, ao mesmo tempo, transferindo nutrientes de uma planta para outra, via hifa. Essa transferência de nutrientes ainda não foi demonstradà, mas há evidências de que isso possa ocorrer, principalmente com o $N$ fixado pelas legumi nosas (BAREA et alii, 1987).

o crescimento e a sobrevivência de Stylosanthes no campo são frequentemente limitados por fatores ambientais, e sua adaptação a tais condições envolve a presença de micorrizas (JEHNE, 1984). S. guianensis é extremamente dependente de fósforo, em relação a outras espécies de Stylosanthes, e é comum em solos com concentrações de $P$ de até 1 ppm (PROBERT, 1984), sugerindo uma grande dependência da formação de MVA, tanto para a absorção de $P$ quanto para a nodulação (MOSSE et alii, 1976).

O estudo das MVA em Stylosanthes pode esclare cer muitos aspectos sobre a ecologia desse gênero. A seleção de genótipos de planta e fungos micorrizicos mais eficientes no aproveitamento de nutrientes e água, e mais tolerantes a niveis tóxicos de Al e Mn, principalmente, poderia ser feita, visando - aproveitamento de solos distróficos em regiões de baixa precipitação pluviométrica. 


\section{MATERIAL E MÉTODOS}

Experimento 1 - Efeito da calagem em um solo áci do na germinação de esporos de fungos micorrizicos vesiculo-arbusculares.

o solo utilizado foi uma areia quartzosa (quartzipsamment) esterilizado a $120^{\circ} \mathrm{C}$ por $2 \mathrm{~h}$, e tratado com 4 niveis de calcário: $0,0,27,0,63$ e 1,10 emg $\mathrm{Ca}(\mathrm{OH})_{2} / 100 \mathrm{~g}$ TFSA, e 2 ni veis de fósforo: 0 e $20 \mathrm{ppm}$ de $\mathrm{P}$ na forma de $\mathrm{KH}_{2} \mathrm{PO}_{4}$. Foram adicionados ao solo 0,50 ppm de $Z n, 0,75$ ppm de Cu, 0,04 ppm de Mo e $0,60 \mathrm{ppm}$ de $\mathrm{B}$, nas formas de $\mathrm{ZnSO}_{4} \cdot 7 \mathrm{H}_{2} \mathrm{O}, \mathrm{CuSO}_{4} \cdot 5 \mathrm{H}_{2} \mathrm{O}, \mathrm{Na}_{2} \mathrm{MoO}_{4}$ e $\mathrm{H}_{3} \mathrm{BO}_{3}$, respectivamente. As quantidades de calcário foram determinadas para a elevação do $\mathrm{pH}$ do solo a valores pré-determinados, com base em una curva de $\mathrm{pH} \times$ quantidade de calcário adicionado, realida em laboratório sob condições controladas.

A análise química do solo nos diferentes niveis de fertilidade utilizados pode ser vista na Tabela 1.

Após a esterilização, o solo foi incubado por 2 stemanas para recolonização microbiana. Foram utilizados esporos de três fungos micorrizicos-VA Gigaspora margarita Becker \& Hall, Glomus macrocarpum Tulasne \& Tulasne e Acaulospora scrobi culata Trappe. 


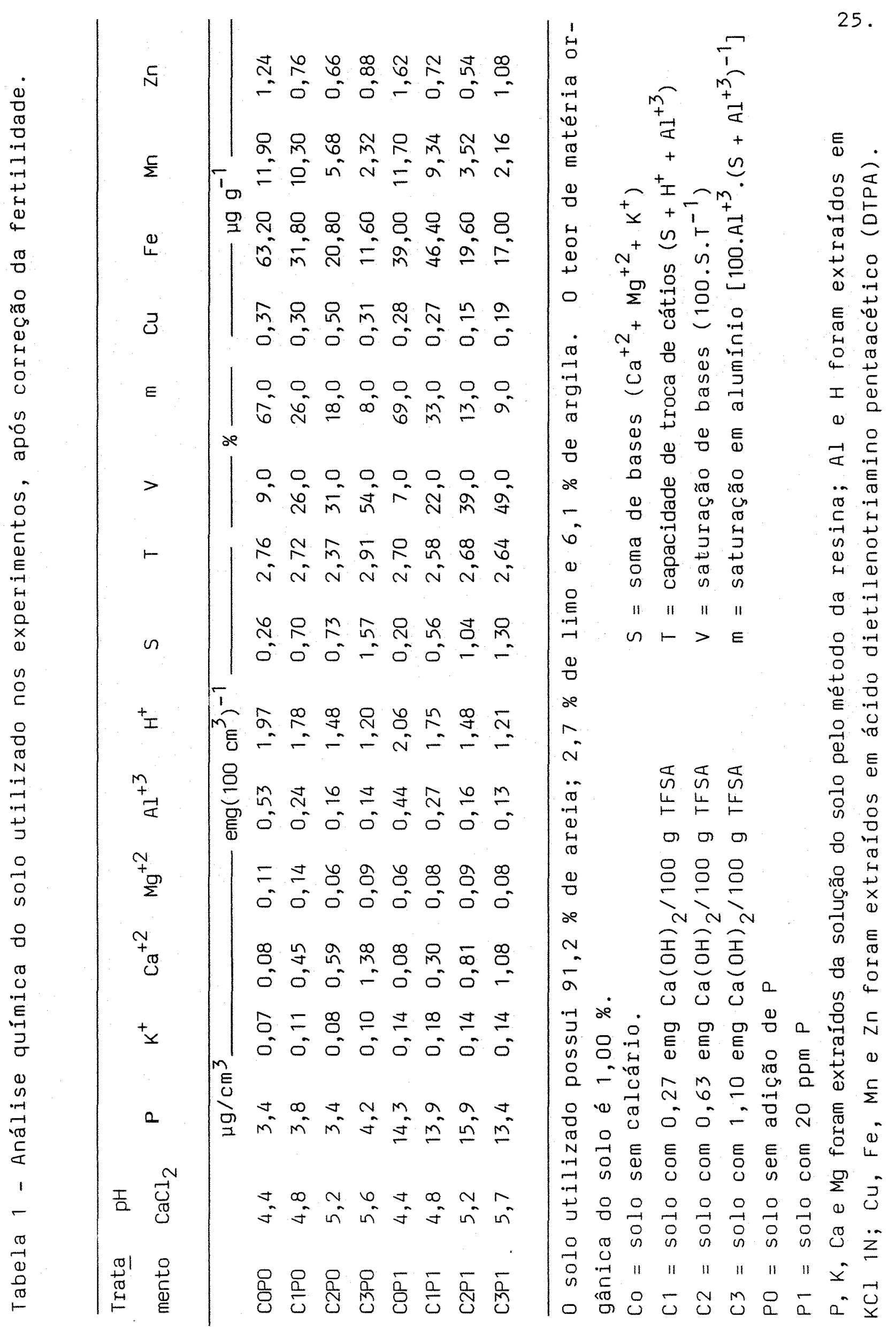


Os esporos foram obtidos por lavagen e peneiramento úmido de terra, proveniente de vasos com plantas multi plicadoras (milho), segundo GERDEMANN e NICOLSON (1963), utili zando-se peneiras de $0,71 \mathrm{~mm}$ para reter o material grosseiro, 0,105 mm para G. margarita e $0,053 \mathrm{~mm}$ para G. macrocarpum e A. scrobiculata. Em seguida os esporos retidos nas peneiras de $0,105 \mathrm{~mm}$ ou $0,053 \mathrm{~mm}$ foram separados por centrifugação em solu ção de sacarose e lavados com água destilada em abundância.

Com o auxilio de um microscópio estereoscópico os esporos foram separados em grupos de 50 e colocados sobre membranas filtrantes (Sartorius) de $47 \mathrm{~mm}$ de diâmetro e 3,0 $\mu \mathrm{m}$ de porosidade, as quais posteriormente foram dobradas "como um envelope", e colocadas entre duas camadas de terra de aproxima damente $50 \mathrm{~g}$, em placas de Petri.

A umidade do solo foi mantida em $70 \%$ da capaci dade máxima de retenção de água $(U=16 \%)$.

As placas foram embrulhadas em folhas de aluminio e incubadas a $30^{\circ} \mathrm{C}$ por 10 dias.

0 delineamento experimental foi um fatorial 4 NÍVEIS DE CALCÁRIO $\times 3$ FUNGOS $\times 2$ NÍVEIS DE $P$, em blocos ao aca so, com 3 repetições. Foram utilizados 50 esporos por parcela.

Após o periodo de incubação, as membranas fil trantes foram abertas, e sobre os esporos gotejou-se uma solução de Trypan-blue em lactofenol (0,05\%).

Os esporos foram observados em microscópio este reoscópico com aumentos de 10 a 45 vezes, e considerados germi nados se houvesse emergido o tubo germinativo. 
Os dados obtidos foram transformados para arc $\operatorname{sen} \sqrt{x / 100}$, onde $x$ é a percentagem de germinação, e analisados segundo o esquema fatorial $4 \times 3 \times 2$, utilizando-se o programa SANEST do Centro de Informática na Agricultura. Na comparação das médias utilizou-se o teste de Tuckey.

Foi feita também a análise de correlação entre as propriedades químicas do solo e a percentagem de germinação dos esporos pelo método dos quadrados mínimos; e a comparação dos coeficientes de correlação foi feita pelo teste $t$.

Experimento 2 - Efeito da calagem em um solo ácido no desenvolvimento de micorrizas vesiculo-arbusculares em Stylonsanthes guianensis.

o solo nos diferentes niveis de fertilidade e os fungos foram os mesmos utilizados no experimento 1.

o experimento foi conduzido em casa-de-vegeta ção durante os meses de outubro-novembro de 1986 , cuja tempera tura minima registrada foi $16^{\circ} \mathrm{C}$ e a máxima $44^{\circ} \mathrm{C}$.

o solo colocado em copos plásticos de $500 \mathrm{ml}$ foi mantido numa umidade de aproximadamente $70 \%$ de sua capacidade máxima de retenção de água $(U=16 \%)$.

A inoculação com os fungos MVA foi feita no mes mo dia do plantio, com $5,0 \mathrm{~g}$ por vaso de inóculo constituido de esporos, hifas e pedaços de raízes infectadas, obtido de vasos com plantas multiplicadoras (milho).

O inóculo de G. margarita continha em média $126 \pm 9$ esporos por $5 \mathrm{~g}$ de terra, o de G. macrocarpum $192 \pm 3$ por $5 \mathrm{~g}$ e o de $A$. scrobiculata $367 \pm 21$ por $5 \mathrm{~g}$, depois de ter sido diluido. 
No tratamento sem fungo foi utilizada a quantida de de $5 \mathrm{~g}$ por vaso de terra com raizes obtidas de vasos com plantas multiplicadoras não micorrizadas.

Foram plantadas 5 sementes de Stylosanthes guianensis ( IZ-NO 1336) por vaso, escarificadas em $\mathrm{H}_{2} \mathrm{SO}_{4}$ concentrado por 2 minutos e embebidos em água destilada por 24 horas.

Após a emergência das plântulas foi feito um desbaste, deixando-se uma planta por vaso.

Duas semanas após o plantio das sementes foi fei ta uma inoculação com Rhizobium spp. estirpes N015 e SEMIA 2469 , utilizando-se uma suspensão de bactérias em meio de NORRIS Iíquido. No entanto, não houve nodulação.

Aos 38 dias após o plantio, pelo fato de haver sintomas de deficiência de nitrogênio e magnésio, foi feita uma adubação complementar com 20 ppm de $\mathrm{N}\left(\mathrm{NH}_{4} \mathrm{NO}_{3}\right)$ e 15 ppm $\mathrm{Mg}\left(\mathrm{MgSO}_{4} \cdot 7 \mathrm{H}_{2} \mathrm{O}\right)$.

O delineamento experimental consistiu de um fato IIII 4 FUNGOS $\times 4$ NIVEIS DE CALCÁRIO $\times 2$ NÍVEIS DE FÓSFORO $\times 3$ ÉPOCAS DE COLHEITA, com 4 repetições, em blocos ao acaso.

As colheitas foram realizadas aos 40,60 e 80 dias após o plantio das sementes.

Na colheita, o sistema radicular foi separado da parte aérea na altura do colo da planta.

As partes aéreas das plantas foram colocadas em sacos de papel e secas em estufa com ventilação forçada, à $60^{\circ} \mathrm{C}$ até peso constante. Em seguida foi determinada a matéria seca da parte aérea (MSPA) em balança analitica. 
$\mathrm{Na}$ terceira época de colheita a MSPA foi enviada para análise química no CENA. Devido a pequena biomassa produzida não foi possivel a determinação do Nitrogênio. As amostras foram submetidas a digestão nitroperclórica por via úmida, e os elementos $\mathrm{P}, \mathrm{Ca}, \mathrm{Mg}, \mathrm{Fe}, \mathrm{Cu}, \mathrm{Mn}, \mathrm{Zn}, \mathrm{B}$ e Al foram determinados, ell análise multielementar simultânea, por espectrometria de emissão atômica com plasma induzido de argônio. o $\mathrm{K}$ e o $\mathrm{Na}$ foram determinados por fotometria de chama por emissão atômica e o s por turbidimetria em sistema de fluxo, na forma de sulfato.

O sistema radicular foi lavado em água corrente, seco com papel absorvente e pesado em balança analitica para de terminação da matéria fresca do sistema radicular (MFSR). Uma vez pesadas, as raizes foram colocadas em frascos contendo A.F.A. (ácido acético: $5 \mathrm{ml}$; formol: $13 \mathrm{ml}$ e etanol a 50 \%: 200 ml) para conservação.

A percentagem de colonização das raízes foi esti mada pelo método modificado de PHILLIPS e HAYMANN (1970) que consiste no seguinte:

- Lavar as raízes fixadas em AFA com água corrente,

- aquecer as raízes em $\mathrm{KOH} 10 \%$ a $90^{\circ} \mathrm{C}$ por $30 \mathrm{mi}$ nutos,

- lavar com água corrente,

- lavar as raizes com HCl 1 \% por 3 a 4 minutos,

- remover o ácido,

- aquecer as raizes em lactoglicerol com "trypanblue" $(0,05 \%)$ a $90^{\circ} \mathrm{C}$ por 2 a 3 minutos,

- remover o lactoglicerol colorido e guardar as raizes em lactoglicerol incolor, 
- distribuir aproximadamente $0,5 \mathrm{~g}$ de raizes co radas em uma placa de Petri com o fundo quadriculado,

- efetuar a contagem dos pontos sobre as Iinhas horizontais onde há infeç̧ão e o total de pon tos observados,

- calcular a percentagem de colonização.

Com os dados da matéria seca da parte aérea e da matéria fresca do sistema radicular calculou-se a relação MSPA/MFSR.

As variáveis MSPA, MFSR, \% colonização e MSPA/ MFSR foram analisadas segundo o esquema fatorial $4 \times 4 \times 2 \times 3$, utilizando-se o mesmo programa do experimento 1.

A variável \% colonização foi transformada para arc sen $\sqrt{x / 100}$; onde $x$ é a percentagem de colonização micorrizica, e a variável MSPA/MFSR para $\sqrt{x+0,5}$, sendo $x$ a relação MSPA/MFSR.

Como nos solos sen adição de $P$ a produção de MSPA foi muito baixa, não foi possivel fazer a determinação de nutrientes na parte aérea em todas as parcelas, de modo que desprezou-se o fator FóSFORO do delineamento experimental inicial, e as variáveis $P$ \%, P total, K\%, K total, Ca \%, Ca total; Mg\%, Mg total, S\%, S total, Fe ppm, Fe total, Cu ppm, Cu total, Mn ppm, Mn total, Zn ppm, Zn total, B ppm, B total, $\mathrm{Na}$ ppm, Na total, Al ppm e Al total foram analisadas segundo o esquema fatorial 4 FUNGOS $x 4$ NÍVEIS DECALCÁRIO. 
As médias de todas as variáveis foram comparadas pelo teste de Tuckey.

As análises de correlação realizadas utilizaram - método dos quadrados mínimos, e a comparação dos coeficientes de correlação foi feita pelo teste $t$. 


\section{RESULTADOS E DISCUSSÃO}

4.1. Experimento 1. Efeito da calagem em um solo ácido na germinação de esporos de fungos micorrizicos vesiculoarbusculares

Neste experimento foi avaliada a percentagem de germinação dos esporos de populações de Gigaspora margarita,Glomus macrocar pum e Acaulospora scrobiculata.

As médias da percentagem de germinação, obtidas de 3 repetições, são apresentadas na Tabela 2.

Foi feita análise de variância dos dados obti dos, utilizando-se uma transformação estatística adequada (arc sen $\sqrt{x / 100}$ ), sendo que os valores de $F$ encontrados podem ser vistos na Tabela 3 .

Podellos observar que houve efeitos altamente significativos dos fatores FUNGO e CALAGEM, e que o fator FósFORO só teve efeito significativo $\operatorname{com} p=0,10$. Com excessão da interação CALCÁRIO x FÓSFORO, as demais interações foram altamente significativas. 


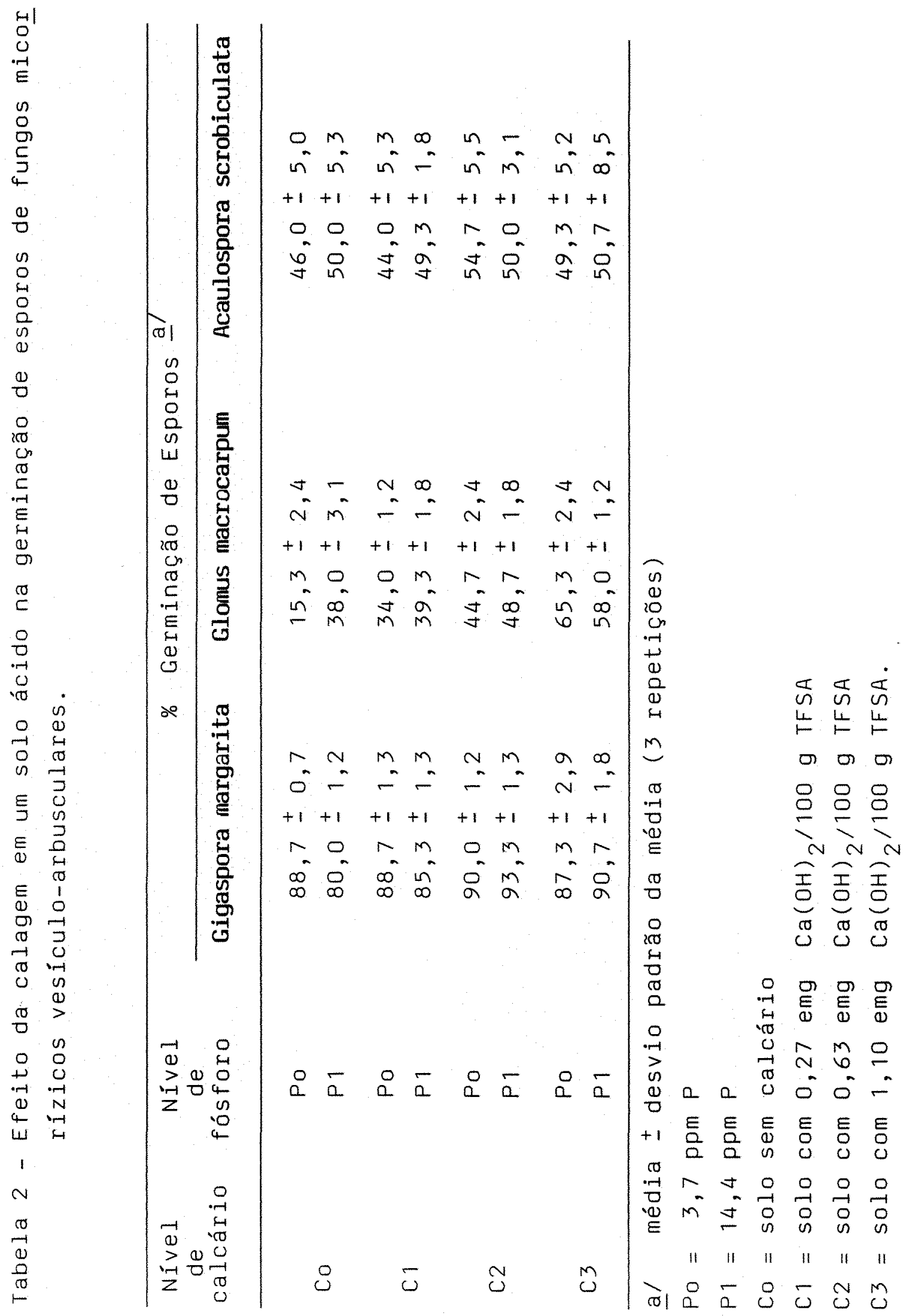


34.

Tabela 3 - Valores de F obtidos na análise de variância da percentagem de germinação de esporos.

Causas da variação

GL

F

Fungos $(F)$

Calcário (C)

Fósforo (P)

$F \times C$

$F \times P$

$C \times P$

$F \times C \times P$
2

3

1

6

2

3

6
$584,97 * *$

$28,32 * *$

$3,25 *$

$12,06 * *$

$3,50 * *$

$1,04 \mathrm{~ns}$

$6,44 * *$

Coeficiente de variação: $6,25 \%$

* = significativo com $p=0,10$.

** = significativo com $p \leqslant 0,05$.

$n s=$ não significativo.

A Figura 1 mostra o efeito do fator FUNGO na percentagem de germinação dos esporos. A germinação de G.mar garita foi $105,1 \%$ maior do que a germinação de $G$. macrocarpum e esta foi $12,8 \%$ menor do que a germinação de $A$. scrobiculata, cuja média foi $49,2 \%$.

o efeito do fator CALCARIO é mostrado na Figura 2. A tendência observada foi de haver um aumento da germinação dos esporos com o aumento do nivel de calcário do solo, sen do que a germinação no solo com o nivel 3 de calcário foi $26,2 \%$ maior do que a germinação no solo sem calcário (53,0\%). A calagem do solo aumentou ell $7,2 \%$ e $20,6 \%$ a percentagem de germinação dos esporos, nos niveis 1 e 2 de calcário respecti vamente, em relação ao solo sem calcário. 


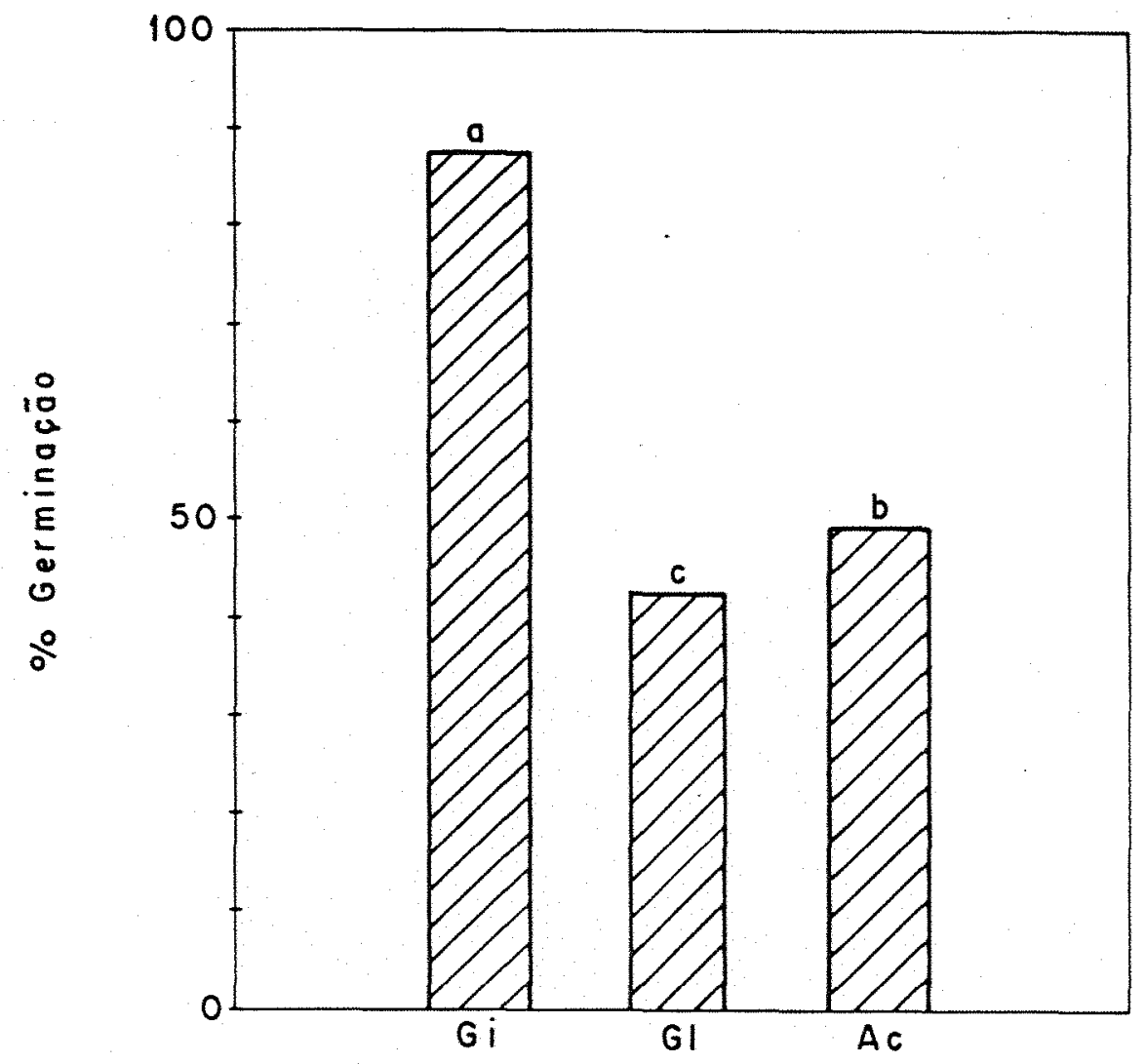

$G i=$ Gigaspora margarita

$G I=$ Glomus macrocarpum

$A C=$ Acaulospora scrobiculata

Letras diferentes diferem estatisticamente pelo teste de Tuckey $(p \leqslant 0,05)$.

Figura 1 - Variação da percentagem de germinação de esporos para diferentes espécies de fungos micorrizicos - VA. 


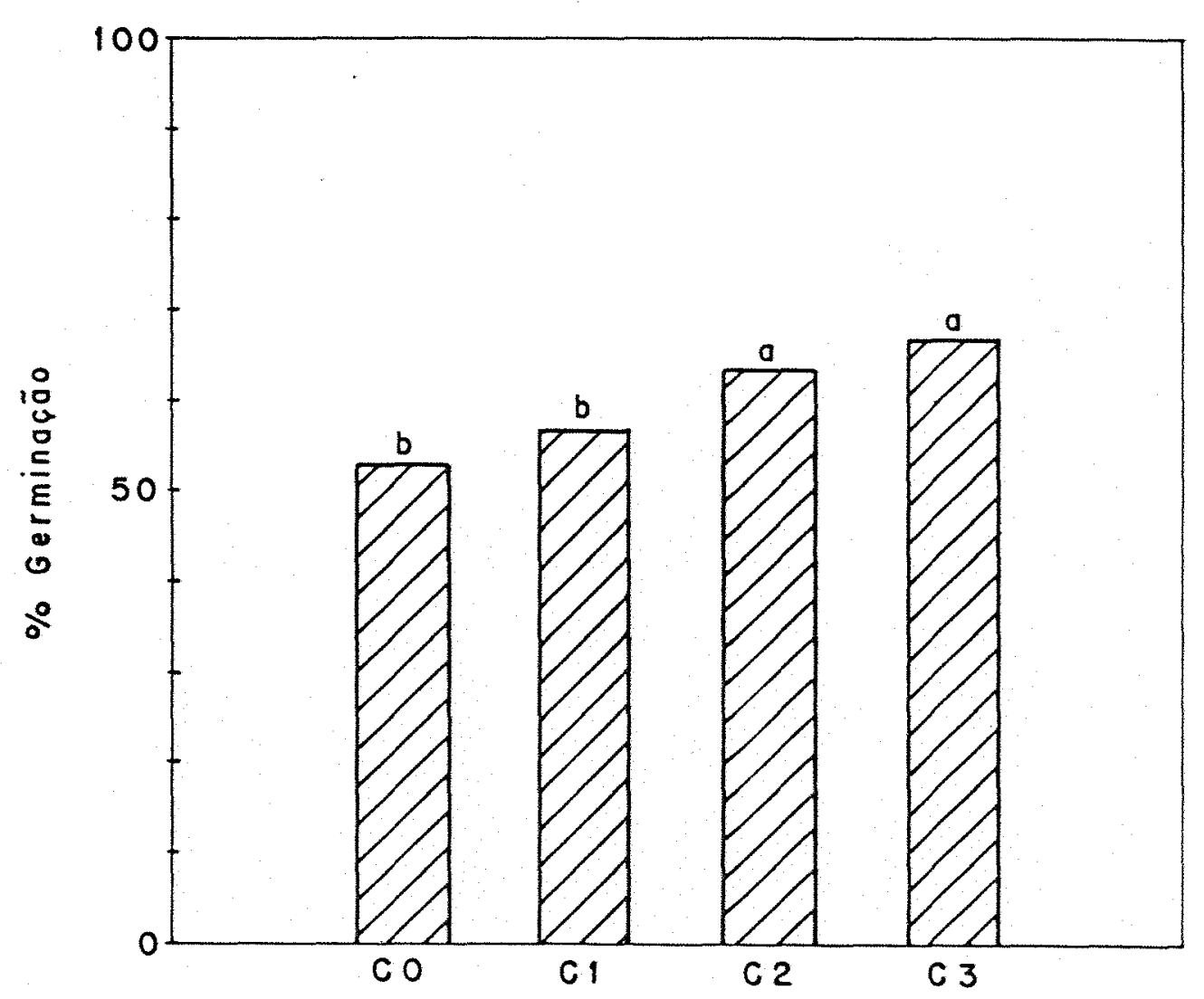

CO $=$ solo sem calcário .

$\mathrm{C1}=$ solo com $0,27 \mathrm{emg} \mathrm{Ca}(\mathrm{OH})_{2} / 100 \mathrm{~g}$ TFSA.

$\mathrm{C} 2=$ solo com $0,63 \mathrm{emg} \mathrm{Ca}(\mathrm{OH})_{2} / 100 \mathrm{~g}$ TFSA.

$\mathrm{C3}=$ solo com 1,10 emg $\mathrm{Ca}(\mathrm{OH})_{2} / 100 \mathrm{~g}$ TFSA.

Letras iguais não diferem estatisticamente pelo teste de Tuckey $(p \leqslant 0,05)$.

Figura 2 - Variação da percentagem de germinação de esporos de fungos micorrizicos - VA em um solo ácido com dife rentes niveis de calcário. 
No geral, a adição de fósforo ao solo causou um aumento de 3,6 \% na germinação, significativo somente com $p=$ 0,10 . No entanto, a germinação de G. macrocarpum aumentou $15,6 \%$ com a adição de fósforo ao solo, enquanto que G. margarita e A. scrobiculata não responderam significativamente, con forme pode ser visto na Figura 3 .

SIQUEIRA et alii (1982) observaram um aumento significativo de $34,6 \%$ na germinação de esporos de G. margari ta, com a adição de 20 ppm de $P$ em meio de cultura agarizado, enquanto KOSKE (1981) não obteve diferenças significativas na germinação de esporos de G. gigantea ell niveis mais elevados de $P$. Concentrações de até $600 \mathrm{mM}$ também não reduziram a germinação de Glomus mosseae em areia (SIQUEIRA et alii, 1984). DANIELS e TRAPE (1980) encontraram que a germinação de esporos de G. epigaeum é máxima com aproximadamente 14 ppm de $P$ no solo havendo um incremento de aproximadamente $14 \%$, em relação ao solo com $10 \mathrm{ppm}$ de $\mathrm{P}$, diminuindo com o aumento da concentra ção de $P$ no solo.

A variabilidade das condições experimentais, alia da à variabilidade genética das espécies e até mesmo das populações de fungos micorrizicos-VA não permite fazer uma generaIização sobre o efeito do fósforo na germinação dos esporos.o que ocorre com mais frequência é que as espécies de Glomus têm uma germinação ótima numa determinada concentração de $P$ no solo, com uma tendência a diminuir com o aumento dessa concentra ção.

As espécies de Gigaspora normalmente não respon dem ao aumento da concentração de $P$ no solo. 


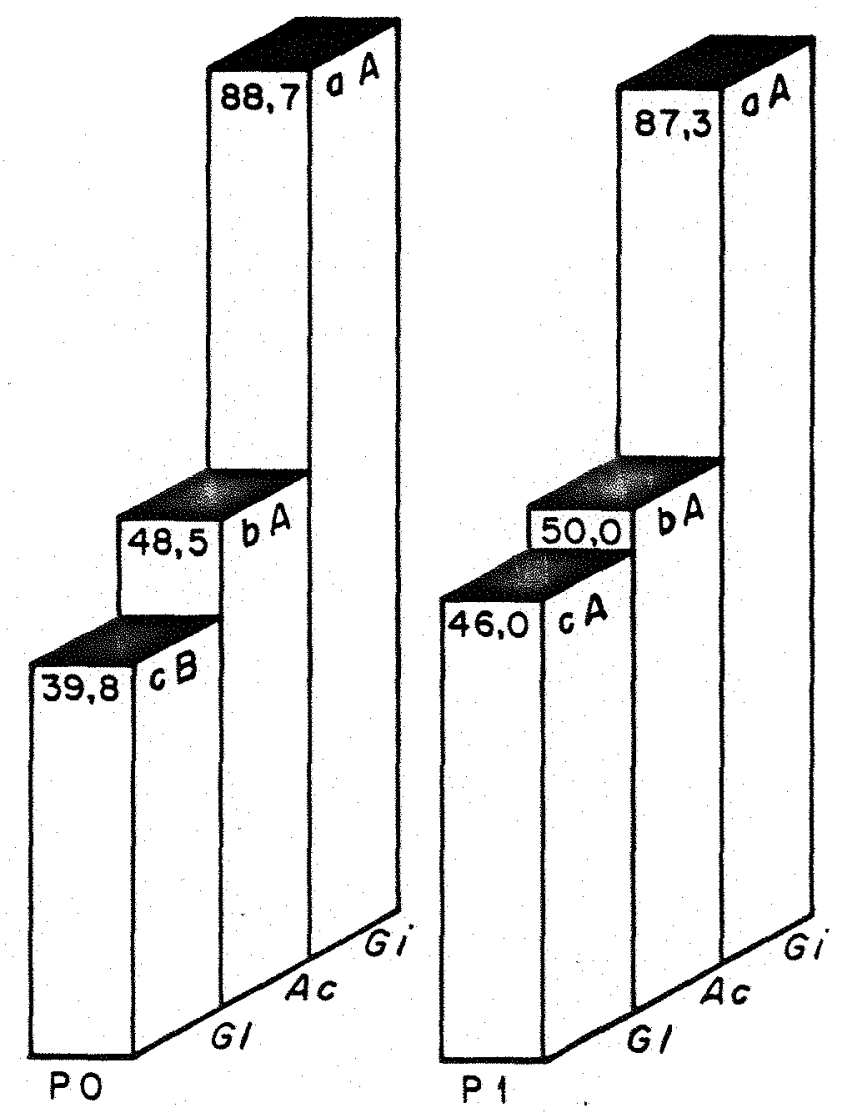

$P O=3,7 \mathrm{pPm} P$.

P1 $=14,4$ ppm P.

Letras iguais não diferem estatisticamente (Tukey $\leqslant 0,05$ ).

As letras maiúsculas são usadas para comparar as médias dos tra tamentos com e sem fósforo; e a minúsculas para comparar as médias no mesmo nivel de fósforo.

Figura 3 - Efeito de diferentes níveis de fósforo na germinação de esporos de Glomus macrocarpum, Acaulospora scrobi culata e Gigaspora margarita. 
Pelas respostas obtidas neste experimento pode mos dizer que as populações de G. margarita e A. scrobiculata utilizadas são mais tolerantes a condições de solos distróficos do que a população de G. macrocarpum, que responde pronta mente ao aumento de $P$ no solo.

A adição de $P$ ao solo sem calcário causou um incremento de 12,0 \% na germinação dos esporos, enquanto que nos solos com calcário não houve efeito significativo, conforme da dos apresentados na Tabela 4.

Esses dados sugerem que deve haver um balanço nutricional no solo para que a germinação dos esporos seja ótima. Resultados semelhantes foram encontrados por SIQUEIRA et alii (1982) os quais mostraram que a taxa de germinação em meio suplementado com $N, P$ e $K$ era a mesma daquela obtida em meio suplementado somence com $P$, em concentração 10 vezes maior.

As populações das três espécies de fungos micorrízicos VA testadas respondem diferentemente à correção do solo com cala gem, como pode ser visto na Figura 4, provavelmente devido à maior ou menor adaptabilidade dessas populações a solos áci dos.

A tendência observada foi de haver uma germina ção máxima no solo com o nível 2 de calcário., correspondendo ao pH 5,2, tanto para G. margarita, quanto para A. scrobiculata. G. macrocarpum mostrou percentagens de germinação crescentes com o aumento do nivel de calcário. 
Tabela 4 - Efeito de diferentes niveis de fósforo e de calcário na germinação de esporos de fungos micorrizicos-VA.

Nivel de calcário

Nivel de Fósforo

PO

$50,0 \mathrm{bB}$

56,0 aB

C1

55,6 aB

58,0 aB

C2

63,1 aA

64,0 aA

C3

67,3 a $A$

66,5 a $A$

As letras minúsculas são usadas para comparar as médias na linha, e as maiúsculas para comparar as médias na coluna. Letras iguais não diferem estatisticamente (Tukey $p \leqslant 0,05$ ).

CO = solo sem calcário.

$\mathrm{C1}=$ solo com 0,27 emg $\mathrm{Ca}(\mathrm{OH})_{2} / 100 \mathrm{~g}$ TFSA

$\mathrm{C} 2=$ solo com $0,63 \mathrm{emg} \cdot \mathrm{Ca}(\mathrm{OH})_{2} / 100 \mathrm{~g}$ TFSA

$\mathrm{C3}=$ solo com $1,10 \mathrm{emg} \mathrm{Ca}(\mathrm{OH})_{2} / 100 \mathrm{~g}$ TFSA

$\mathrm{PO}=3,7 \mathrm{ppm} P$

$P 1=14,4 \mathrm{pPmP}$.

0 incremento na percentagem de germinação de G. margarita foi de $8,6 \%$, e de A. scrobiculata de 9,2 \% no nivel 2 de calcário, em relação a germinação no solo sem calcário. G. macrocarpum teve um incremento de 131,1 \% na germinação no nivel 3 de ralcário, em relação ao solo sem calcário.

Pela resposta das três populações aos diferen tes niveis de calcário do solo, e consequentemente aos diferentes valores de $\mathrm{pH}$ e concentrações de $\mathrm{Al}^{+3}$, além de outros nutrientes que têm sua disponibilidade afetada pelo pH do solo, existem evidências de que A. scrabiculata está muito mais adap 

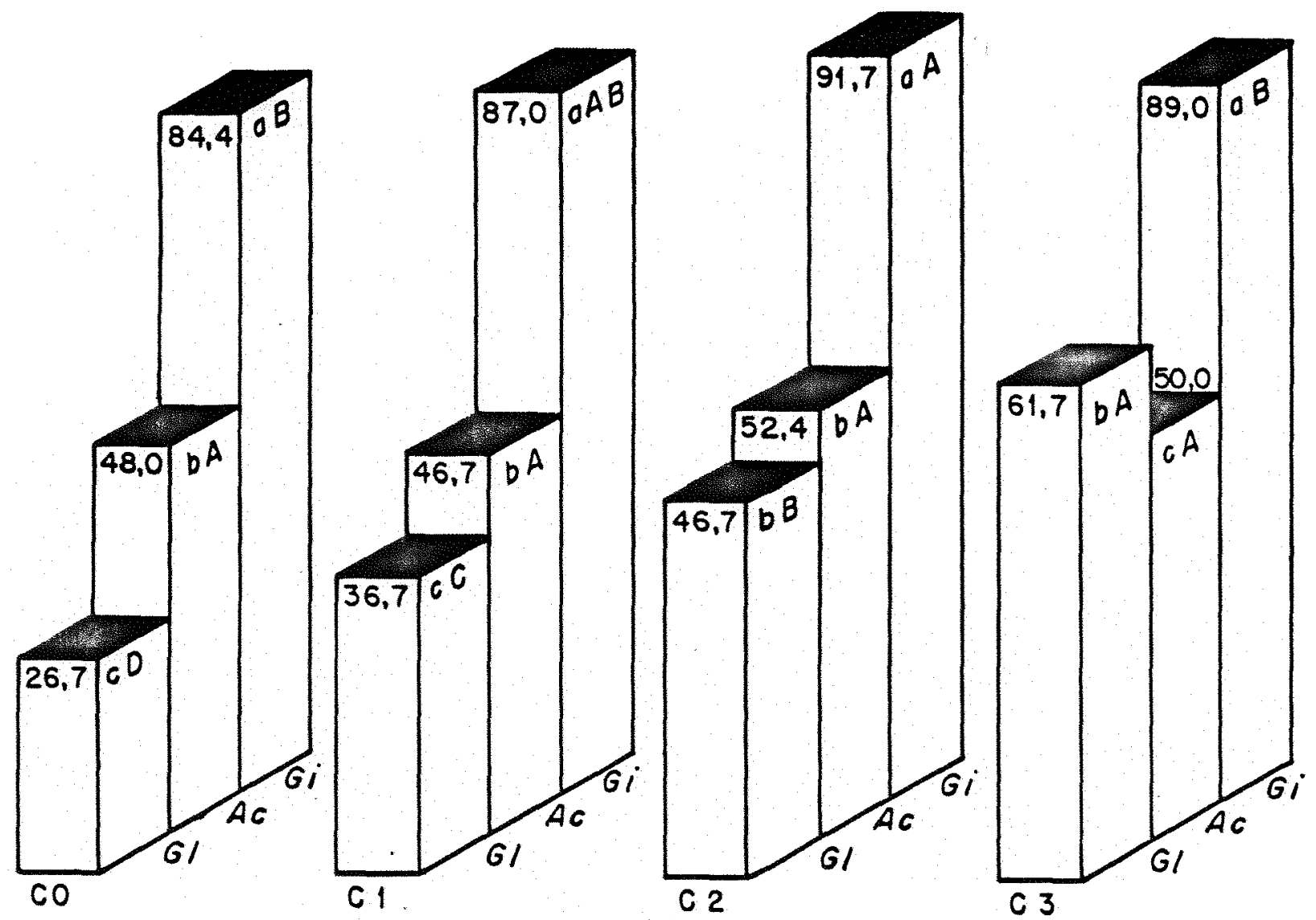

CO = solo sem calcário.

$C 1=$ solo com $0,27 \mathrm{emg} / 100 \mathrm{~g}$ TFSA.

$C 2=$ solo com $0,63 \mathrm{emg} / 100 \mathrm{~g}$ TFSA.

$C 3=$ solo com $1,10 \mathrm{emg} / 100 \mathrm{~g}$ TFSA.

Letras iguais não diferem estatisticamente (Tuckey $p \leqslant 0,05$ ). As letras maiúsculas são usadas para comparar as médias dos diferentes niveis de calcário e as minúsculas para comparar as mé dias no mesmo nível de calcário.

Figura 4 - Efeito de diferentes niveis de calcário na germinação de esporos de Glomus macrocarpum, Acaulospora scrobi culata e Gigaspora margarita. 
tada a condições de solos ácidos com altos niveis de $\mathrm{Al}^{+3}$ do que G. margarita, que por sua vez é mais tolerante a tais con dições do que G. macrocarpum.

Essas evidências podem ser confirmadas pela presença generalizada de $A$. scrobiculata nas mais variadas con dições edáficas, e a presença mais restrita de G. margarita e G. macrocarpum (COLOZZI FILHO et alii, 1986; FERNANDES et alii, 1987).

SIQUEIRA et alii (1982) obtiveram respostas seme lhantes de G. margarita a diferentes niveis de calcário Estes autores observaram que a germinação de Glomus mosseae tende a aumentar com o aumento do nivel de calcário, com o mesmo tipo de comportamento que G. macrocarpum mostrou neste experimenco. Segundo DANIELS e TRAPPE (1980) a germinação de Glomus epigaeum é máxima em $\mathrm{pH}$ 7,0, e ocorre numa ampla faixa de $\mathrm{pH}$.

Mais uma vez, a grande variação das condições experimentais e do material biológico testado não permite fazer nenhuma generalização sobre níveıs de pH ótimos para germinação de cada espécie, permitindo somente comparar a adapta bilidade das populações testadas a diferentes condições edáfí cas.

Foram feitas análises de correlação entre a per centagem de germinação dos esporos e as propriedades químicas do solo, nos oito niveis de fertilidade utilizados. Os resul tados estão na Tabela 5 .

Para as três espécies avaliadas em conjunto, hou ve correlações positivas com $\mathrm{pH}, \mathrm{Ca}^{+2}$, Soma de bases ( $\mathrm{S}$ ) e $\mathrm{Sa}-$ turação de bases $(V)$. Correlações negativas com $\mathrm{Al}^{+3}, \mathrm{H}^{+}, \mathrm{Sa}$ 


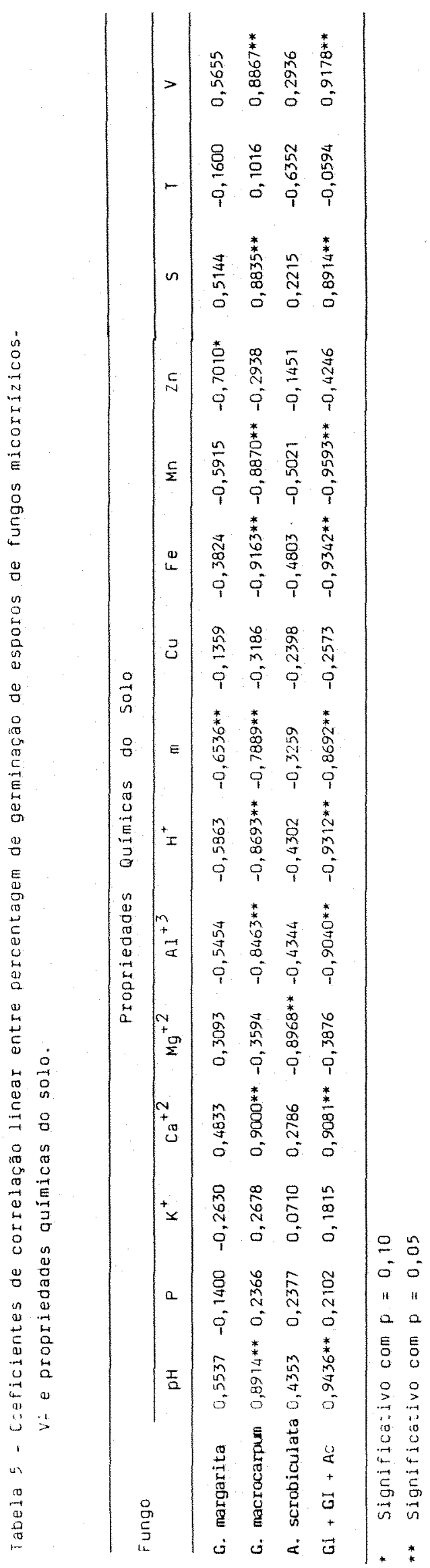


turação de aluminio ( $m$ ), Fe e Mn, também foram obtidas. Es sas correlações foram significativas com $p \leqslant 0,05$.

Tratando as espécies individualmente, essas cor relações mantiveram-se significativas somente em alguns casos.

A percentagem de germinação de esporos de G. ma

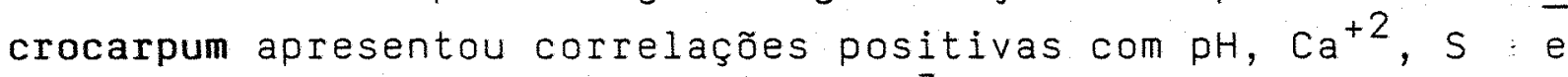
$V$, e correlações negativas com $\mathrm{Al}^{+3}, \mathrm{H}^{+}$, Fe e $\mathrm{Mn}$. Para G. margarita, a percentagem de germinação de esporos correlacio nou-se negativamence com $m$ e $Z n$, enquanto $A$. scrobiculata mostrou correlação negativa somente com a concentração de $\mathrm{Mg}^{+2}$ no solo.

SIQUEIRA et alii (1984) encontraram um maior nú mero de correlações entre percentagem de germinação de esporos e caracteristicas quimicas do solo significativas para G. mosseae, en relação a G. margarita.

Estes resultados confirmam novamente a maior adaptabilidade de $A$. scrobiculata a solos ácidos, em relação a G. margarita e G. macrocarpum, cuja sensibilidade a tais condi ções foi maior.

- pH do solo isoladamente não pode ser considerado como um fator preponderante na otimização da germinação de esporos de fungos micorrizicos-VA. Os fatores que variam em função do pH, principalmente a solubilidade de elementos tóxicos, também devem ser considerados.

A saturação do solo em $\mathrm{Al}^{+3}$ talvez seja uma caracteristica mais adequada para se avaliar o efeito da acidez na germinação dos esporos, já que correlacionou-se significativamente com a percentagem de germinação dos esporos na maioria dos casos. 
A germinação de espécies de Glomus em ágar, é inibida reversivelmente pela presença de $\mathrm{Mn}, \mathrm{Zn}$ e $\mathrm{Cu}$, em concentrações normalmente encontradas na solução do solo (HEPPER e SMITH, 1976; HEPPER, 1979). Assim, a concentração desses elementos é um componente fundamental do efeito da acidez do solo sobre a germinação dos esporos, pois suas concentrações estão inversamente correlacionadas com o pH do solo.

No geral, os fungos testados correlacionaram se negativamente com a concentração de $\mathrm{Fe}$ e $\mathrm{Mn}$ no solo.

G. margarita mostrou-se mais sensivel ao $\mathrm{Zn}$ e G. macrocarpum ao $\mathrm{Mn}$ e ao $\mathrm{Fe}$. A. scrobiculata mostrou-se tolerante ao $\mathrm{Cu}, \mathrm{Fe}, \mathrm{Mn}$ e $\mathrm{Zn}$ nas concentrações usadas neste experimento, não apresentando correlação significativa com nenhum desses elementos.

4.2. Experimento 2. Efeito da calagem em um solo ácido no desenvolvimento de micorrizas vesiculo-arbusculares em Stylosanthes guianensis

4.2.1. Desenvolvimento da colonização micorrízica

A percentagem de colonização das raizes de $S$. guianensis foi avaliada, e as médias, obtidas de 4 repetições, podem ser vistas na Tabela 6 .

Os dados obtidos foram submetidos a análise de variância, utilizando-se a transformação estatistica arc sen $\sqrt{x / 100}$, e os valores de $F$ resultantes são apresentados na Tabela 7 .

Podemos observar que o valor $F$ mais significativo foi para o fator FUNGo, seguido do fator FósForo. 
Tabela 6 - Efeito da calagem e do nivel de fósforo do solo na colonização micorrízica de Stylosanthes guianensis.

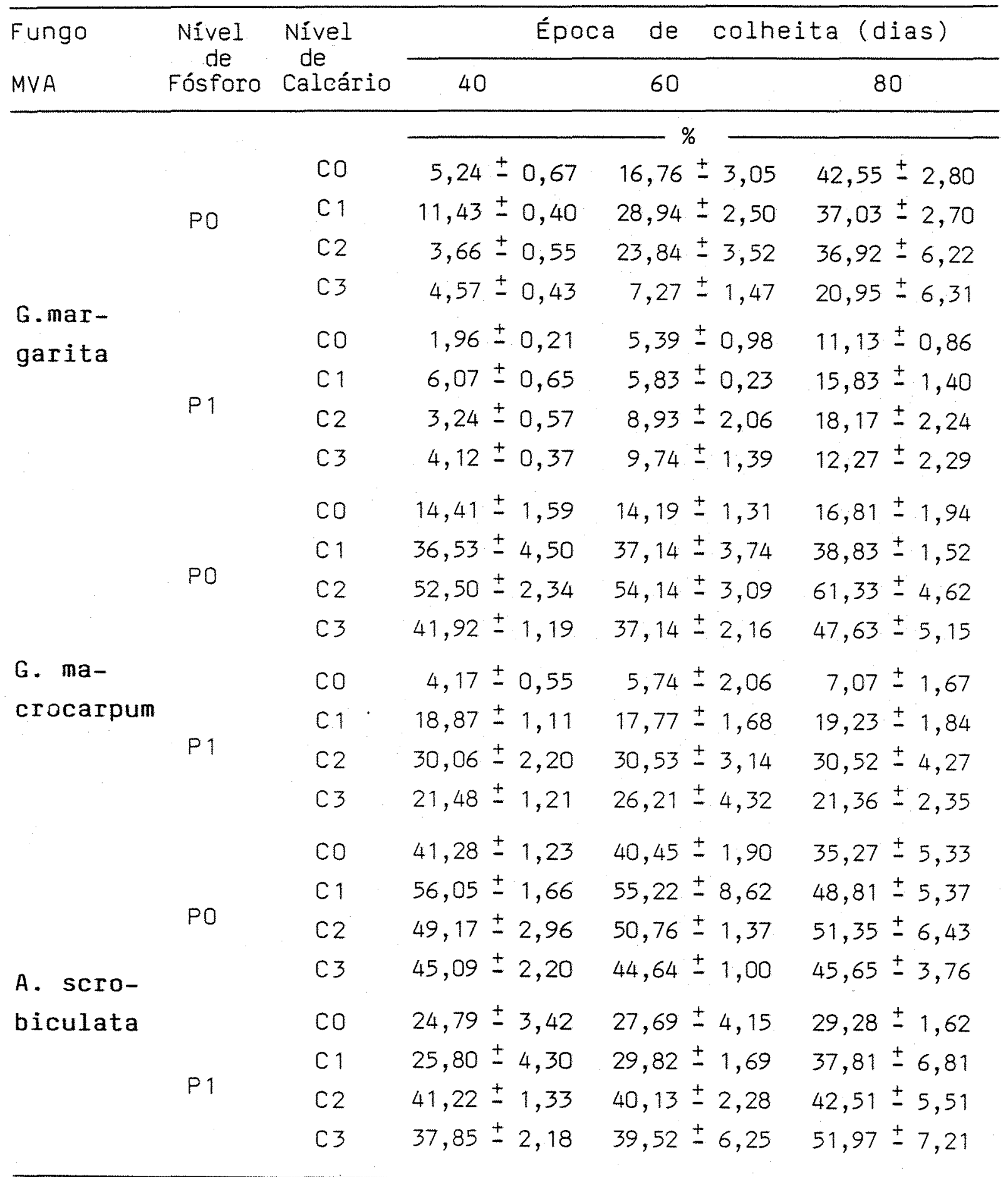

Os valores apresentados representam a média \pm desvio padrão de média ( 4 repetiçães).

os tratamentos controle não apresentaram colonização micorrizi ca. 


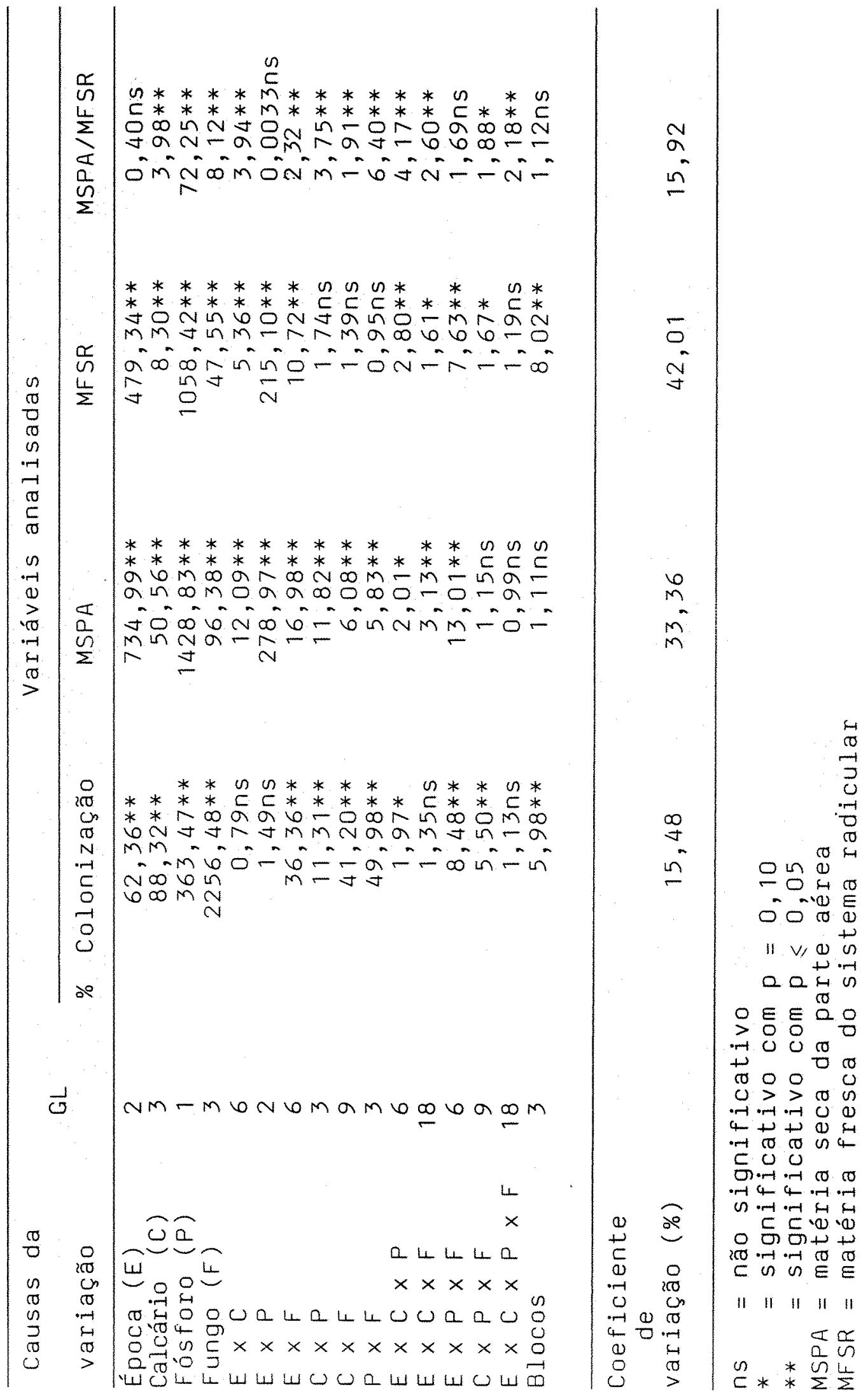


Na Tabela 8 verificamos que a variação da média da percentagem de colonização das raízes, em relação a colonização por G. margarita, foi de 190,31 \% para A. scrobiculata e $100,56 \%$ para G. macrocarpum.

No geral, a colonização das raízes foi máxima no nivel 2 de calcário (Tabela 9), da mesma forma que a germinação dos esporos. A colonização das raízes no solo com o nível 2 de calcário foi 82,77 maior do que no solo sem calcário, mostrando que as condições de solos ácidos têm um efeito fungistático sobre o desenvolvimento das micorrizas-VA. A variação da colo nização micorrízica foi de 53,14\% no nivel 1 de calcário e de $50,91 \%$ no nivel 3, em relação ao solo sem calcário.

Analisando a interação CALCÁRIO x FUNGO podemos observar que o grau de colonização das raizes pelos diferentes fungos testados variou em função do nivel de calcário do solo. (Tabela 10).

Houve uma colonização máxima por G.margarita no nivel 1 de calcário diminuindo com o aumento do nivel de calcá rio. A variação, em relação ao solo sem calcário, foi de $26,59 \%$.

G. macrocarpum apresentou uma colonização máxima no solo com o nível 2 de calcário, sendo 315,19\% maior do que no solo sem calcário, e 32,37 maior do que no solo com o nível 3 de calcário.

A colonização das raízes por A. scrobiculata não diferiu estatisticamente nos solos com calcário, sendo estes ní veis em média 33 \% superiores ao encontrado no solo sem calcário. 
Tabela 8 - Efeitos de diferentes associações micorrízicas vesiculo-arbusculares sobre algumas variáveis analisadas.

\begin{tabular}{lllll}
\hline \multirow{2}{*}{ Fungo } & \multicolumn{5}{c}{ Variáveis analisadas } \\
\cline { 2 - 5 } & MFSR $(\mathrm{g})$ & MSPA $(\mathrm{g})$ & MSPA/MFSR & \% Colonização \\
\hline Controle & $0,7557 \mathrm{c}$ & $0,2954 \mathrm{c}$ & $0,5192 \mathrm{bc}$ & $0,00 \mathrm{~d}$ \\
G. margarita & $0,7809 \mathrm{c}$ & $0,3073 \mathrm{c}$ & $0,8273 \mathrm{a}$ & $14,24 \mathrm{c}$ \\
G. macrocarpum & $1,0553 \mathrm{~b}$ & $0,4981 \mathrm{~b}$ & $0,6364 \mathrm{ab}$ & $28,56 \mathrm{~b}$ \\
A. scrabiculata & $1,3856 \mathrm{a}$ & $0,5770 \mathrm{a}$ & $0,4983 \mathrm{c}$ & $41,34 \mathrm{a}$
\end{tabular}

As letras minúsculas são usadas para comparar as médias das diferentes associações micoríizicas.

Letras iguais não diferem estatisticamente (Tuckey $p \leqslant 0,05$ ).

os valores apresentados são médias de 96 repetições.

Tabela 9 - Efeito da calagem em um solo ácido sobre algumas variáveis analisadas.

\begin{tabular}{ccccc}
\hline \multirow{2}{*}{$\begin{array}{c}\text { Nivel de } \\
\text { Calcário }\end{array}$} & MFSR $(\mathrm{g})$ & MSPA $(\mathrm{g})$ & MSPA/MFSR & \% Colonização \\
\cline { 2 - 5 } & $0,8300 \mathrm{~b}$ & $0,2702 \mathrm{~b}$ & $0,5272 \mathrm{~b}$ & $14,34 \mathrm{c}$ \\
C0 & $1,0914 \mathrm{a}$ & $0,4613 \mathrm{a}$ & $0,7582 \mathrm{a}$ & $21,96 \mathrm{~b}$ \\
C1 & $1,0852 \mathrm{a}$ & $0,4968 \mathrm{a}$ & $0,6578 \mathrm{a}$ & $26,21 \mathrm{a}$ \\
C2 & $0,9709 \mathrm{ab}$ & $0,4495 \mathrm{a}$ & $0,5379 \mathrm{ab}$ & $21,64 \mathrm{~b}$ \\
\hline
\end{tabular}

As letras minúsculas são usadas para comparar as médias dos diferentes niveis de calcário

Letras iguais não diferem estatisticamente (Tuckey $p \leqslant 0,05$ ).

Co = solo sem calcário

$\mathrm{C} 1=$ solo com 0,27 emg $\mathrm{Ca}(\mathrm{OH}) / 100 \mathrm{~g}$ TFSA.

$\mathrm{C2}=$ solo com 0,63 emg $\mathrm{Ca}(\mathrm{OH}) 2 / 100 \mathrm{~g}$ TFSA.

$\mathrm{C3}=$ solo com 1,10 emg $\mathrm{Ca}(\mathrm{OH}) / 100 \mathrm{~g}$ TFSA.

MSPA = matéria seca da parte aérea.

MFSR = matéria fresca do sistema radicular. 
No solo sem calcário, as colonizações por G.mar garita e G. macrocarpum não diferiram estatisticamente, sendo em média 2,8 vezes menores que a colonização por A. scrobicula ta. No solo com o nivel 2 de calcário, a colonização por G.macrocarpum não diferiu estatisticamente da colonização por $A$. scrobiculata, sendo em média 2,8 vezes maior do que a coloniza ção por G. margarita.

Estes resultados mostram que a população de $A$. scrobiculata utilizada praticamente não responde a calagem de solos áci dos sendo entretanto mais tolerante a niveis de pHbaixo, enquanto G. margarita mostrou uma tolerância intermediária, e G. macrocarpum uma maior sensibilidade. No entanto, o grau de coloniza ção atingido por G. macrocarpum foi superior aquele atingido por G. margarita, provavelmente pelo fato dos esporos de G.mar garita terem germinado muito rapidamente, não encontrando um sistema radicular adequado para a colonização, pois o stylosan thes tem um desenvolvimento inicial lento.

CORDEIRO et alii (1986) e MOSQUIM et alii (1986) não obtiveram resposta da colonização micorrizica de stylosanthes à calagem nem ao nivel de $P$ do solo.

Analisando o efeito do fator $P$, podemos dizer que no solo com adição de $P(14,4$ pm $P)$, a colonização das raí zes foi 48,40 \% menor do que no solo sem adição de $P$ ( 3,7 ppm P), como consta da Tabela 11. É evidente o efeito inibitório da alta concentração de $P$ na formação das micorrizas, como já foi verificado por vários autores (SIQUEIRA et alii, 1984; MOS SE, 1981; LAMBERT et alii, 1979; MENGE, 1978).

$A$ adição de $P$ ao solo reduziu a colonização das raízes por G. margarita en $57,05 \%$, por G. macrocarpum em $48,50 \%$ e por A. scrobiculata em $24,01 \%$, em relação as percentagens de colonização obtidas no solo sem a adição de $P$ (Tabela 12). 
Tabela 10 - Efeito da calagem em um solo ácido na colonização de raizes de 5 . guianensis por diferentes fungos micorrizicos-VA.

\begin{tabular}{lcccc}
\hline \multirow{2}{*}{$\begin{array}{c}\text { Fungo } \\
\text { MVA }\end{array}$} & \multicolumn{4}{c}{ Nóvel de calcário } \\
\cline { 2 - 5 } Controle & $0,00 \mathrm{aC}$ & $0,00 \mathrm{aD}$ & $0,00 \mathrm{aC}$ & $0,00 \mathrm{aD}$ \\
G.margarita & $13,84 \mathrm{bcB}$ & $17,52 \mathrm{aC}$ & $15,79 \mathrm{abB}$ & $9,82 \mathrm{cC}$ \\
G.macrocarpum & $10,40 \mathrm{~dB}$ & $28,06 \mathrm{cB}$ & $43,18 \mathrm{aA}$ & $32,62 \mathrm{bB}$ \\
A. scrobiculata & $33,13 \mathrm{bA}$ & $42,25 \mathrm{aA}$ & $45,86 \mathrm{aA}$ & $44,12 \mathrm{aA}$ \\
\hline
\end{tabular}

As letras minúsculas são usadas para comparar as médias na linha, e as maiús culas na coluna.

Letras iguais não diferem estatisticamente (Tukey $p \leqslant 0,05$ ).

$\mathrm{CO}=$ solo sem calcário.

$\mathrm{Cl}=$ solo com $0,27 \mathrm{emg} \mathrm{Ca}(\mathrm{OH}) / 100 \mathrm{~g}$ TFSA

$\mathrm{C} 2=$ solo com 0,63 emg $\mathrm{Ca}(\mathrm{OH}) \frac{2}{2} / 100 \mathrm{~g}$ TFSA

$\mathrm{C} 3=$ solo com $1,10 \mathrm{emg} \mathrm{Ca}(\mathrm{OH})_{2}^{2} / 100 \mathrm{~g}$ TFSA.

Tabela 11 - Efeitos do nivel de fósforo no solo sobre algumas va Iiáveis analisadas.

\begin{tabular}{ccccc}
\hline Nivel de & \multicolumn{4}{c}{ Variáveis analisadas } \\
\cline { 2 - 5 } Fósforo & MFSR (g) & MFSR $(\mathrm{g})$ & MSPA/MFSR & $\%$ colonização \\
\hline PO & $0,3008 \mathrm{~b}$ & $0,1496 \mathrm{~b}$ & $0,8044 \mathrm{a}$ & $26,61 \mathrm{a}$ \\
P1 & $1,6879 \mathrm{a}$ & $0,6893 \mathrm{a}$ & $0,4362 \mathrm{~b}$ & $13,73 \mathrm{~b}$ \\
\hline
\end{tabular}

As letras minúsculas são usadas para comparar as médias dos diferentes niveis de fósforo.

Letras diferentes diferem estatisticamente (Tuckey $p \leqslant 0,05$ ).

Os valores apresentados são médias de 192 repetições.

$\mathrm{PO}=3,7 \mathrm{ppm} P$

$P 1=14,4$ ppm $P$

MSPA = matéria seca da parte aérea

MFSR = matéria fresca do sistema radicular. 
Tabela 12 - Efeito do nivel de fósforo de um solo ácido sobre a colonização micorrízica em S. guianensis.

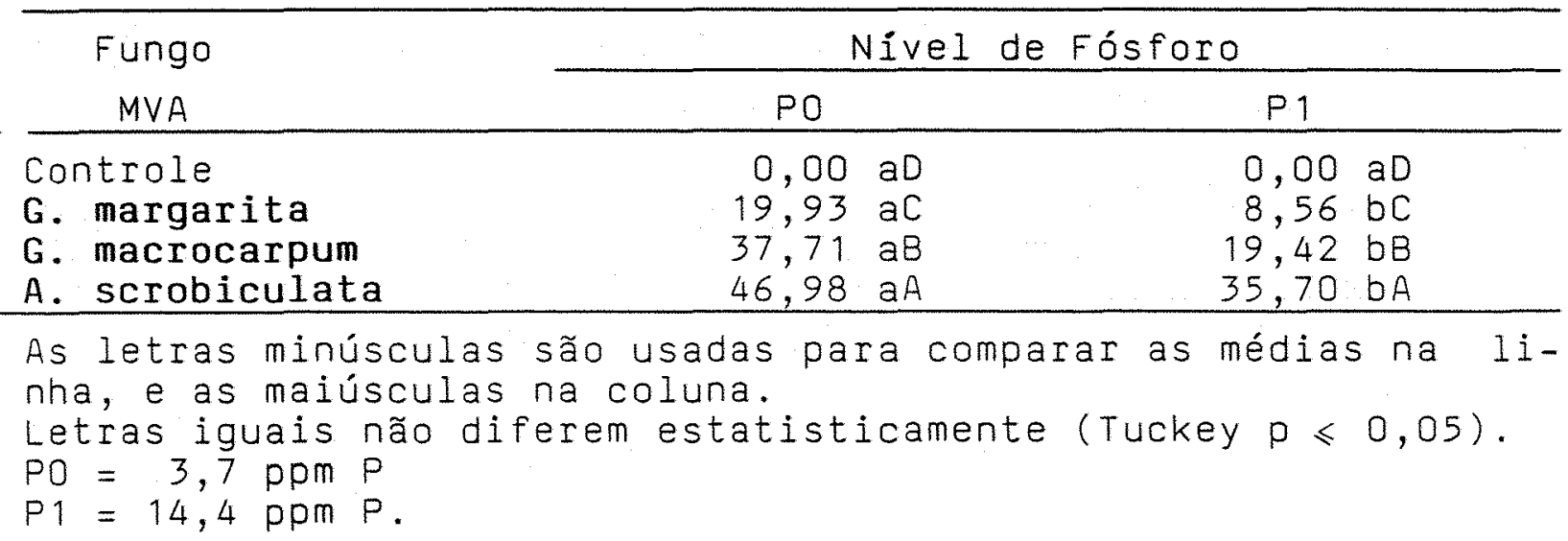

Tabela 13 - Variação percentual da colonização das raízes e da germinação dos esporos no solo com diferentes niveis de calcário, em relação ao solo sem calcário.

\begin{tabular}{|c|c|c|c|c|c|c|}
\hline \multirow{2}{*}{ Fungo } & \multicolumn{2}{|c|}{ C 1} & \multicolumn{2}{|c|}{$C 2$} & \multicolumn{2}{|c|}{$C 3$} \\
\hline & $\begin{array}{l}\Delta \% \\
\mathrm{Col} .\end{array}$ & $\begin{array}{l}\Delta \% \\
\text { Germ. }\end{array}$ & $\begin{array}{l}\Delta \% \\
\operatorname{Col} .\end{array}$ & $\begin{array}{c}\triangle \% \\
\text { Germ. }\end{array}$ & $\begin{array}{l}\Delta \% \\
\text { Col. }\end{array}$ & $\begin{array}{c}\Delta \% \\
\text { Germ. }\end{array}$ \\
\hline $\begin{array}{l}\text { G. margarita } \\
\text { G. macrocarpum } \\
\text { A. scrobiculata }\end{array}$ & $\begin{array}{r}26,59 \\
169,81 \\
27,53\end{array}$ & $\begin{array}{r}3,08 \\
37,45 \\
-2,71\end{array}$ & $\begin{array}{r}14,09 \\
315,19 \\
38,42\end{array}$ & $\begin{array}{r}8,65 \\
74,90 \\
9,17\end{array}$ & $\begin{array}{r}-29,05 \\
213,65 \\
33,17\end{array}$ & $\begin{array}{r}5,45 \\
131,09 \\
4,17\end{array}$ \\
\hline
\end{tabular}

$\Delta \%=\frac{\% \text { Col/Germ em C }-\% \text { Col/Germ em Co }}{\% \text { Col/Germ em Co }} \cdot 100$ 
Estes resultados indicam que $A$. scrobiculata é um fungo mais adaptado a solos distróficos e ácidos do que $G$. margarita e G. macrocarpum, as quais se mostraram menos tolerantes a tais condições.

Nas condições deste experimento, a colonização das raízes mostrou-se muito mais sensivel à variação da acidez do solo do que a germinação dos esporos,para as populações das três escies (Tabela 13),sugerindo que a acidez do solo afeta mais o proces so de infecção e colonização do que a germinação dos esporos.

Foram feitas análises de correlação entre a per centagem de germinação dos esporos e o grau de colonização na primeira época de colheita, considerando-se as médias nos diferentes niveis de calcário (Tabela 14).

Foram encontradas correlações positivas, no en tanto estas não foram estatisticamente significativas, provavelmente pelo fato do inóculo utilizado no experimento ser constituído de outros tipos de propágulos, além dos esporos, com infectividades variáveis, além do fato de exsudações radi culares interferirem na germinação dos esporos, o que não foi avaliado nos ensaios de germinação.

0 desenvolvimento da colonização micorrízica em S. guianensis, crescendo em solo ácido pode ser visto na Figu ra 5 .

Podemos observar que G. margarita possui uma taxa inicial de colonização ( $\Delta \% / \Delta t$ ) muito pequena em relação a G. macrocarpum e A.scrobiculata. No entanto, entre os 60 e 80 dias após o plantio, a taxa de colonização de G.margarita é aproximadamente 4,4 vezes maior do que a taxa de coloniza ção de G. macrocarpum, e 6,1 vezes maior do que a taxa de colonização de A. scrobiculata. 
Tabela 14 - Coeficientes de correlação entre a percentagem de germinação dos esporos e a percentagem de colonização das raízes.

Fungo MVA

G. margarita

G. macrocarpum

A. scrobiculata

$G i+G I+A C$

$n s=$ não significativo com $p \geqslant 0,80$

$$
\begin{array}{r}
-0,0171 \mathrm{~ns} \\
0,7011 \mathrm{~ns} \\
0,5739 \mathrm{~ns} \\
0,6045 \mathrm{~ns}
\end{array}
$$

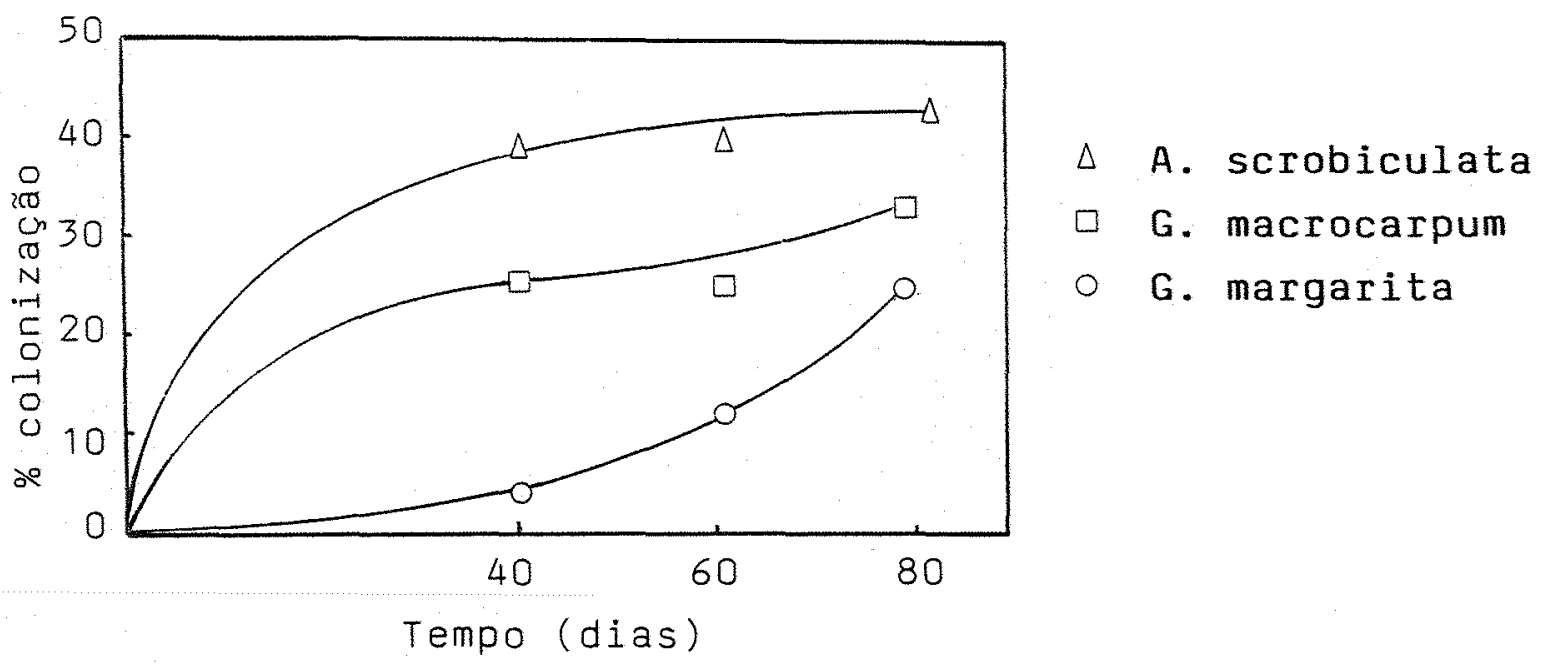

Figura 5 - Desenvolvimento da colonização micorrízica em S.guia nensis crescendo em solo ácido. 
No geral, A. scrobiculata apresentou a maior ta xa de colonização do sistema radicular, e G. margarita a menor.

As características de uma curva de colonização em função do tempo podem ser de grande utilidade na discrimina ção de espécies ou populações de fungos-MVA mais eficientes em colonizar rápida e extensivamente o sistema radicular, já que normalmente a colonização está diretamente relacionada com o aumento da absorção de $P$ e da produção vegetal. Porém, outros fatores devem ser considerados, tais como a eficiência da hifa em absorver $P$ e outros nutrientes da solução do solo e translo cá-los para a raiz do hospedeiro, e a capacidade da hifa em crescer além da rizosfera (ABBOTT e ROBSON, 1984).

Foram feitas análises de correlação entre as ca racteristicas quimicas do solo, nos oito niveis de fertilidade utilizados, e a colonização das raizes aos 40 e 80 dias após o plantio (Tabela 15).

As correlações encontradas variaram com a espécie do fungo e com a época de colheita, sendo que G. macrocarpum apresentou maior número de correlações significativas aos 40 dias após o plantio, e A. scrobiculata e G. margarita aos 80 dias.

Baseado no fato das correlações significativas entre colonização na primeira época de colheita e as caracte rísticas químicas do solo serem até certo ponto semelhantes àquelas obtidas para germinação dos esporos (Tabela 5), pode se levantar a seguinte hipótese:

- no início do processo de colonização, as caracteristicas quimicas do solo, nas condições experimentais uti lizadas, afetaram mais o fungo en si do que a simbiose propria 


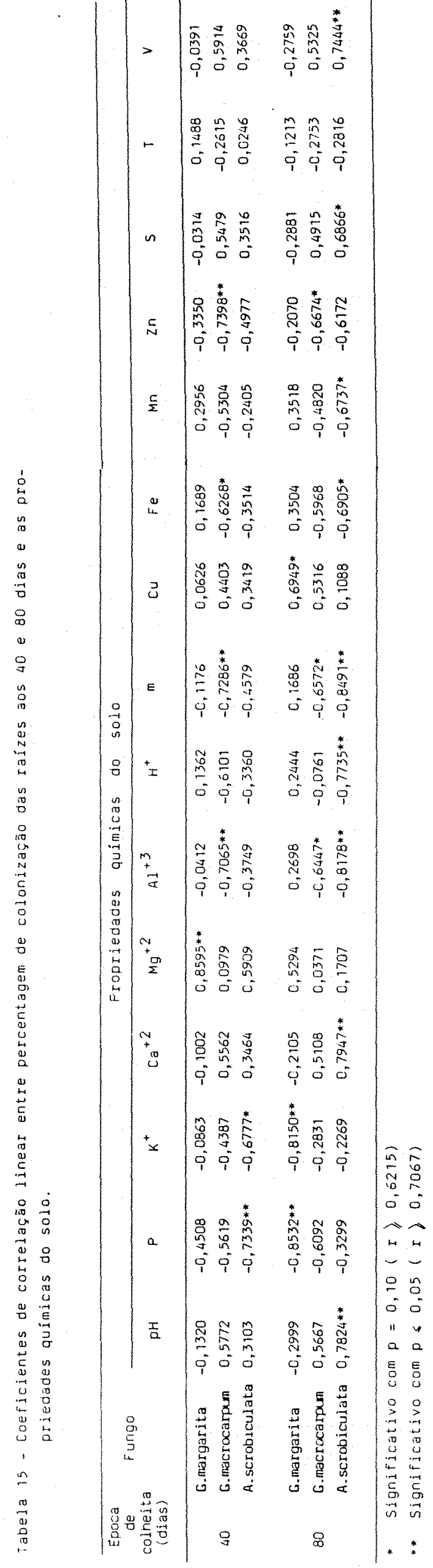


mente dita. Já que nessa fase prevalece a capacidade do fungo em germinar, emitir uma hifa infectiva e penetrar na raiz. Com o desenvolvimento do processo de colonização, o metabolismo do hos pedeiro passa a interferir mais intensamente no desenvolvimento do fungo nas raizes, e a simbiose é que passa a interagir com o ambiente. Essa interação é provavelmente mais intensa onde a simbiose é mais extensa e eficiente, explicando a correlação da colonização das raizes por A. scrobiculata com um grande número de características do solo na terceira época de colheita.

\subsubsection{Desenvolvimento vegetativo de 5 . guianensis}

4.2.2.1. Desenvolvimento da parte aérea

As médias de produção de matéria seca da parte aérea (MSPA) por S. guianensis podem ser vistas na Tabela 16.

Com os dados obtidos foi feita a análise de variância, e os valores de $F$ para as causas da variação são apre sentados na Tabela 7 .

Houve efeitos altamente significativos de todos os fatores avaliados, e de 8 das 11 interações desses fatores.

De uma maneira geral, a produção de MSPA não dife riu estatisticamente nos tratamentos com calcário, os quais diferiram dos tratamentos sem calcário, havendo um incremento médio de $73,65 \%$ (Tabela 9).

O efeito mais significativo foi do fator $P$, que causou um incremento de 360,72 \% na produção de MSPA, em relação aos solos sem adição de $P$. Resultados semelhantes foram encon trados por CORDEIRO et alii (1986), os quais encontraram um efei to pronunciado do aumento do nivel de $P$ no crescimento da parte aérea de $S$. guianensis e S. macrocephala. 
Tabela 15 - Variaçōo da produção de matéria seca da parte aérea de S.guianensis em um solo ácido com diferentes níveis de calcário e ce $P$, diferentes associações MVA,e em diferentes épocas de colheita.

\begin{tabular}{|c|c|c|c|c|c|c|}
\hline \multirow{2}{*}{ Fungo } & \multirow{2}{*}{$\begin{array}{l}\text { Nivel } \\
\text { de } \\
\text { Fósforo }\end{array}$} & \multirow{2}{*}{$\begin{array}{c}\text { Nivel } \\
\text { de } \\
\text { Calcário }\end{array}$} & \multicolumn{3}{|c|}{ Época de colheita (dias) } & \multirow[b]{2}{*}{80} \\
\hline & & & & 40 & 60 & \\
\hline \multirow{10}{*}{ Controle } & & $\mathrm{CO}$ & 0,0165 & $\pm 0,0010$ & $0,0215 \pm 0,0011$ & $0,0159 \pm 0,0018$ \\
\hline & PO & $\mathrm{Cl}$ & 0,0183 & $\pm 0,0010$ & $0,0198 \pm 0,0017$ & $0,0206 \pm 0,0007$ \\
\hline & & $c 2$ & 0,0173 & $\pm 0,0006$ & $0,0252 \pm 0,0047$ & $0,0177 \pm 0,0010$ \\
\hline & & C3 & 0,0173 & $\pm 0,0006$ & $0,0184 \pm 0,0019$ & $0,0209 \pm 0,0029$ \\
\hline & & $\mathrm{CO}$ & 0,0974 & $\pm 0,0099$ & $0,3334 \pm 0,1136$ & $0,3745 \pm 0,1095$ \\
\hline & Pl & $\mathrm{Cl}$ & 0,1611 & $\pm 0,0425$ & $0,5365 \pm 0,0567$ & $1,2539 \pm 0,1653$ \\
\hline & & $\mathrm{c2}$ & 0,1354 & $\pm 0,0294$ & $0,4229 \pm 0,0797$ & $1,2462 \pm 0,0559$ \\
\hline & & C3 & 0,0557 & $\pm 0,0206$ & $0,3745 \pm 0,0711$ & $1,3699 \pm 0,0681$ \\
\hline & & $\mathrm{CO}$ & 0,0114 & $\pm 0,0008$ & $0,0336 \pm 0,0027$ & $0,1662 \pm 0,0150$ \\
\hline & Po & $\mathrm{Cl}$ & 0,0145 & $\pm 0,0008$ & $0,0858 \pm 0,0554$ & $0,1513 \pm 0,0296$ \\
\hline \multirow{6}{*}{ G.margarita } & & $\mathrm{C2}$ & 0,0163 & $\pm 0,0019$ & $0,0259 \pm 0,0041$ & $0,2922 \pm 0,0139$ \\
\hline & & c3 & 0,0164 & $\pm 0,0016$ & $0,0173 \pm 0,0030$ & $0,0667 \pm 0,0 \approx 27$ \\
\hline & & CO & 0,0798 & $\pm 0,0264$ & $0,2760 \pm 0,0307$ & $0,8573 \pm 0,0695$ \\
\hline & P1 & $\mathrm{Cl}$ & 0,0981 & $\pm 0,0291$ & $0,4468 \pm 0,1027$ & $1,2187 \pm 0,1037$ \\
\hline & & $c 2$ & 0,1407 & $\pm 0,0739$ & $0,6764 \pm 0,0956$ & $1,2733 \pm 0,2 \equiv \equiv 9$ \\
\hline & & C3 & 0,1096 & $\pm 0,0249$ & $0,5387 \pm 0,1277$ & $1,0229 \pm 0,1810$ \\
\hline \multirow{8}{*}{ G.macrocarpum } & & $\mathrm{CO}$ & 0,0189 & $\pm 0,0019$ & $0,0278 \pm 0,0060$ & $0,0363 \pm 0,0057$ \\
\hline & PO & $\mathrm{Cl}$ & 0,0483 & $\pm 0,0055$ & $0,3016 \pm 0,0668$ & $0,4194 \pm 0,0733$ \\
\hline & & $\mathrm{C2}$ & 0,0365 & $\pm 0,0056$ & $0,1855 \pm 0,0222$ & $0,4758 \pm 0,0578$ \\
\hline & & C3 & 0,0256 & $\pm 0,0068$ & $0,1837 \pm 0,0235$ & $0,4881 \pm 0,0 \equiv 31$ \\
\hline & & CO & 0,1290 & $\pm 0,0201$ & $0,4950 \pm 0,1082$ & $0,3624 \pm 0,1 \equiv \vdots 2$ \\
\hline & p1 & $\mathrm{Cl}$ & 0,2016 & $\pm 0,0160$ & $1,0132 \pm 0,0797$ & $1,3867 \pm 0,1277$ \\
\hline & & $\mathrm{C} 2$ & 0,7873 & $\pm 0,0533$ & $1,1755 \pm 0,0416$ & $1,4485 \pm 0,1 \equiv 10$ \\
\hline & & C3 & 0,1782 & $\pm 0,0195$ & $1,1138 \pm 0,0516$ & $1,5736 \pm 0,0547$ \\
\hline \multirow{8}{*}{ A.scrobiculata } & & $\mathrm{CO}$ & 0,0442 & $\pm 0,0028$ & $0,1586 \pm 0,0135$ & $0,2710 \pm 0,0357$ \\
\hline & PO & $\mathrm{Cl}$ & 0,0642 & $\pm 0,0025$ & $0,3386 \pm 0,0994$ & $0,6701 \pm 0,1395$ \\
\hline & & $\mathrm{C2}$ & 0,0562 & $\pm 0,0017$ & $0,3224 \pm 0,0948$ & $0,9256 \pm 0,025 z$ \\
\hline & & C3 & 0,0376 & $\pm 0,0073$ & $0,3649 \pm 0,0593$ & $0,8115 \pm 0,0932$ \\
\hline & & $\mathrm{CO}$ & 0,1210 & $\pm 0,0199$ & $0,7478 \pm 0,0148$ & $0,7877 \pm 0,1084$ \\
\hline & P1 & $\mathrm{Cl}$ & 0,2007 & $\pm 0,0549$ & $1,0155 \pm 0,1280$ & $1,3856 \pm 0,0330$ \\
\hline & & $\mathrm{C} 2$ & 0,2045 & $\pm 0,0349$ & $1,0973 \pm 0,0852$ & $1,8449 \pm 0,0839$ \\
\hline & & $\mathrm{C}_{3}$ & 0,1817 & $\pm 0,0177$ & $0,9393 \pm 0,1176$ & $1,2532 \div 0,1 \div 34$ \\
\hline
\end{tabular}

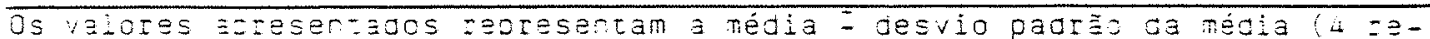
petizes, e- gramas. 
A comparação das médias de MSPA do fator fungo mostrou que as plantas de $S$. guianensis micorrizadas apresenta ram maior produção de MSPA em relação ao controle não inoculado. A associação com A. scrobiculata foi a mais eficiente, cau sando um incremento de MSPA de $95,33 \%$, enquanto G. macrocar pum foi de $68,62 \%$ e G. margarita de $4,03 \%$, não diferindo estatisticamente do controle (Tabela 8 ).

A inoculação de fungos MVA em $S$. guianensis cres cendo em solo ácido com baixo nivel de p foi altamente benéfica.

Houve incrementos de produção de MSPA de até $5129,28 \%$, em relação ao controle não inoculado, demonstrando o micotrofismo extremamente elevado do S. guianensis.

Na Tabela 17 podemos verificar a variação per centual média, ou eficiência relativa média, de cada fungo MVA em relação ao controle não inoculado de cada tratamento.

Observamos que o beneficio maior das MVA se dá justamente nos solos com baixo nivel de $P$, onde o crescimento das plantas não micorrizadas é bastante limitado.

Nos solos sen adição de $P$ e sem calcário a inocu lação com G. margarita causou um incremento máximo de $945,28 \%$ na produção de MSPA, que diminuiu com o aumento do nível de cal cário do solo. A inoculação com G. macrocarpum apresentou um comportamento contrário à inoculação com G. margarita, aumentou - incremento de MSPA com o aumento do calcário, atingindo um má ximo de $2235,41 \%$ no nivel 3 de calcário. o incremento na produção de MSPA pela inoculação de A. scrobiculata foi máximo no solo com o nível 2 de calcário $(5129,38 \%)$. 
Tabela 17 - Variação percentual média $(\Delta \%)$ da produção de matéria seca da parte aérea por $S$. guianensis, em relação ao controle não inoculado de cada tratamento.

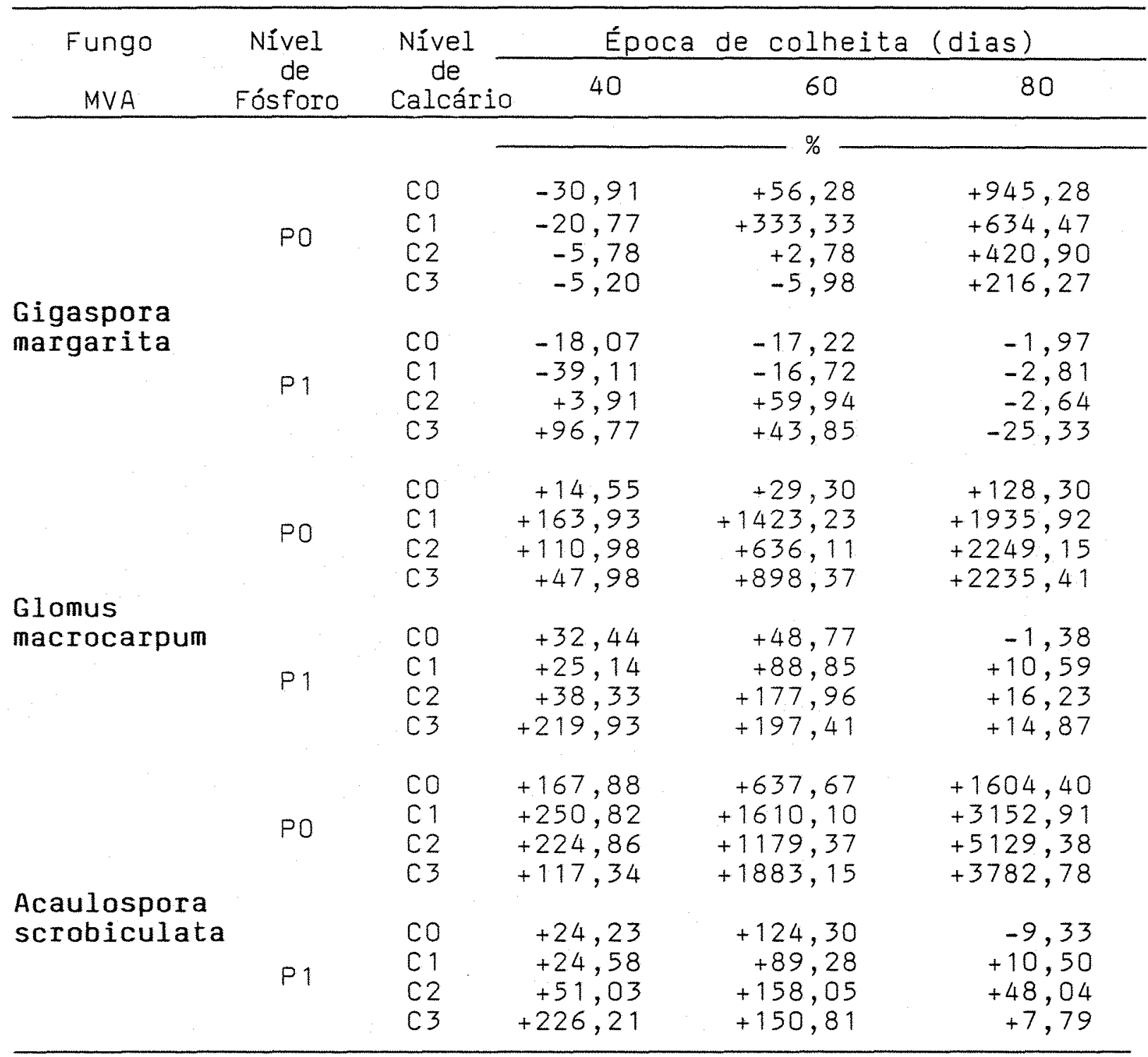

$\Delta \%=\frac{\text { MSPA com Fungo - MSPA controle }}{\text { MSPA controle }} \cdot 100$ 
A inoculação nos solos com adição de $P$ não foi tão benéfica quanto no solo sem $P$, havendo incrementos de produção de MSPA variando de $10,50 \%$ a 48,04\%, na 3a época de co Iheita. Em alguns casos houve até decrementos na produção,mos trando que o fungo está competindo com a planta por nutrientes e metabólitos, parasitando-a.

A presença de fungos MVA em solos com adição de $P$ foi mais benéfica no início do ciclo da planta, provavelmente pelo fato das MVA aumentarem a velocidade de absorção de $P$, conforme já foi demonstrado por FAQUIN et alii (1987) e SILVEI RA et alii (1987). Assim, em solos pobres em $P$, o microtrofis mo foi sempre crescente com o desenvolvimento, e em solos com adição de $P$ foi decrescente, nas condições deste experimento. Talvez isto tenha ocorrido pelo efeito das MVA na maior absorção de nutrientes, devida a maior exploração do solo pelas hifas do fungo, no primeiro caso, e pelo efeito das MVA em aumen tar a velocidade de absorção do $P$, quando a planta ainda está com um sistema radicular pouco desenvolvido, no segundo caso.

A produção de MSPA mostrou correlações significativas com a percentagem de colonização das raizes em solos com e sern adição de $P$ (Figura 6 ).

Analisando-se a interação FUNGO x CALCÁRIO podemos verificar que a produção de MSPA pelas plantas inoculadas com diferentes fungos MVA variou com o nivel de calcário do so10, conforme o que está representado graficamente na figura 7 .

As médias de produção de MSPA das plantas sem inoculação não apresentaram diferenças significativas nos solos com calcário, e estas foram aproximadamente $41 \%$ superiores às do solo sem calcário. 
200070

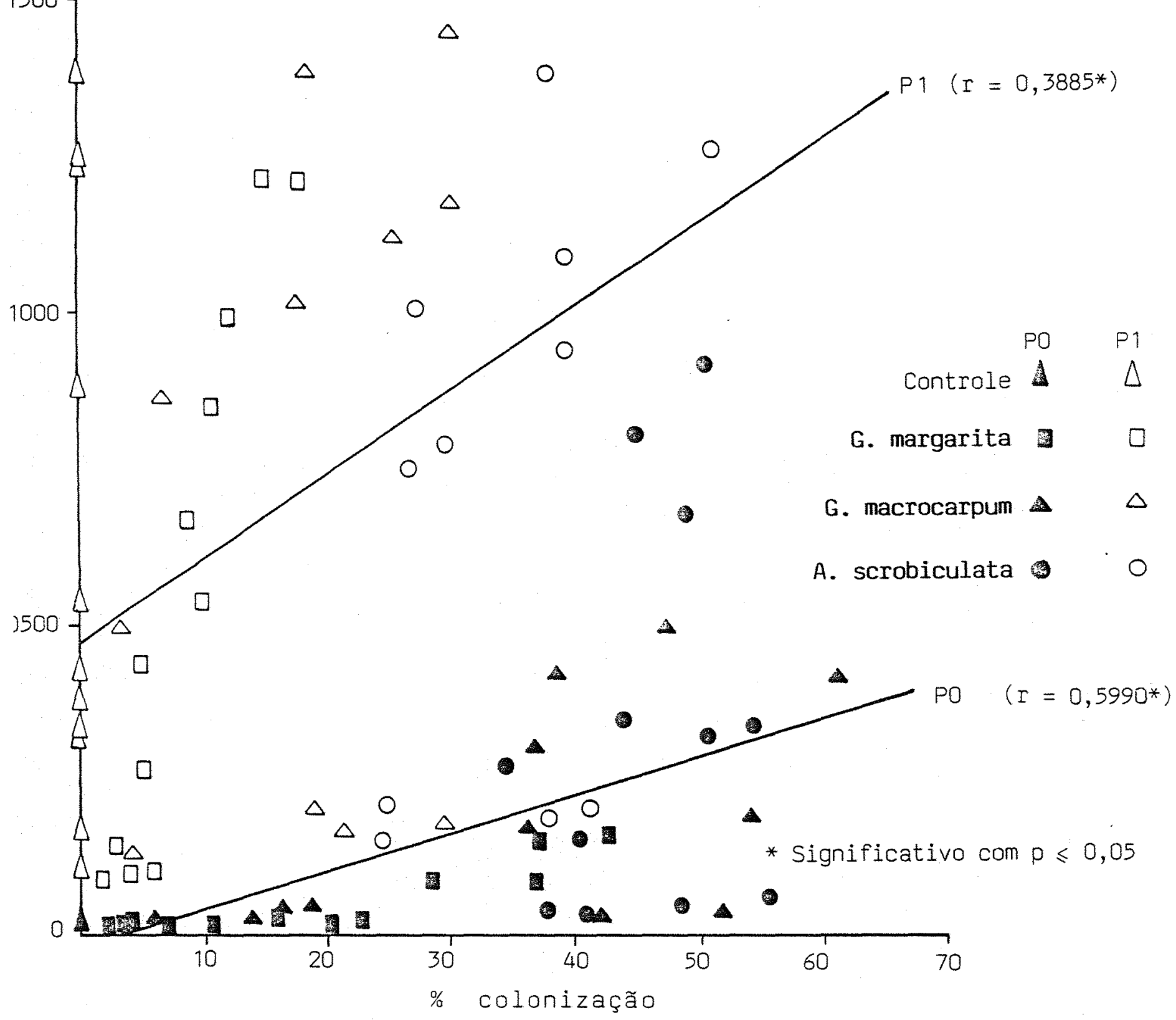

Figura 6 - Correlação entre percentagem de colonização das raízes por fungos MVA e produção de matéria seca da parte aérea por 5 . guianensis em solos ácidos com e sem adição de fósforo. 


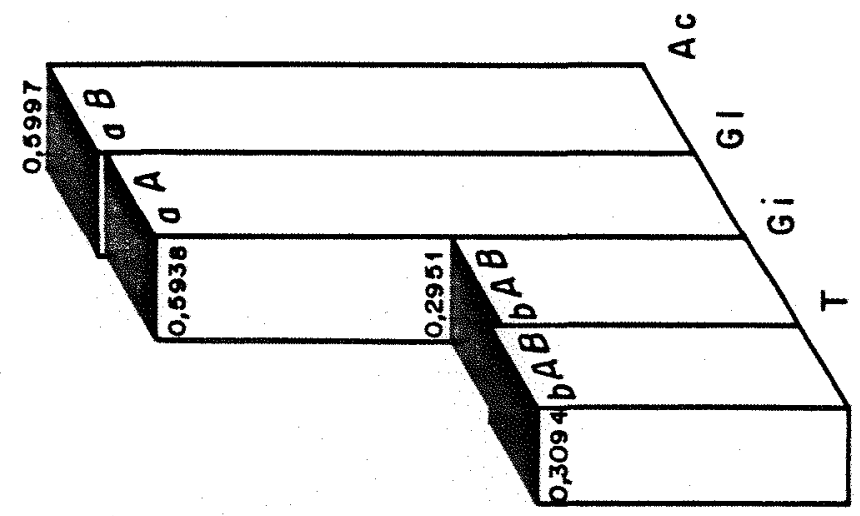

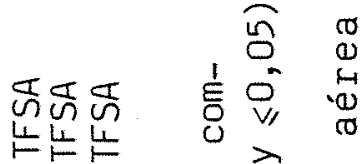

orom

898

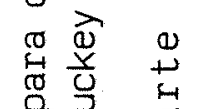

皮

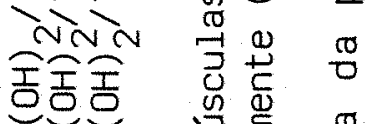

का ๘

ऽU凹

$m$

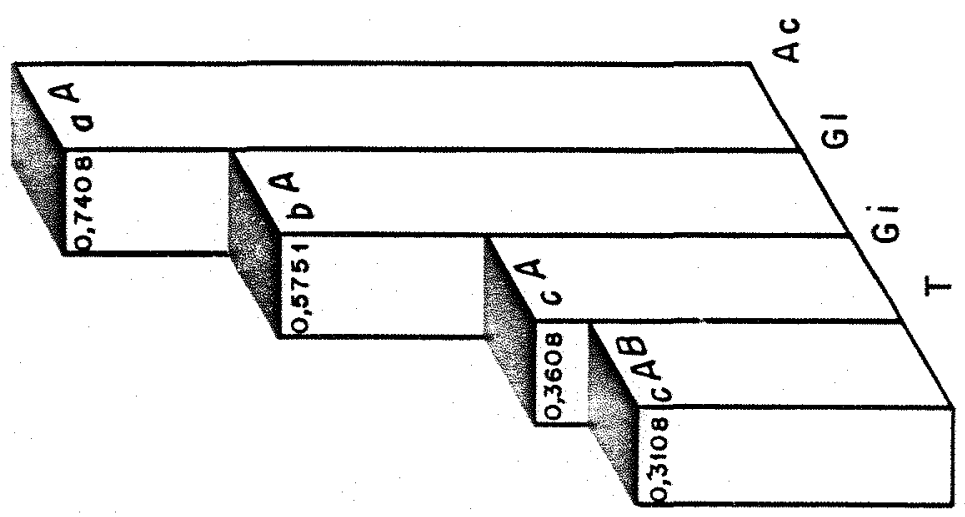

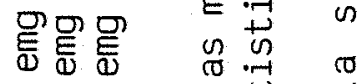

N

ஸे-

E E E .

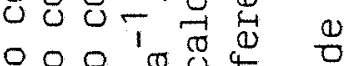

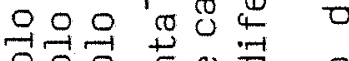

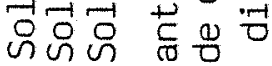

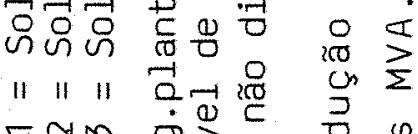

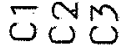

$0>$

है

0 리

$\stackrel{N}{\mho}$

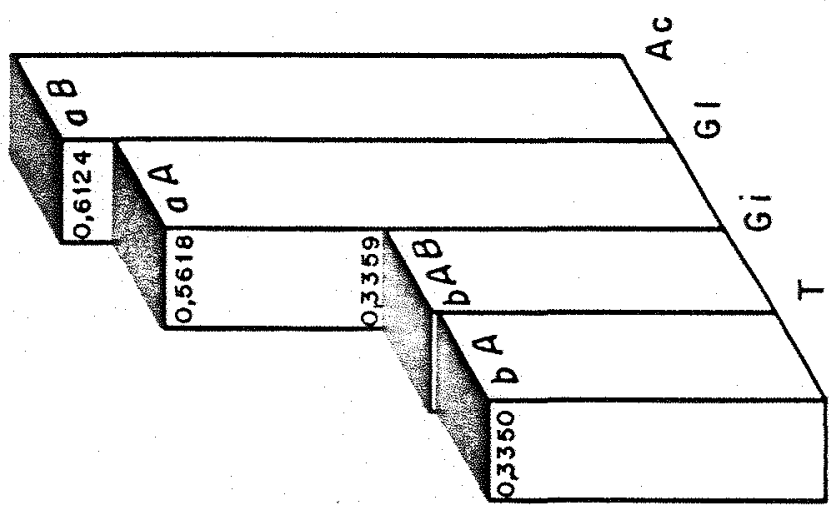

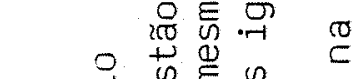

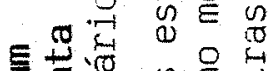

万人

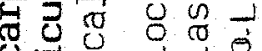

- 0 o 4

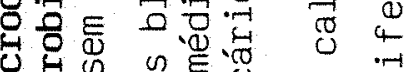

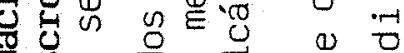

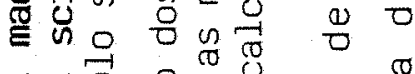

$\dot{\theta} \dot{0}$

$\stackrel{8}{0}, \frac{0}{0}$

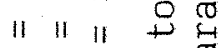

$\square 0$

$\overline{0}$

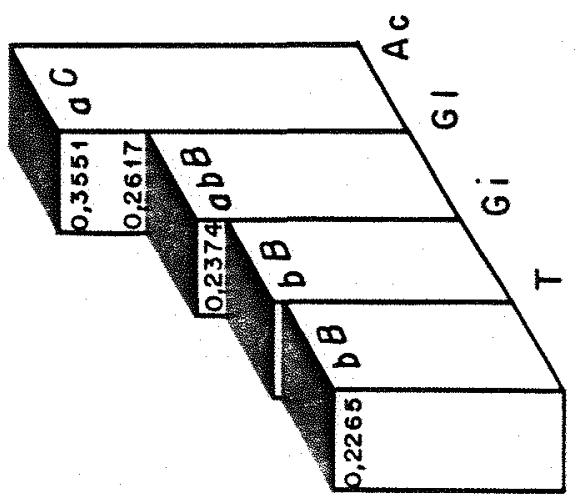

음

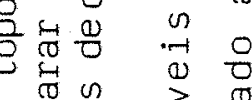

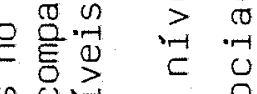

ज. 0 . $\subset$ व

号

$+\pi 0$

(1)

(1) 0

400

की

응

㗐

동

n

$4 \cdot-1$

कृ

-

$\stackrel{0}{\circ}$

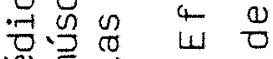

0

(a)

Л

a $n$

$\Leftrightarrow$ 吕

I II

$\rightarrow \underset{\infty}{\infty} \stackrel{1}{\infty}$

$\stackrel{0}{4}$ 
Para as plantas inoculadas com G. margarita, a produção de MSPA foi máxima no nível 2 de calcário, sendo $51,98 \%$ superior a do solo sem calcário. As plantas inoculadas com A. scrobiculata também apresentaram uma produção máxima no nível 2 de calcário, havendo um incremento de $108,62 \%$ em relação ao solo sem calcário.

Porém, a inoculação com G. macrocarpum não aumentou significativamente a produção de MSPA nos solos com cal cario, embora tenha havido uma tendência dessa produção ser má xima no nível 3 de calcário. Nos solos com calcário, a micorriza formada por G. macrocarpum aumentou em média 120,44 \% a produção MSPA do S. guianensis, em relação ao solo sem calcário.

Em todos os niveis de calcário os valores da MSPA das plantas micorrizadas por G. margarita não diferiram estatisticamente do controle não inoculado.

As maiores diferenças relativas entre as médias da MSPA das plantas micorrizadas pelos diferentes fungos e o controle não inoculado aparecem no nivel 2 de calcário.

Em vista dos resultados obtidos, podemos dizer que a produção de MSPA, estando correlacionada positivamente com a colonização das raizes, reflete a eficiência do fungo MVA em absorver nutrientes do solo e translocá-los para a planta.

Desta forma, A. scrobiculata mostrou-se mais efi ciente para S. guianensis em solos ácidos e distróficos, den tro das condições deste experimento, tanto na formação da micorriza quanto no incremento da produção de MSPA. A MVA forma da por G. margarita que apresentou uma tolerância intermediá ria a condições de solos ácidos foi a menos eficiente em promo ver o crescimento de S. guianensis. O G. macrocarpum que for- 
ma uma MVA mais sensivel a essas condições mostrou uma eficiên cia intermediária.

Porém, avaliar a tolerância de uma associação micorrizica a condições de solos ácidos e distróficos através da produção de MSPA é bastante complexo, pois existe uma interação entre o genótipo da planta, o genótipo do fungo e o meio ambiente, determinando a maior ou menor produ ção vegetativa.

Nos solos sem adição de $P$, as diferenças em relação ao controle foram muito maiores do que no solo com $\mathrm{P}$. Na Figura 8 podemos visualizar claramente essas diferenças.

A. scrobiculata que foi o fungo mais eficiente eın promover o crescimento de $S$. guianensis causou um incremento de $1673,30 \%$ no solo seın adição de $P$, em relação ao controle, enquanto que no solo com adição de $P$ esse incremento foi de $42,58 \%$.

As diferenças relativas entre os fungos também variaram com a época de colheita (Figura 9), apresentando valores máximos na 2 a época. Isto pode ser explicado pelo fato da micorriza mais eficiente ter aumentado a taxa de crescimento ( $\triangle$ MSPA/ $\Delta$ ) inicial das plantas, o que pode ser uma grande vantagem ecológica, pois a competitividade inicial, muito importante no estabelecimento de leguminosas em pastagens consor ciadas com gramineas (AZCON-AGUILAR et alii, 1982; REEVES et alii, 1979), sofre um grande aumento.

4.2.2.2. Desenvolvimento do sistema radicular

Na Tabela 18 são apresentadas as médias da maté ria fresca do sistema radicular (MFSR) obtidas no experimento. 
Tabela 18 - Variação da matéria fresca do sistema radicular de S.guianensis ell um solo ácido com diferentes niveis de calcário e de $P$, diferentes associações MVA, e em diferentes épocas de colneita.

\begin{tabular}{|c|c|c|c|c|c|}
\hline \multirow{2}{*}{ Fungo } & \multirow{2}{*}{$\begin{array}{c}\text { Nível } \\
\text { de } \\
\text { Fósforo }\end{array}$} & \multirow{2}{*}{$\begin{array}{c}\text { Nivel } \\
\text { de } \\
\text { Caicário }\end{array}$} & \multicolumn{3}{|c|}{ Época de colneita (dias) } \\
\hline & & & 40 & 60 & 80 \\
\hline \multirow{8}{*}{ Controle } & \multirow{4}{*}{ PO } & CO & $0,0250 \pm 0,0036$ & $0,0367 \pm 0,0037$ & $0,0215 \pm 0,0031$ \\
\hline & & $\mathrm{Cl}$ & $0,0308 \pm 0,0031$ & $0,0346 \pm 0,0030$ & $0,0183 \pm 0,0011$ \\
\hline & & C2 & $0,0287 \pm 0,0026$ & $0,0370 \pm 0,0013$ & $0,0283 \pm 0,0032$ \\
\hline & & C3 & $0,0294 \pm 0,0024$ & $0,0292 \pm 0,0010$ & $0,0480 \pm 0,0112$ \\
\hline & \multirow{4}{*}{ P1 } & CO & $0,4171 \pm 0,0652$ & $1,0527 \pm 0,2964$ & $2,1261 \pm 0,3684$ \\
\hline & & $\mathrm{Cl}$ & $0,5108 \pm 0,0990$ & $1,3293 \pm 0,1089$ & $2,9714 \pm 0,4876$ \\
\hline & & $\mathrm{C} 2$ & $0,4310 \pm 0,1000$ & $1,3634 \pm 0,2149$ & $3,1414 \pm 0,1264$ \\
\hline & & $\mathrm{C} 3$ & $0,1620 \pm 0,0716$ & $1,1432 \pm 0,3018$ & $3,1208 \pm 0,2422$ \\
\hline \multirow{8}{*}{ G. margar } & \multirow{4}{*}{ PO } & $\mathrm{CO}$ & $0,0174 \div 0,0017$ & $0,0232 \pm 0,0024$ & $0,3284 \pm 0,0466$ \\
\hline & & $\mathrm{Cl}$ & $0,0194 \pm 0,0011$ & $0,1407 \pm 0,0960$ & $0,1723 \pm 0,1125$ \\
\hline & & $C 2$ & $0,0154 \pm 0,0023$ & $0,0150 \pm 0,0019$ & $0,2542 \pm 0,0720$ \\
\hline & & C3 & $0,0178 \pm 0,0018$ & $0,0237 \pm 0,0030$ & $0,1437 \pm 0,0556$ \\
\hline & \multirow{4}{*}{ P1 } & $\mathrm{CO}$ & $0,2729 \pm 0,0192$ & $0,8422 \pm 0,1083$ & $3,0288 \pm 0,3547$ \\
\hline & & $\mathrm{Cl}$ & $0,2279 \pm 0,0712$ & $0,8710 \pm 0,0999$ & $3,4326 \pm 0,6762$ \\
\hline & & $c 2$ & $0,2584 \pm 0,1535$ & $1,4382 \pm 0,1694$ & $3,0805 \pm 0,7233$ \\
\hline & & 03 & $0,2138 \pm 0,0614$ & $1,4547 \pm 0,3325$ & $2,4504 \pm 0,6972$ \\
\hline \multirow{8}{*}{ G. macroc } & \multirow{3}{*}{ PO } & $C O$ & $0,0284 \pm 0,0033$ & $0,0241 \pm 0,0027$ & $0,0343 \div 0,0047$ \\
\hline & & $\mathrm{Cl}$ & $0,0988 \pm 0,0216$ & $0,5101 \pm 0,1037$ & $0,8246 \pm 0,1460$ \\
\hline & & $\mathrm{c} 2$ & $0,0376 \pm 0,0093$ & $0,2864 \pm 0,0859$ & $0,9327 \div 0,1901$ \\
\hline & \multirow{5}{*}{ PI } & $c 3$ & $0,0372 \pm 0,0095$ & $0,2711 \pm 0,0283$ & $0,0554 \div 0,0402$ \\
\hline & & $c 0$ & $0,3790 \pm 0,0443$ & $1,5680 \pm 0,3284$ & $2,6726 \pm 0,3243$ \\
\hline & & 61 & $0,3703 \pm 0,0473$ & $1,8227 \pm 0,4142$ & $3,6503 \pm 0,3477$ \\
\hline & & $\mathrm{C} 2$ & $0,2642 \pm 0,1218$ & $1,3342 \pm 0,1508$ & $3,5694 \pm 0,6199$ \\
\hline & & c3 & $0,3226 \pm 0,0763$ & $2,2785 \pm 0,2088$ & $3,1536 \pm 0,2915$ \\
\hline \multirow{8}{*}{ A. scrobic } & \multirow{3}{*}{ PO } & co & $0,0851 \pm 0,0128$ & $0,6344 \pm 0,0708$ & $0,7182 \pm 0,0088$ \\
\hline & & $\mathrm{cl}$ & $0,0512 \pm 0,0070$ & $0,8656 \pm 0,2167$ & $1,0872 \pm 0,1691$ \\
\hline & & $C 2$ & $0,0606 \pm 0,0060$ & $0,7908 \pm 0,2883$ & $2,1625 \pm 0,2316$ \\
\hline & \multirow{5}{*}{ P1 } & 83 & $0,0736 \pm 0,0183$ & $0,3712 \pm 0,2248$ & $1,5602 \div 0,1947$ \\
\hline & & 60 & $0,5163 \pm 0,12 E i$ & $2,5417 \pm 0,2256$ & $2,5254 \div 0,1649$ \\
\hline & & 6 & $0,4289 \pm 0,1355$ & $2,6900 \pm 0,2816$ & $4,0358=0,2700$ \\
\hline & & $: 2$ & $0,4285 \div 0,057 \equiv$ & $2,5738 \pm 0,1797$ & $3,5684 \div 0,1632$ \\
\hline & & 23 & $0,3986 \pm 0,062 \vdots$ & $2,3758 \pm 0,1212$ & $2,2667 \div 0,3750$ \\
\hline
\end{tabular}

Os valores apresentaczs reprosentan a mécia = oesvio padrão a nédia 4 repetiços, an gienas. 


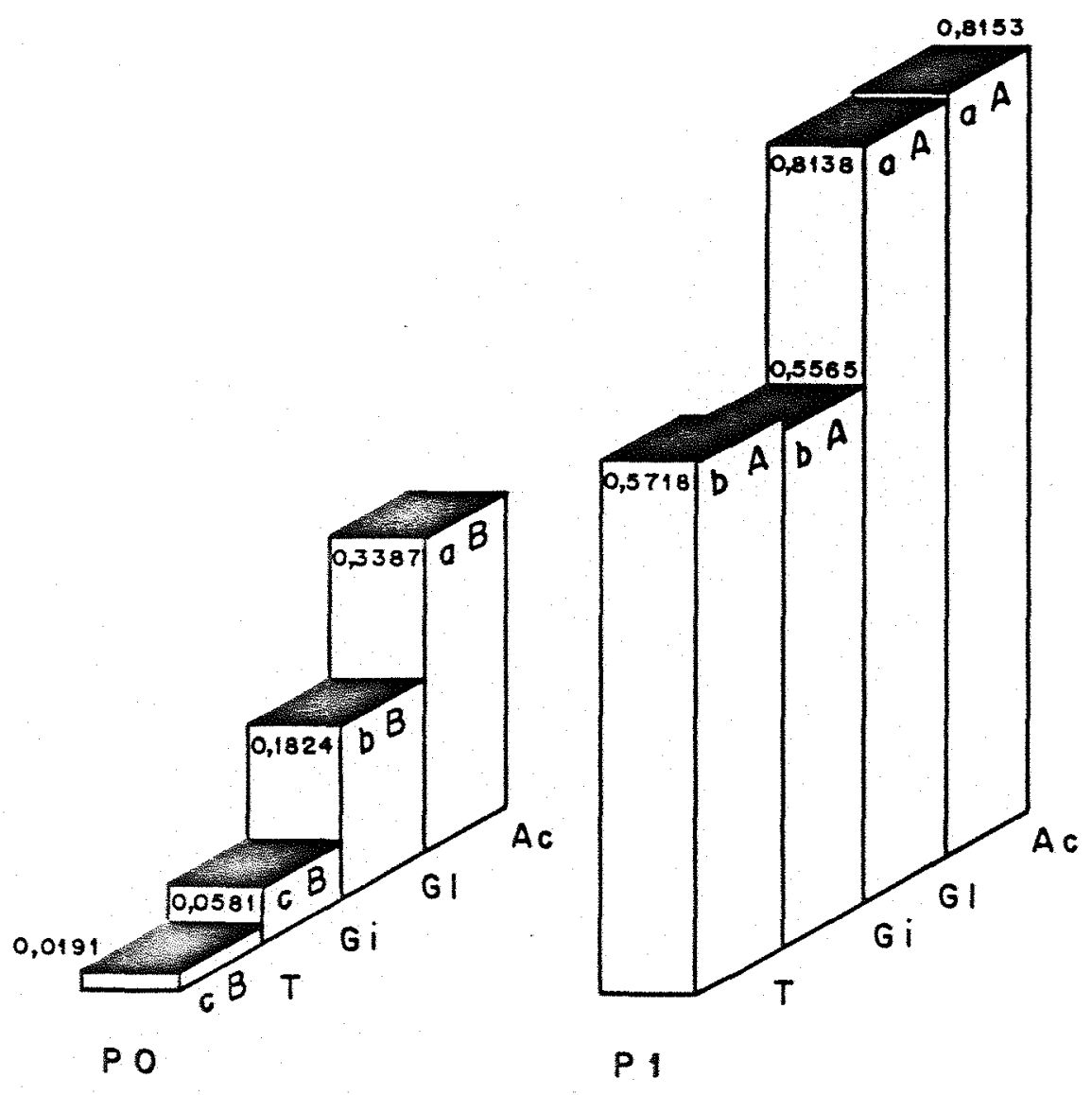

$T$ = Controle não inoculado

$G i=G$. margarita

$A C=A$. scrobiculata

$G I=G$. macrocarpum

$\mathrm{PO}=3,7 \mathrm{pPm} P$

$P 1=14,4$ ppm P

Os valores médios de MSPA apresentados no topo dos blocos estão em g.planta ${ }^{-1}$.

As letras minúsculas são usadas para comparar as médias no mesmo nivel de $P$, e as maiúsculas para comparar as médias entre os niveis de $P$.

Letras iguais não diferem estatisticamente (Tuckey $\leqslant 0,05$ ).

Figura 8 - Efeitos de diferentes niveis de fósforo e diferentes associações micorríicas na produção de matéria seca da parte aérea de $\mathrm{S}$. guianensis. 


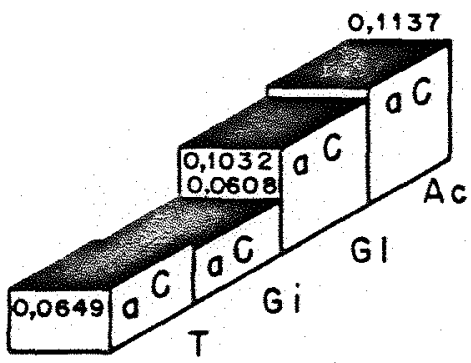

E1

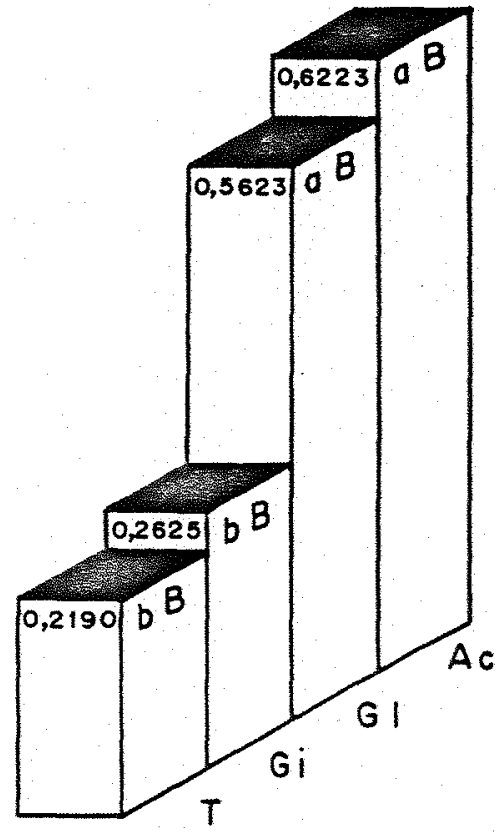

E 2

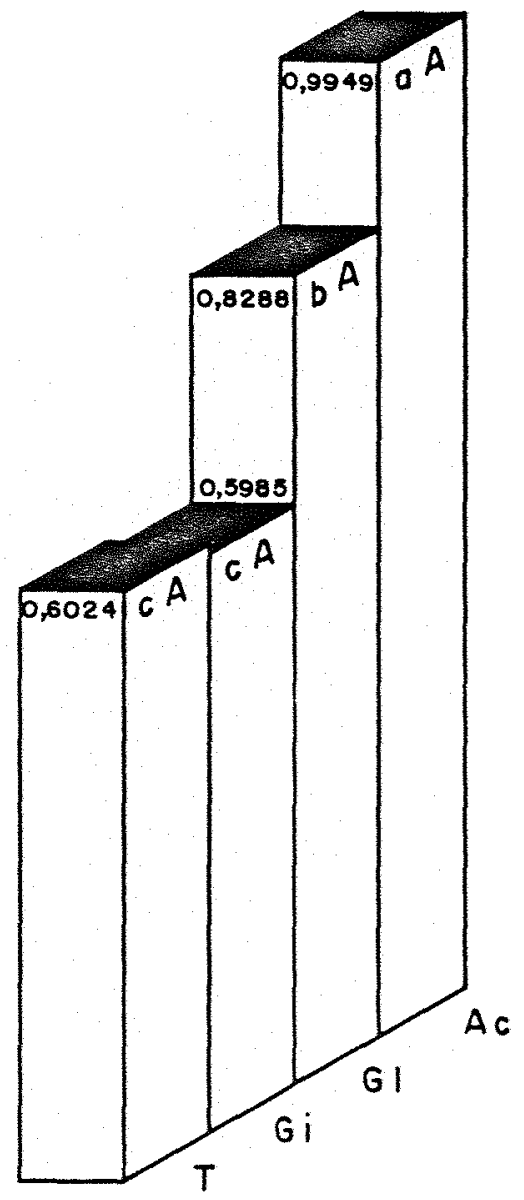

E 3

$T$ = Controle não inoculado

$E 1=40$ dias após o plantio

$G i=$. margarita

$G I=G$. macrocarpum

$A c=A$. scrobiculata

$E 2=60$ dias após o plantio

$E 3=80$ dias após o plantio

Os valores médios de MSPA apresentados no topo dos blocos estão em g.planta ${ }^{-1}$. As letras minúsculas são usadas para comparar as médias na mesma época de co lheita, e as maiúsculas para comparar as médias entre as épocas de colheita. Letras iguais não diferem estatisticamente (Tuckey $P \leqslant 0,05$ ).

Figura 9 - Efeito de associações micorrízicas na produção de maté ria seca da parte aérea de $\mathrm{S}$. guianensis em diferentes épocas de colheita. 
Foi feita a análise de variância com os dados de MFSR, e os valores de F encontrados estão na Tabela 7 .

o efeito do fator CALCARIO. pode ser visto na Tabe 1a: 9. Notamos que o maior desenvolvimento do sistema radicular se deu no solo com os niveis 1 e 2 de calcário, sendo em média $31,12 \%$ superior àquele observado no solo sem calcário.

o fator FósFORO teve o efeito mais significativo no desenvolvimento do sistema radicular. No solo com adição de $P$, o crescimento das raizes foi 5,61 vezes maior do que no solo sem adição de $P$.

A inoculação de fungos MVA também teve efeito significativo no crescimento das raizes (Tabela 8). A. scrobiculata foi o fungo mais eficiente em promover o crescimento das raizes, que cresceram 1,83 vezes mais do que nas plantas sem inoculação. G. macrocarpum causou um incremento de $39,65 \%$ na MFSR, e G. margarita de $3,33 \%$, não significativo pelo teste de Tuckey $(p=0,05)$.

A comparação das médias da interação FUNGO $\times$ CAL CARIO (Tabela 19), mostrou que as plantas não micorrizadas não responderam à calagem, da mesma forma que as inoculadas com $G$. margarita. As plantas micorrizadas por G. macrocarpum não apre sentaram diferenças na MFSR nos solos com calcário, no entanto, essas médias foram 1,46 vezes maiores do que no solo sem calcário. A inoculação com A. scrobiculata causou um incremento máximo na MFSR nos niveis 1 e 2 de calcário.

Nos solos sem calcário, somente a inoculação com A. scrobiculata aumentou significativamente a MFSR, e nos solos com calcário tanto A. scrobiculata quanto G. macrocarpum foram eficientes. 
Tabela 19 - Efeito da calagem em um solo ácido no desenvolvimen to do sistema radicular de $\mathrm{S}$. guianensis associado a diferentes fungos micorrizicos.

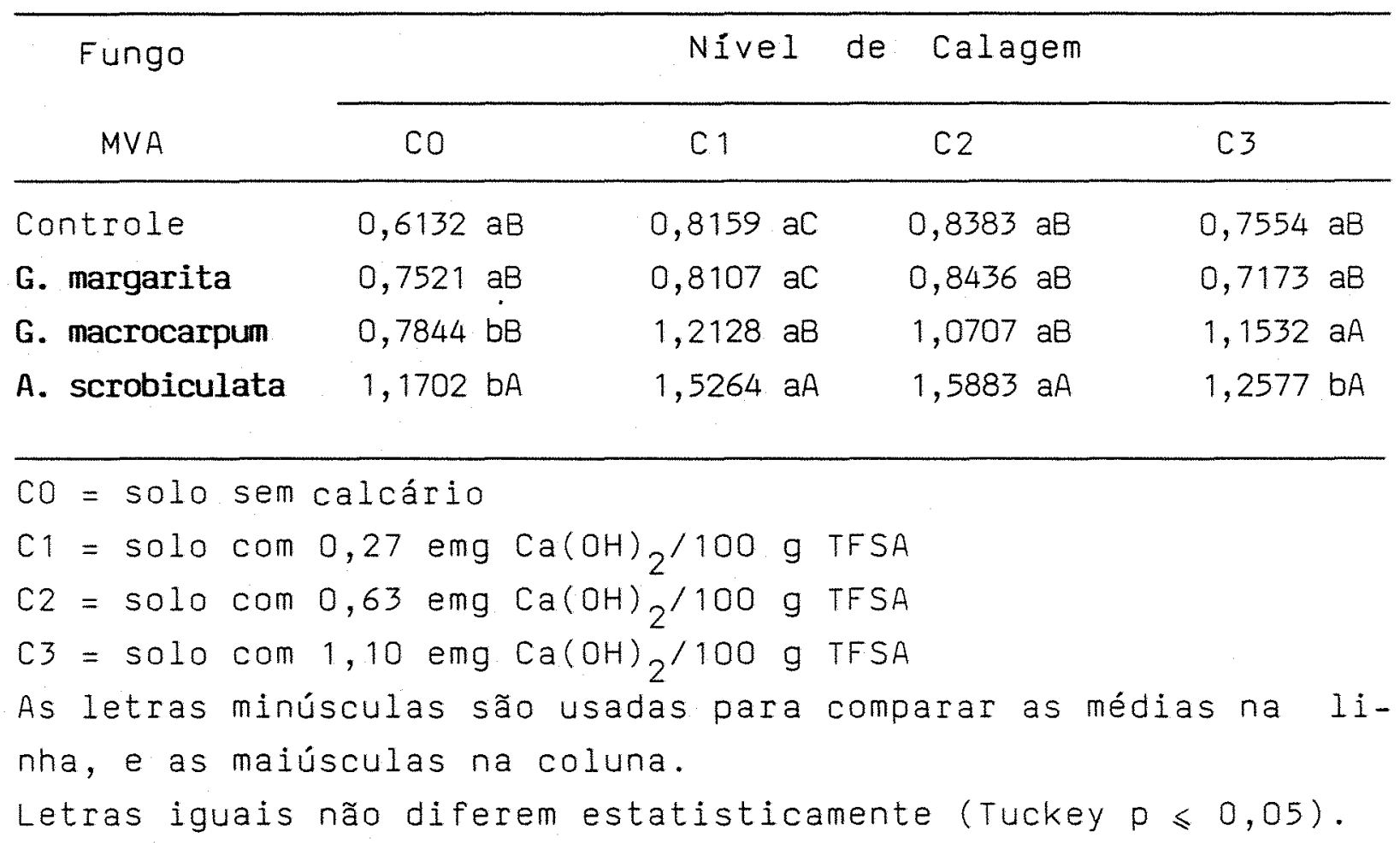


De uma maneira geral, o desenvolvimento do sistema radicular acompanhou o desenvolvimento da parte aérea.

\subsubsection{Relação entre parte aérea e sistema ra dicular}

Com os dados da relação entre matéria seca da parte aérea e matéria fresca do sistema radicular (MSPA/MFSR) foi feita a análise de variância utilizando-se a transformação estatistica $\sqrt{x+0,5}$. Os valores de $F$ obtidos são mostrados na Tabela 7 .

Notamos que o fator FóSFORO teve o efeito mais significativo sobre essa relação.

Nos solos com adição de fósforo, o sistema radi cular foi 1,84 vezes maior em relação a parte aérea do que nos solos sem fósforo (Tabela 11).

o nivel de calcário do solo também causou efei tos significativos na relação MSPA/MFSR, sendo que os niveis de calcário intermediários favoreceram mais o desenvolvimento da parte aérea em relação ao sistema radicular (Tabela 9).

A inoculação de fungos MVA, de uma maneira geral, não alterou significativamente a relação MSPA/MFSR, em re lação ao controle não inoculado ( $T$ abela 8 ). Somente com a ino culação de G. margarita a relação MSPA/MFSR foi maior do que a do controle, isto é, o sistema radicular cresceu menos em rela ção a parte aérea do que nas plantas não inoculadas.

CARDOSO ( 1984 ) observou em plantas de soja que tan to o fosfato quanto a micorriza, na presença e na ausência de fosfató, levaram a um menor desenvolvimento do sistema radicular em relação a parte aérea. HAYMAN e MOSSE (1971) obtiveram resulta- 
dos semelhantes para cebola. NEMEC (1978) verificou uma diminuição significativa do sistema radicular em relação a parte aérea em porta-enxertos de citros inoculados com fungos MVA.

Todos esses resultados são conflitantes com os obtidos para Stylosanthes guianensis neste experimento e para Stylosanthes hamata $c v$ verano em experimentos realizados por JEHNE (1984).

Normalmente as plantas cultivadas são seleciona das, em altos niveis de $P$, para maximização da parte aérea em detrimento do sistema radicular, de modo que a resposta da par te aérea ao incremento de $P$ é proporcionalmente maior do que a resposta do sistema radicular.

Provavelmente o mesmo não aconteça para plantas tropicais como o Stylosanthes que evoluiram en solos ácidos com baixa fertilidade, onde as plantas com sistema radicular mais desenvolvido estão mais adaptadas. Talvez a evolução do stylo santhes tenha se dado no sentido de selecionar plantas que tenham um sistema radicular com maior capacidade de desenvolvi mento do que a parte aérea, e a adubação fosfatada, dentro de certos limites, ou a inoculação com fungos MVA, aumentando o nivel nutricional das plantas causaria um maior crescimento do sistema radicular em relação a parte aérea, explicando as divergências encontradas. No entanto, este é um aspecto da ecologia do Stylosanthes que merece maiores estudos.

4.2.3. Absorção de nutrientes

As médias das concentrações e quantidades totais de nutrientes na parte aérea de $S$. guianensis podem ser vistas na Tabela 20. 
Tabela 20 - Efeitos da calagem, doses de fósforo e inoculação com fungos MVA na absorção de nutrientes por $S$. guianensis.

\begin{tabular}{|c|c|c|c|c|c|c|}
\hline \multirow[t]{2}{*}{ Fungo } & $\begin{array}{c}\text { Nivel } \\
\text { de }\end{array}$ & $\begin{array}{c}\text { Nivel } \\
\text { de }\end{array}$ & $\begin{array}{l}P \\
\%\end{array}$ & $\begin{array}{c}P \text { total } \\
(m g)\end{array}$ & $\begin{array}{l}k \\
\%\end{array}$ & $\begin{array}{c}\text { K total } \\
(\mathrm{mg})\end{array}$ \\
\hline & Fósforo & Calcário & & & & \\
\hline \multirow{4}{*}{ Controle } & \multirow{4}{*}{ PI } & $\mathrm{CO}$ & $0,085 \pm 0,010$ & $0,774^{+} 0,167$ & $1,380 \pm 0,066$ & $11,881 \pm 1,087$ \\
\hline & & $\mathrm{Cl}$ & $0,078 \pm 0,008$ & $1,127 \pm 0,154$ & $1,900^{ \pm}=0,163$ & $16,568 \pm 0,627$ \\
\hline & & $\mathrm{C} 2$ & $0,075^{+}-0,012$ & $0,927 \pm 0,137$ & $1,298 \pm 0,121$ & $16,020 \pm 1,109$ \\
\hline & & $\mathrm{C} 3$ & $0,108 \pm 0,005$ & $1,478^{+}-0,125$ & $1,490 \pm 0,117$ & $20,191 \pm 0,739$ \\
\hline \multirow{8}{*}{$\begin{array}{l}\text { G. marga- } \\
\text { rita }\end{array}$} & \multirow{3}{*}{ PO } & $\mathrm{CO}$ & $0,115^{ \pm}-0,081$ & $0,191 \pm 0,004$ & $2,330 \pm 0,300$ & $3,841^{ \pm}-0,262$ \\
\hline & & $\mathrm{Cl}$ & $0,125 \pm 0,005$ & $0,192 \div 0,068$ & $2,320 \pm 0,250$ & $3,391 \pm 0,739$ \\
\hline & & $\mathrm{C} 2$ & $0,155 \pm 0,035$ & $0,145-0,038$ & $2,635^{ \pm}-0,005$ & $1,480 \pm 0,020$ \\
\hline & \multirow{5}{*}{ P1 } & $\mathrm{C3}$ & 0,130 & 0,086 & 2,580 & 1,704 \\
\hline & & $\mathrm{CO}$ & $0,123 \pm 0,011$ & $1,031 \pm 0,044$ & $1,393 \pm 0,121$ & $11,833 \pm 1,060$ \\
\hline & & $\mathrm{Cl}$ & $0,090 \pm 0,004$ & $1,229 \pm 0,045$ & $1,380 \pm 0,152$ & $18,283 \pm 1,411$ \\
\hline & & $\mathrm{C2}$ & $0,108 \pm 0,008$ & $1,256 \div 0,194$ & $1,730 \pm 0,144$ & $19,989 \pm 2,843$ \\
\hline & & c3 & $0,115^{+}-0,003$ & $1,187 \pm 0,232$ & $1,788^{+}-0,108$ & $17,949-2,457$ \\
\hline \multirow{8}{*}{$\begin{array}{l}\text { G. macro- } \\
\text { carpum }\end{array}$} & \multirow{4}{*}{ PO } & co & 0,110 & 0,040 & 1,140 & 0,413 \\
\hline & & $\mathrm{Cl}$ & $0,070 \pm 0,000$ & $0,294-0,019$ & $2,130 \pm 0,000$ & $8,932 \pm 0,569$ \\
\hline & & $\mathrm{C} 2$ & 0,090 & 0,374 & 2,220 & 9,231 \\
\hline & & $\mathrm{C3}$ & $0,080 \pm 0,010$ & $0,393 \pm 0,053$ & $2,025 \div 0,085$ & $9,917 \pm 0,327$ \\
\hline & \multirow{4}{*}{ P1 } & $\mathrm{CO}$ & $0,113 \pm 0,008$ & $0,970 \pm 0,086$ & $1,408 \pm 0,056$ & $12,047 \pm 0,351$ \\
\hline & & $\mathrm{Cl}$ & $0,138 \div 0,011$ & $1,875 \pm 0,113$ & $1,333 \div 0,114$ & $18,106^{+}-0,964$ \\
\hline & & $\mathrm{C2}$ & $0,140 \pm 0,009$ & $1,987 \pm 0,077$ & $1,458 \pm 0,101$ & $20,682^{+}-0,891$ \\
\hline & & C3 & $0,133 \pm 0,009$ & $2,088 \pm 0,170$ & $1,253 \pm 0,135$ & $19,520 \pm 1,523$ \\
\hline \multirow{8}{*}{$\begin{array}{l}\text { A. scrobi- } \\
\text { culata }\end{array}$} & \multirow{3}{*}{ PO } & $\mathrm{CO}$ & $0,100 \div 0,010$ & $0,266 \pm 0,022$ & $1,555^{+} 0,175$ & $4,300 \pm 1,238$ \\
\hline & & $\mathrm{Cl}$ & $0,078 \pm 0,008$ & $0,519 \pm 0,113$ & $1,500 \pm 0,163$ & $12,299 \pm 2,043$ \\
\hline & & $C 2$ & $0,075 \div 0,006$ & $0,689 \pm 0,041$ & $1,478 \pm 0,058$ & $13,718 \div 0,936$ \\
\hline & \multirow{5}{*}{$P 1$} & $\mathrm{C3}$ & $0,067 \pm 0,009$ & $0,555 \pm 0,050$ & $1,310 \div 0,215$ & $10,793 \pm 0,786$ \\
\hline & & $\mathrm{CO}$ & $0,153 \pm 0,015$ & $1,237^{+}-0,099$ & $1,337 \pm 0,019$ & $10,912-r, 123$ \\
\hline & & $\mathrm{Cl}$ & $0,178 \div 0,012$ & $2,452 \pm 0,132$ & $1,353 \pm 0,041$ & $18,734^{+}-0,647$ \\
\hline & & $C 2$ & $0,213 \div 0,066$ & $3,909 \pm 1,221$ & $1,540^{ \pm}-0,268$ & $28,329^{+}-4,944$ \\
\hline & & $\mathrm{C3}$ & $0,200 \pm 0,029$ & $2,402 \pm 0,113$ & $1,623 \pm 0,094$ & $20,117 \pm 1,370$ \\
\hline
\end{tabular}


Tabela 20 - Continuação.

\begin{tabular}{|c|c|c|c|c|c|c|}
\hline Fungo & $\begin{array}{l}\text { Nivel } \\
\text { de } \\
\text { Fósforo }\end{array}$ & $\begin{array}{l}\text { Nivel } \\
\text { de } \\
\text { Calcário }\end{array}$ & $\mathrm{Ca}$ & $\begin{array}{l}\text { Ca } \\
\text { total } \\
\text { (mg) }\end{array}$ & $\mathrm{Mg}$ & $\begin{array}{l}\mathrm{Mg} \\
\text { total } \\
\text { (mg) }\end{array}$ \\
\hline \multirow{4}{*}{ Controle } & \multirow{4}{*}{$P 1$} & $\mathrm{CO}$ & $0,943^{+} 0,070$ & $8,460^{ \pm}-1,546$ & $0,570 \pm 0,025$ & $5,047^{ \pm}-0,770$ \\
\hline & & $\mathrm{Cl}$ & $1,273 \pm 0,076$ & $18,668 \pm 2,547$ & $0,440 \pm 0,011$ & $4,535 \pm 0,387$ \\
\hline & & $\mathrm{C} 2$ & $1,533 \pm 0,189$ & $18,916-2,058$ & $0,258 \pm 0,029$ & $3,176 \pm 0,289$ \\
\hline & & $\mathrm{C3}$ & $2,390 \pm 0,182$ & $33,001 \pm 3,996$ & $0,315^{ \pm}-0,018$ & $4,326 \pm 0,394$ \\
\hline \multirow{8}{*}{$\begin{array}{l}\text { G. marga- } \\
\text { rita }\end{array}$} & \multirow{4}{*}{ PO } & $\mathrm{CO}$ & $0,815 \pm 0,075$ & $1,362 \pm 0,208$ & $0,595 \pm 0,045$ & $0,993 \pm 0,135$ \\
\hline & & $\mathrm{Cl}$ & $1,500 \pm 0,080$ & $2,232 \pm 0,602$ & $0,445 \pm 0,035$ & $0,691 \pm 0,268$ \\
\hline & & $\mathrm{C} 2$ & $1,480 \pm 0,020$ & $1,365 \pm 0,069$ & $0,345 \pm 0,015$ & $0,319 \pm 0,026$ \\
\hline & & $\mathrm{C3}$ & 1,800 & 1,189 & 0,280 & 0,185 \\
\hline & \multirow{4}{*}{$P 1$} & $\mathrm{CO}$ & $1,148 \pm 0,061$ & $9,773 \pm 0,641$ & $0,555 \pm 0,040$ & $4,686 \pm 0,204$ \\
\hline & & $\mathrm{Cl}$ & $1,490 \pm 0,035$ & $19,654 \pm 1,841$ & $0,370 \pm 0,024$ & $4,860 \pm 0,403$ \\
\hline & & $\mathrm{C} 2$ & $1,818 \pm 0,073$ & $21,509 \pm 3,722$ & $0,323 \pm 0,020$ & $3,817 \pm 0,710$ \\
\hline & & $\mathrm{C} 3$ & $2,195 \pm 0,073$ & $22,680 \pm 4,491$ & $0,313 \pm 0,015$ & $3,124 \pm 0,404$ \\
\hline \multirow{9}{*}{$\begin{array}{l}\text { G. macro- } \\
\text { carpum }\end{array}$} & \multirow{4}{*}{ PO } & CO & 1,720 & 0,624 & 1,140 & 0,413 \\
\hline & & $\mathrm{Cl}$ & $1,225 \pm 0,045$ & $5,125 \pm 0,138$ & $0,440 \pm 0,000$ & $1,846^{ \pm}-0,118$ \\
\hline & & $\mathrm{C} 2$ & 1,52 & 6,321 & 0,360 & 1,497 \\
\hline & & $\mathrm{C3}$ & $2,040 \pm 0,240$ & $9,998 \pm 1,265$ & $0,320 \pm 0,010$ & $1,567 \pm 0,063$ \\
\hline & \multirow{4}{*}{$P 1$} & $\mathrm{CO}$ & $1,260 \pm 0,074$ & $10,828 \pm 0,756$ & $0,645 \pm 0,063$ & $5,466 \pm 0,313$ \\
\hline & & $\mathrm{Cl}$ & $1,660 \pm 0,062$ & $22,998 \pm 2,087$ & $0,398 \pm 0,032$ & $5,451 \pm 0,446$ \\
\hline & & $\mathrm{C} 2$ & $1,958 \pm 0,084$ & $28,121 \pm 2,359$ & $0,328 \pm 0,031$ & $4,620 \pm 0,232$ \\
\hline & & $c 3$ & $1,833 \pm 0,116$ & $28,808 \pm 2,012$ & $0,265 \pm 0,019$ & $4,150 \pm 0,237$ \\
\hline & \multirow{4}{*}{ PO } & CO & $0,925 \pm 0,025$ & $2,519 \pm 0,522$ & $0,555 \pm 0,045$ & $1,527 \pm 0,395$ \\
\hline \multirow{7}{*}{$\begin{array}{l}\text { A. scrobi- } \\
\text { culata }\end{array}$} & & 01 & $1,273 \pm 0,076$ & $8,801 \pm 2,241$ & $0,440 \pm 0,011$ & $2,919 \pm 0,563$ \\
\hline & & $\mathrm{C} 2$ & $1,620 \pm 0,102$ & $14,937 \pm 0,693$ & $0,380 \pm 0,025$ & $3,498 \pm 0,142$ \\
\hline & & $\mathrm{C3}$ & $1,707 \pm 0,240$ & $14,298 \pm 1,984$ & $0,307^{+}=0,043$ & $2,893=0,468$ \\
\hline & \multirow{4}{*}{$P 1$} & $\mathrm{CO}$ & $1,283 \pm 0,065$ & $10,513 \div 1,298$ & $0,627 \pm 0,007$ & $5,121 \pm 0,545$ \\
\hline & & $\mathrm{Cl}$ & $1,538 \pm 0,039$ & $21,268 \pm 0,190$ & $0,383 \pm 0,017$ & $5,295 \pm 0,221$ \\
\hline & & $\mathrm{C} 2$ & $1,720 \pm 0,147$ & $31,61.3 \pm 2,577$ & $0,375 \div 0,051$ & $6,957 \pm 1,047$ \\
\hline & & $\mathrm{C3}$ & $2,163 \pm 0,121$ & $27,232 \pm 3,423$ & $0,338 \pm 0,014$ & $4,208 \pm 0,331$ \\
\hline
\end{tabular}


Tabela 20 - Continuação.

\begin{tabular}{|c|c|c|c|c|c|c|}
\hline Fungo & $\begin{array}{l}\text { Nivel } \\
\text { de } \\
\text { Fósforo }\end{array}$ & $\begin{array}{l}\text { Nível } \\
\text { de } \\
\text { Calcário }\end{array}$ & $\mathrm{S}$ & $\begin{array}{c}s \\
\text { total } \\
\text { (mg) }\end{array}$ & $\begin{array}{l}\mathrm{Fe} \\
\mathrm{ppm}\end{array}$ & $\begin{array}{c}\text { Ee } \\
\text { total } \\
\text { (mg) }\end{array}$ \\
\hline \multirow{4}{*}{ Controle } & \multirow{4}{*}{$P 1$} & $\mathrm{CO}$ & $0,160 \pm 0,016$ & $1,451 \div 0,302$ & $353,3 \div 27,2$ & $0,317 \pm 0,062$ \\
\hline & & $C 1$ & $0,188 \pm 0,015$ & $2,162 \pm 0,288$ & $348,0 \pm 32,5$ & $0,447 \pm 0,086$ \\
\hline & & $\mathrm{C} 2$ & $0,143 \pm 0,018$ & $1,767 \div 0,228$ & $232,0 \pm 53,6$ & $0,280 \pm 0,0.5 i$ \\
\hline & & $C 3$ & $0,190 \pm 0,004$ & $2,610 \pm 0,180$ & $267,8 \pm 74,1$ & $0,358 \pm 0,086$ \\
\hline \multirow{8}{*}{$\begin{array}{l}\text { G. marga- } \\
\text { rita }\end{array}$} & \multirow{5}{*}{ PO } & $\mathrm{CO}$ & $0,245 \pm 0,015$ & $0,406^{+}-0,001$ & $579,5 \pm 327,5$ & $0,100 \pm 0,061$ \\
\hline & & $\mathrm{Cl}$ & $0,255 \pm 0,005$ & $0,343 \pm 0,116$ & $223,5 \pm 6,5$ & $0,034 \pm 0,012$ \\
\hline & & $\mathrm{C} 2$ & $0,235 \pm 0,025$ & $0,218 \pm 0,032$ & $339,0 \pm 140,0^{\circ}$ & $0,032^{ \pm}=0,014$ \\
\hline & & $C 3$ & 0,250 & 0,165 & 258,0 & 0,017 \\
\hline & & CO & $0,195 \pm 0,013$ & $1,648 \pm 0,057$ & $334,5 \pm 63,4$ & $0,280 \pm 0,044$ \\
\hline & \multirow{3}{*}{$P 1$} & Ci & $0,173 \pm 0,006$ & $2,119 \pm 0,169$ & $307,3 \pm 67,4$ & $0,353 \pm 0,045$ \\
\hline & & $C 2$ & $0,183 \pm 0,006$ & $2,191 \pm 0,422$ & $224,0 \pm 39,5$ & $0,247 \pm 0,028$ \\
\hline & & $\mathrm{C3}$ & $0,193 \pm 0,019$ & $2,030 \pm 0,546$ & $200,5 \pm 41,3$ & $0,208^{ \pm}-0,049$ \\
\hline \multirow{8}{*}{$\begin{array}{l}\text { G. macro- } \\
\text { carpum }\end{array}$} & \multirow{4}{*}{ PO } & $\mathrm{CO}$ & 0,260 & 0,094 & 3682,0 & 0,133 \\
\hline & & $\mathrm{Cl}_{1}$ & $0,180 \pm 0,010$ & $0,758 \pm 0,090$ & $320,0 \pm 15,0$ & $0,134 \pm 0,002$ \\
\hline & & $\mathrm{C}_{2}$ & 0,220 & 0,915 & 177,0 & 0,074 \\
\hline & & $\mathrm{C3}$ & $0,175 \pm 0,005$ & $0,857 \pm 0,032$ & $205,5 \pm 80,5$ & $0,101 \pm 0,040$ \\
\hline & \multirow{4}{*}{$P 1$} & Co & $0,188 \pm 0,019$ & $1,637 \pm 0,231$ & $290,0 \pm 18,7$ & $0,253 \div 0,031$ \\
\hline & & $C_{1}$ & $0,225 \pm 0,009$ & $3,087 \pm 0,159$ & $420,3 \pm 79,8$ & $0,596 \div 0,156$ \\
\hline & & $\mathrm{C}_{2}$ & $0,233 \pm 0,008$ & $3,391 \pm 0,425$ & $638,0 \div 246,5$ & $3,947 \div 0,401$ \\
\hline & & C3 & $0,245^{ \pm} 0,019$ & $3,855^{ \pm}-0,334$ & $352,0 \pm 37,3$ & $0,555 \pm 0,068$ \\
\hline \multirow{8}{*}{$\begin{array}{l}\text { A. scrobi- } \\
\text { culata* }\end{array}$} & \multirow{4}{*}{ PO } & $\mathrm{CO}$ & $0,205 \pm 0,025$ & $0,543 \pm 0,033$ & $607,0 \pm 376,0$ & $0,180 \div 0,115$ \\
\hline & & $\mathrm{Cl}$ & $0,188 \pm 0,015$ & $1,273 \pm 0,296$ & $357,5 \pm 56,7$ & $0,242 \div 0,076$ \\
\hline & & $\mathrm{C} 2$ & $0,190 \pm 0,012$ & $1,754 \pm 0,102$ & $454,3 \pm 145,8$ & $0,417 \div 0,132$ \\
\hline & & $\mathrm{C3}$ & $0,173 \pm 0,032$ & $1,440 \pm 0,231$ & $180,3 \pm 19,2$ & $0,157 \div 0,014$ \\
\hline & \multirow{4}{*}{$P 1$} & $\mathrm{CO}$ & $0,260 \pm 0,006$ & $2,114 \pm 0,169$ & $551,0 \pm 57,5$ & $0,45=0,078$ \\
\hline & & $\mathrm{Cl}$ & $0,263 \pm 0,013$ & $3,644 \pm 0,230$ & $444,0 \pm 25,4$ & $0,613 \div 0,025$ \\
\hline & & $\mathrm{C} 2$ & $0,285 \pm 0,033$ & $5,237 \pm 0,594$ & $265,3^{ \pm}+1,0$ & $0,485 \div 0,068$ \\
\hline & & $c 3$ & $0,320 \pm 0,026$ & $3,934 \pm 0,175$ & $337,8 \pm 26,3$ & $0,423 \pm 0,061$ \\
\hline
\end{tabular}




\begin{tabular}{|c|c|c|c|c|c|c|}
\hline Fungo & $\begin{array}{l}\text { Nivel } \\
\text { de } \\
\text { Fósforo }\end{array}$ & $\begin{array}{l}\text { Nível } \\
\text { de } \\
\text { Calcário }\end{array}$ & $p p m$ & $\begin{array}{c}\text { Cu } \\
\text { total } \\
\text { (mg) }\end{array}$ & $\begin{array}{l}M n \\
p p m\end{array}$ & $\begin{array}{l}M n \\
\operatorname{total} \\
(\mathrm{mg})\end{array}$ \\
\hline \multirow{4}{*}{ Controle } & \multirow{5}{*}{$P 1$} & $\mathrm{CO}$ & $12,80 \pm 2,24$ & $0,011 \pm 0,001$ & $1957,7 \pm 123,3$ & $1,727 \pm 0,271$ \\
\hline & & C 1 & $27,90 \pm 7,30$ & $0,037 \pm 0,012$ & $757,3 \pm 73,4$ & $0,924 \div 0,095$ \\
\hline & & $C 2$ & $25,80 \pm 3,50$ & $0,032 \pm 0,003$ & $252,8 \pm 32,4$ & $0,325 \pm 0,037$ \\
\hline & & $\mathrm{c3}$ & $36,20 \pm 6,00$ & $0,049 \pm 0,007$ & $182,0 \pm 29,8$ & $0,247 \pm 0,035$ \\
\hline \multirow{8}{*}{$\begin{array}{l}\text { G. marga- } \\
\text { rita }\end{array}$} & & $\mathrm{CO}$ & $40,15 \pm 24,25$ & $0,007 \pm 0,005$ & $1840,5-123,5$ & $0,307 \pm 0,039$ \\
\hline & \multirow{3}{*}{ PO } & $C_{1}$ & $19,30 \pm 5,10$ & $0,003 \pm 0,002$ & $887,5 \pm 71,5$ & $0,138 \pm 0,054$ \\
\hline & & $C 2$ & $17,4 \pm 2,6$ & $0,002 \pm 0,001$ & $141,0 \pm 9,9$ & $0,013 \pm 0,002$ \\
\hline & & $C 3$ & 14,4 & 0,001 & 204,0 & 0,013 \\
\hline & \multirow{4}{*}{$? 1$} & CO & $21,00 \pm 2,20$ & $0,018 \pm 0,001$ & $1775,0 \pm 218,9$ & $1,524 \div 0,217$ \\
\hline & & $C_{1}$ & $46,40 \pm 11,40$ & $0,057 \pm 0,016$ & $909,8 \pm 19,4$ & $1,113 \div 0,114$ \\
\hline & & $\mathrm{C} 2$ & $29,60 \pm 3,30$ & $0,035 \pm 0,006$ & $359,8 \div 28,1$ & $0,428 \div 0,089$ \\
\hline & & $c 3$ & $43,30 \pm 13,10$ & $0,045 \pm 0,013$ & $174,0 \div 20,2$ & $0,187 \pm 0,049$ \\
\hline \multirow{8}{*}{$\begin{array}{l}\text { G. macro- } \\
\text { carpum }\end{array}$} & \multirow{4}{*}{ PO } & co & 57,50 & 0,002 & 3201,0 & 0,116 \\
\hline & & $\mathrm{Cl}$ & $47,70 \pm 5,80$ & $0,020 \pm 0,001$ & $832,0 \pm 12,0$ & $0,334 \pm 0,003$ \\
\hline & & $\mathrm{C} 2$ & 28,10 & 0,012 & 152,0 & 0,063 \\
\hline & & $c 3$ & $36,40 \pm 13,30$ & $0,018 \pm 0,007$ & $135,0 \div 38,0$ & $0,066 \pm 0,019$ \\
\hline & \multirow{4}{*}{$P_{1}$} & $\mathrm{CO}$ & $39,80 \pm 4,80$ & $0,035 \pm 0,006$ & $2094,0 \pm 230,9$ & $1,768^{+} \pm 0,088$ \\
\hline & & $C_{1}$ & $45,30 \pm 6,80$ & $0,062 \pm 0,007$ & $875,8 \pm 79,2$ & $1,187 \div 0,052$ \\
\hline & & $C 2$ & $17,40 \pm 1,40$ & $0,025 \pm 0,002$ & $281,0^{ \pm}=45,9$. & $0,392 \div 0,042$ \\
\hline & & $c 3$ & $37,50 \pm 1,90$ & $0,059 \pm 0,002$ & $134,5 \pm 18,7$ & $0,213 \pm 0,033$ \\
\hline \multirow{8}{*}{$\begin{array}{l}\text { A. scrobi- } \\
\text { culata }\end{array}$} & \multirow{8}{*}{ PO } & CO & $31,10^{ \pm} 6,80$ & $0,009 \pm 0,004$ & $1662,5 \pm 78,5$ & $0,454 \div 0,103$ \\
\hline & & $C_{1}$ & $27,00 \pm 4,50$ & $0,020 \pm 0,006$ & $706,3 \pm 43,7$ & $0,469 \pm 0,094$ \\
\hline & & $\mathrm{C} 2$ & $50,20 \pm 8,50$ & $0,046 \pm 0,007$ & $169,5 \div 19,5$ & $0,157 \div 0,017$ \\
\hline & & C3 & $32,20 \pm 5,60$ & $0,027 \pm 0,005$ & $88,0 \div 16,6$ & $0,075 \pm 0,018$ \\
\hline & & Co & $30,00 \pm 6,10$ & $0,023 \pm 0,003$ & $1870,3 \div 24,7$ & $1,527 \pm 0,159$ \\
\hline & & $C_{1}$ & $55,50 \pm 12,60$ & $0,076 \div 0,016$ & $612,3 \div 23,2$ & $0,850 \div 0,048$ \\
\hline & & $c 2$ & $52,10 \pm 4,40$ & $0,096 \pm 0,008$ & $194,0=30,6$ & $0,359 \pm 0,059$ \\
\hline & & $\mathrm{c3}$ & $40,10 \pm 10,30$ & $0,048 \pm 0,008$ & $110,5 \div 9,9$ & $0,141 \pm 0,023$ \\
\hline
\end{tabular}




\begin{tabular}{|c|c|c|c|c|c|c|}
\hline Fungo & $\begin{array}{l}\text { Nivel } \\
\text { de } \\
\text { Fósforo }\end{array}$ & $\begin{array}{c}\text { Nivel } \\
\text { de } \\
\text { Calcário }\end{array}$ & $p p m$ & $\begin{array}{l}Z n \\
\text { total } \\
(m g)\end{array}$ & $p p m$ & $\begin{array}{c}B \\
\text { total } \\
(m g)\end{array}$ \\
\hline \multirow{4}{*}{ Controle } & \multirow{4}{*}{$P 1$} & Co & $157,0 \pm 17,6$ & $0,143 \pm 0,030$ & $87,0 \pm 3,5$ & $0,076 \pm 0,008$ \\
\hline & & $c_{1}$ & $80,3 \pm 7,9$ & $0,099 \pm 0,014$ & $70,0 \pm 9,2$ & $0,084 \pm 0,008$ \\
\hline & & $C_{2}$ & $43,0 \pm 6,9$ & $0,053 \pm 0,006$ & $58,2 \pm 8,6$ & $0,056 \pm 0,012$ \\
\hline & & $\mathrm{C3}$ & $45,8 \pm 3,9$ & $0,062 \pm 0,004$ & $87,3 \pm 7,0$ & $0,121 \pm 0,015$ \\
\hline \multirow{8}{*}{$\begin{array}{l}\text { G. marga- } \\
\text { rita }\end{array}$} & \multirow{4}{*}{ PO } & CO & $127,5 \pm 10,5$ & $0,021 \pm 0,003$ & $96,5 \pm 0,5$ & $0,016 \pm 0,001$ \\
\hline & & $C 1$ & $81,0 \pm 4,0$ & $0,013 \pm 0,005$ & $91,5 \pm 4,5$ & $0,014 \pm 0,004$ \\
\hline & & $\mathrm{C}_{2}$ & $63,0 \pm 10,0$ & $0,006 \pm 0,001$ & $105,5 \pm 4,5$ & $0,010 \pm 0,001$ \\
\hline & & $\mathrm{C3}$ & 51,0 & 0,003 & 96,0 & 0,006 \\
\hline & \multirow{4}{*}{$P 1$} & $\mathrm{CO}$ & $126,0 \pm 1,7$ & $0,108 \pm 0,010$ & $87,8 \pm 0,7$ & $0,076 \pm 0,011$ \\
\hline & & CI & $81,5 \pm 6,0$ & $0,100 \pm 0,012$ & $84,5 \pm 2,8$ & $0,104 \pm 0,012$ \\
\hline & & $\mathrm{C} 2$ & $53,8 \pm 0,3$ & $0,065 \pm 0,014$ & $75,3 \pm 2,2$ & $0,090 \pm 0,016$ \\
\hline & & $c 3$ & $44,0 \pm 6,5$ & $0,046 \pm 0,010$ & $81,5 \div 1,6$ & $0,083 \neq 0,015$ \\
\hline \multirow{8}{*}{$\begin{array}{l}\text { G. macro- } \\
\text { carpum }\end{array}$} & \multirow{4}{*}{ PO } & Co & 317,0 & 0,011 & 203,0 & 0,007 \\
\hline & & $C_{1}$ & $85,5 \pm 2,5$ & $0,036 \pm 0,001$ & $95,0 \pm 1,0$ & $0,040 \pm 0,002$ \\
\hline & & $c 2$ & 55,0 & 0,023 & 98,0 & 0,041 \\
\hline & & $\mathrm{C3}$ & $49,5-10,5$ & $0,025 \div 0,006$ & $84,0 \pm 3,0$ & $0,041 \pm 0,002$ \\
\hline & \multirow{4}{*}{$P 1$} & $\mathrm{CO}$ & $143,3 \pm 5,2$ & $0,124 \pm 0,009$ & $92,3 \pm 6,8$ & $0,079 \pm 0,006$ \\
\hline & & C 1 & $95,5^{ \pm} 8,7$ & $0,131 \pm 0,013$ & $79,3 \pm 4,8$ & $0,108 \div 0,004$ \\
\hline & & $\mathrm{C2}$ & $53,0 \pm 3,7$ & $0,076 \pm 0,003$ & $76,3 \pm 3,1$ & $0,110 \pm 0,010$ \\
\hline & & $\mathrm{C3}$ & $42,0 \pm 1,7$ & $0,066 \pm 0,003$ & $71,8 \pm 7,7$ & $0,113 \pm 0,012$ \\
\hline \multirow{8}{*}{$\begin{array}{l}\text { A. scrobi- } \\
\text { culata }\end{array}$} & \multirow{5}{*}{ PO } & CO & $191,5 \pm 1,5$ & $0,052 \pm 0,009$ & $96,0 \pm 2,0$ & $0,027 \pm 0,008$ \\
\hline & & $\mathrm{C}_{1}$ & $73,0 \pm 5,0$ & $0,057 \pm 0,013$ & $85,0 \div 75,3$ & $0,052 \pm 0,007$ \\
\hline & & $c 2$ & $62,8 \pm 7,5$ & $0,058 \div 0,006$ & $67,5 \pm 13,0$ & $0,063 \pm 0,013$ \\
\hline & & $c 3$ & $33,0 \pm 3,8$ & $0,028 \pm 0,004$ & $58,7 \pm 11,4$ & $0,049 \pm 0,009$ \\
\hline & & CO & $177,3 \pm 8,1$ & $0,147 \pm 0,020$ & $111,7 \pm 6,2$ & $0,097 \pm 0,008$ \\
\hline & \multirow{3}{*}{$P 1$} & $C_{1}$ & $103,8 \pm 8,5$ & $0,143 \div 0,009$ & $78,3^{ \pm}-6,7$ & $0,109 \pm 0,010$ \\
\hline & & 62 & $76,3^{ \pm} 7,6$ & $0,140 \div 0,014$ & $66,3 \pm 4,7$ & $0,122 \pm 0,010$ \\
\hline & & 63 & $49,3 \pm 8,3$ & $0,059 \pm 0,004$ & $78,0 \pm \approx, \exists$ & $0,099 \neq 0,016$ \\
\hline
\end{tabular}


Tabela 20 - Continuação.

78.

\begin{tabular}{|c|c|c|c|c|c|c|}
\hline Fungo & $\begin{array}{c}\text { Nivel } \\
\text { de } \\
\text { Fósforo }\end{array}$ & $\begin{array}{c}\text { Nivel } \\
\text { de } \\
\text { Caleário }\end{array}$ & $\begin{array}{l}\mathrm{Na} \\
\mathrm{ppm}\end{array}$ & $\begin{array}{c}\mathrm{Na} \\
\text { total } \\
(\mathrm{mg})\end{array}$ & $\begin{array}{r}A I \\
\text { ppm }\end{array}$ & $\begin{array}{c}\text { Al } \\
\text { total } \\
(\mathrm{mg})\end{array}$ \\
\hline \multirow{5}{*}{ Controle } & \multirow{5}{*}{$P \uparrow$} & CO & $99,3 \pm 12,5$ & $0,085=0,013$ & $525,5^{ \pm} 88,3$ & $0,437 \pm 0,040$ \\
\hline & & $\mathrm{Cl}$ & $206,3^{ \pm} 19,0$ & $0,249^{ \pm} 0,013$ & $542,0^{ \pm} 65,7$ & $0,454^{ \pm} 0,143$ \\
\hline & & $\mathrm{C2}$ & $78,5^{ \pm} 31,0$ & $0,099 \pm 0,041$ & $375,8^{ \pm} 139,5$ & $0,449 \div 0,151$ \\
\hline & & C3 & $107,3^{ \pm} 32,8$ & $0,144 \pm_{0}, 041$ & $483,8 \pm 258,6$ & $0,630 \div 0,317$ \\
\hline & & CO & $184,5 \pm 108,5$ & $0,030 \pm 0,017$ & $966,5 \pm 579,5$ & $0,167 \pm 0,107$ \\
\hline \multirow{7}{*}{$\begin{array}{l}\text { G. marga- } \\
\text { rita }\end{array}$} & \multirow{3}{*}{ PO } & $C_{1}$ & $39,5 \pm \quad 5,5$ & $0,006 \pm 0,001$ & $266,0^{ \pm} \quad 8,0$ & $0,040 \pm 0,012$ \\
\hline & & $C 2$ & $65,0^{ \pm} 40,0$ & $0,00 € \pm 0,004$ & $298,0 \pm 88,0$ & $0,028 \pm 0,009$ \\
\hline & & $C 3$ & 34,0 & 0,002 & 304,0 & 0,020 \\
\hline & \multirow{4}{*}{$P 1$} & CO & $129,5 \pm 41,2$ & $0,113 \pm 0,038$ & $562,3 \neq 782,0$ & $0,465 \pm 0,134$ \\
\hline & & C 1. & $130,0 \pm 45,0$ & $0,145 \pm 0,041$ & $491,3 \pm 94,9$ & $0,569 \pm 0,058$ \\
\hline & & $\mathrm{C} 2$ & $116,0 \pm 27,0$ & $0,154 \pm 0,062$ & $322,8 \pm 60,2$ & $0,377 \neq 0,082$ \\
\hline & & C3 & $56,3 \pm 11,7$ & $0,052 \pm 0,003$ & $370,3 \neq 785,6$ & $0,381 \pm 0,178$ \\
\hline \multirow{9}{*}{$\begin{array}{l}\text { G. macro- } \\
\text { carpum }\end{array}$} & \multirow{4}{*}{ PO } & CO & 270,0 & 0,010 & 7224,0 & 0,262 \\
\hline & & $\mathrm{Cl}$ & $235,5^{ \pm} 85,5$ & $0,097 \pm 0,030$ & $474,0 \pm 2,0$ & $0,199 \pm 0,014$ \\
\hline & & $C 2$ & 146,0 & 0,061 & 303,0 & 0,126 \\
\hline & & C3 & $75,5^{ \pm} 22,5$ & $0,037 \pm 0,011$ & $279,0 \pm 721,0$ & $0,138 \pm 0,061$ \\
\hline & \multirow{4}{*}{$P 1$} & $\mathrm{CO}$ & $134,3 \pm 46,6$ & $0,110 \pm 0,032$ & $448,0 \pm 93,4$ & $0,399 \div 0,103$ \\
\hline & & C.1 & $69,0 \pm 3,0$ & $0,097 \pm 0,012$ & $728,3 \pm 224,3$ & $1,060 \pm 0,418$ \\
\hline & & $\mathrm{C2}$ & $87,3=32,9$ & $0,116 \pm 0,033$ & $374,0 \pm 129,7$ & $0,707 \pm 0,195$ \\
\hline & & $\mathrm{c3}$ & $127,5 \pm 26,5$ & $0,198 \pm 0,037$ & $712,3 \pm 64,8$ & $1,128 \pm 0,128$ \\
\hline & \multirow{4}{*}{ PO } & Co & $121,5 \pm 3,5$ & $0,033 \pm 0,005$ & $1309,0 \pm 805,0$ & $0,395 \pm 0,283$ \\
\hline \multirow{7}{*}{$\begin{array}{l}\text { A. scrobi- } \\
\text { culata }\end{array}$} & & $\mathrm{Cl}_{1}$ & $143,3 \pm 39,6$ & $0,097 \pm 0,024$ & $569,8 \pm 136,9$ & $0,375 \div 0,130$ \\
\hline & & $C 2$ & $75,0 \div 15,8$ & $0,069 \pm 0,013$ & $973,8 \pm 263,5$ & $0,832 \pm 0,230$ \\
\hline & & $\mathrm{C3}$ & $187,7 \div 10,2$ & $0,165 \pm 0,105$ & $323,3 \div 28,3$ & $0,234 \pm 0,044$ \\
\hline & \multirow{4}{*}{$P_{1}$} & Co & $205,7 \pm 96,1$ & $0,173 \pm 0,078$ & $1125,0 \pm 215,9$ & $0,926 \pm 0,200$ \\
\hline & & $C_{1}$ & $97,0 \pm 13,4$ & $0,134 \pm 0,016$ & $876,8 \pm 83,0$ & $1,213 \pm 0,108$ \\
\hline & & $C 2$ & $58,0 \pm 8,7$ & $0,106 \pm 0,015$ & $502,0 \pm 124,4$ & $0,908 \pm 0,207$ \\
\hline & & C3 & $101,5 \pm 32,3$ & $0,132 \pm 0,050$ & $523,3 \pm 136,5$ & $0,645 \pm 0,741$ \\
\hline
\end{tabular}

Nos tratamentos controle sem adição de $F$ go solo, năo foi feita a determinação za juantidade de nutrientes na parte aérea, por falta je biorissa.

Cs valor ss apresentacos zeoresentem a média t desvio padrão da nécia.

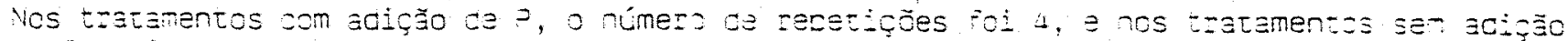
de o varizu de: $a 4$. 
Nos tratamentos controle sem adição de $P$ ao solo, não foi possivel a determinação da quantidade de nutrientes, de vido a pequena biomassa (MSPA) produzida. Em geral, nos tratamentos sem adição de $P$, houve uma produção de MSPA muito baixa, de modo que para a determinação de nutrientes foi preciso jun tar duas ou mais repetições do mesmo tratamento.

A análise de variância foi feita desprezando - se - fator FóSFORO do delineamento experimental inicial, resultando num fatorial 4 FUNGOS $x 4$ NÍVEIS DE CALCARIO.

Os valores de $F$ obtidos na análise de variância estão na Tabela 21 .

Houve efeitos altamente significativos do fator FUNGO na concentração e quantidade total de alguns nutrientes na parte aérea de S. guianensis, destacando-se o P, Mg, S, Fe, Cu, Zn e Al. o efeito do fator CALCARIo foi mais pronunciado na absorção de $\mathrm{Ca}, \mathrm{Mn}$ e $\mathrm{Zn}$, principalmente.

As médias da concentração e quantidade total de nutrientes na parte aérea das plantas, para o fator FUNGo, nos solos sem adição de $P$ e com adição de $P$ são apresentadas nas Tabelas 22 e 23 , respectivamente.

De uma maneira geral, nos solos com adição de $P$, houve um aumento das concentrações de $\mathrm{P}, \mathrm{Ca}, \mathrm{S}$ e Cu na parte aérea, em relação ao solo sem adição de $P$, enquanto as concen trações de $\mathrm{K}, \mathrm{Mg}, \mathrm{Fe}, \mathrm{Mn}, \mathrm{Zn}, \mathrm{B}$, Na e Al diminuiram. No entanto, essas observações não foram submetidas à análise estatistica.

Nos solos sem àdição de $P$, por falta da análise quimica do controle sem inoculação, não foi possivel verificar 
Tabela 21 - Valores de $F$ obtidos na análise de variância da concentração e quantidade total de nutrientes na parte aérea de $S$. guianensis, nos solos com adição de $P$.

\begin{tabular}{|c|c|c|c|c|}
\hline \multirow{2}{*}{$\begin{array}{l}\text { Variável } \\
\text { analisada }\end{array}$} & \multicolumn{4}{|c|}{ Causas da variação } \\
\hline & Calcário (C) & Fungo $(F)$ & $C \times F$ & Blocos \\
\hline Graus de liberdade & 3 & 3 & 9 & 3 \\
\hline$P \%$ & 0,83 & $17,56^{* *}$ & 0,68 & 1,41 \\
\hline P total & 6,61 & $14,79 * *$ & $2,31 *$ & 0,29 \\
\hline K \% & 2,28 & $4,25 * *$ & 1,28 & $5,79 *$ \\
\hline$k$ total & $20,11 * *$ & 2,35 & 1,99 & 0,10 \\
\hline $\mathrm{Ca} \%$ & $68,90 * *$ & 0,91 & $3,63 * *$ & 1,33 \\
\hline Ca total & $42,61 * *$ & $3,13^{*}$ & $2,19 *$ & 2,13 \\
\hline $\mathrm{Mg} \%$ & $139,54^{* *}$ & $3,68 *$ & $2,18^{*}$ & $12,24 * *$ \\
\hline Mg total & $4,66 * *$ & $5,98 * *$ & $2,73^{*}$ & 0,67 \\
\hline $5 \%$ & $3,78 *$ & $39,51 * *$ & 1,13 & 0,53 \\
\hline S total & $18,15 * *$ & $28,92^{* *}$ & $3,65 * *$ & 1,12 \\
\hline $\mathrm{Fe} \mathrm{ppm}$ & 1,18 & $3,66^{*}$ & 2,02 & 0,22 . \\
\hline Fe total & 1,92 & $5,40 * *$ & 1,51 & 0,68 \\
\hline Cu ppm & $5,06 * *$ & $4,41 * *$ & 1,71 & 0,51 \\
\hline Cu total & $13,39 * *$ & $8,21 * *$ & $3,97 * *$ & 0,61 \\
\hline Mn ppm & $353,94 * *$ & 2,15 & 1,18 & $3,40 *$ \\
\hline Mn total & $163,17^{* *}$ & 1,84 & 0,82 & $2,80^{*}$ \\
\hline Zn ppm & $196,34 * *$ & $9,52 * *$ & $2,12^{*}$ & $4,42 * *$ \\
\hline Zn total & $27,03 * *$ & $7,98 * *$ & $2,39 *$ & 0,53 \\
\hline B ppm & $13,26 * *$ & 1,80 & $2,34 *$ & 1,50 \\
\hline B total & $4,00^{*}$ & $3,30 *$ & 2,08 & $3,32^{*}$ \\
\hline $\mathrm{Na} \mathrm{ppm}$ & 2,39 & 0,23 & 2,00 & 0,15 \\
\hline $\mathrm{Na}$ total & 0,89 & 0,43 & $2,33^{*}$ & 0,27 \\
\hline Al ppm & $3,19 *$ & $3,83 *$ & 1,17 & 0,48 \\
\hline Al total & $2,83 *$ & $5,51 * *$ & 1,20 & 0,97 \\
\hline
\end{tabular}

* Significativo com $p \leqslant 0,05$

* Significativo com $p \leqslant 0,01$ 
Tabela 22 - Médias da concentração e quantidade total de nutrien tes na parte aérea de $S$. guianensis para o fator FUN GQ, nos solos sem adição de $P$.

\begin{tabular}{|c|c|c|c|c|}
\hline \multirow{2}{*}{\multicolumn{2}{|c|}{$\begin{array}{l}\text { Variável } \\
\text { analisada }\end{array}$}} & Fungo & \multicolumn{2}{|l|}{ MVA } \\
\hline & & G. margarita & G. macrocarpum & A. scrobiculata \\
\hline$P$ & $\%$ & 0,131 & 0,088 & 0,080 \\
\hline$P$ & total & 0,154 & 0,275 & 0,507 \\
\hline $\mathrm{K}$ & $\%$ & 2,466 & 1,879 & 1,561 \\
\hline K & total & 2,604 & 7,122 & 10,278 \\
\hline & $\%$ & 1,399 & 1,626 & 1,381 \\
\hline & total & 1,537 & 5,517 & 10,139 \\
\hline $\mathrm{Mg}$ & $\%$ & 0,416 & 0,565 & 0,421 \\
\hline & total & $\therefore 0,547$ & 1,331 & 2,709 \\
\hline$S$ & $\%$ & 0,246 & 0,209 & 0,189 \\
\hline$S$ & total & 0,283 & 0,656 & 1,253 \\
\hline & $p p m$ & 350,0 & 1096,1 & 399,8 \\
\hline & total & 0,046 & 0,111 & 0,248 \\
\hline & ppm & 22,8 & 40,9 & 35,1 \\
\hline & tota 1 & 0,003 & 0,013 & 0,026 \\
\hline & ppm & 768,2 & 1080,0 & 656,5 \\
\hline & total & 0,118 & 0,145 & 0,289 \\
\hline & $p p m$ & 80,6 & 126,7 & 90,0 \\
\hline & total & 0,011 & 0,024 & 0,047 \\
\hline$B$ & ppm. & 97,3 & 120,0 & 76,8 \\
\hline$B$ & total & 0,012 & 0,032 & 0,048 \\
\hline & ppm & 80,7 & 181,7 & 131,8 \\
\hline & total & 0,011 & 0,051 & 0,090 \\
\hline & $p p m$ & 458,6 & 2070,0 & 793,9 \\
\hline & total & 0,064 & 0,181 & 0,484 \\
\hline
\end{tabular}

As quantidades totais de nutrientes estão apresentadas em $m g$. 
Tabela 23 - Médias da concentração e quantidade total de nutrientes na par te aérea de $S$. guianensis, para o fator FUNGo, nos solos com adição de $P$.

Variável.

analisada

\section{Fungo MVA}

Controle G.margarita G.macrocarpum A.scrobiculata

\begin{tabular}{|c|c|c|c|c|c|c|}
\hline $\mathrm{P} \%$ & 0,089 & c & $0,112 \mathrm{bc}$ & $0,131 \mathrm{~b}$ & 0,186 & $a$ \\
\hline P total & 1,076 & $c$ & $1,176 \mathrm{bc}$ & $1,729 b$ & 2,499 & $\mathrm{a}$ \\
\hline$k \%$ & 1,387 & $b$ & $1,604 \mathrm{a}$ & $1,362 \mathrm{~b}$ & 1,463 & $a b$ \\
\hline$k$ total & 16,165 & $\mathrm{a}$ & 17,013 a & 17,588 a & 19,523 & $a$ \\
\hline $\mathrm{Ca} \%$ & 1,588 & $a$ & 1,692 a & $1,677 \mathrm{a}$ & 1,676 & $a$ \\
\hline Ca total & 19,761 & $a$ & $18,403 a$ & $22,689 a$ & 22,656 & $a$ \\
\hline $\mathrm{Mg} \%$ & 0,378 & $b$ & $0,397 a b$ & $0,409 a b$ & 0,431 & $\mathrm{a}$ \\
\hline Mg total & 4,277 & $b$ & $4,121 b$ & $4,927 a b$ & 5,395 & $\mathrm{a}$ \\
\hline $5 \%$ & 0,166 & $c$ & $0,186 \mathrm{c}$ & $0,222 b$ & 0,282 & $\mathrm{a}$ \\
\hline S total & 1,997 & $c$ & $1,997 \mathrm{C}$ & $2,992 b$ & 3,732 & $\mathrm{a}$ \\
\hline $\mathrm{Fe} \mathrm{ppm}$ & 300,2 & $a b$ & $266,5 \quad b$ & $399,5 \quad a b$ & 425,0 & $a$ \\
\hline Fe total & 0,350 & $b$ & $0,272 b$ & $0,586 a$ & 0,494 & $a b$ \\
\hline Cu ppm & 25,6 & $b$ & $35,0 \quad a b$ & $34,9 \quad a b$ & 44,2 & $a$ \\
\hline Cu total & 0,032 & $b$ & $0,039 b$ & $0,045 a b$ & 0,061 & $a$ \\
\hline Mn ppm & 789,9 & a & 804,6 & 846,3 & 696,7 & $a$ \\
\hline Mn total & 0,806 & $a$ & $0,813 a$ & 0,889 a & 0,719 & $a$ \\
\hline $\mathrm{Zn} \mathrm{ppm}$ & 81,5 & $b$ & $76,3 \quad b$ & $83,4 \quad b$ & 100,1 & $a$ \\
\hline In total & 0,089 & $b$ & $0,079 \mathrm{~b}$ & $0,099 a b$ & 0,121 & $a$ \\
\hline B ppm & 74,2 & $a$ & $82,2 \quad a$ & $79,8 \quad a$ & 83,5 & $\mathrm{a}$ \\
\hline B total & 0,086 & $\mathrm{a}$ & $0,088 \mathrm{a}$ & 0,102 a & 0,105 & $a$ \\
\hline $\mathrm{Na}$ ppm & 122,8 & $a$ & $107,9 \quad a$ & $104,5 \quad a$ & 115,5 & a \\
\hline $\mathrm{Na}$ total & 0,144 & $a$ & $0,116 \mathrm{a}$ & 0,130 a & 0,136 & $a$ \\
\hline A1 ppm & 481,7 & $b$ & $436,6 \quad b$ & $565,6 \quad a b$ & 756,7 & $a$ \\
\hline Al total & 0,555 & $b$ & $0,448 b$ & $0,778 a b$ & 0,923 & $a$ \\
\hline
\end{tabular}

Letras iguais não diferem estatisticamente (Tuckey $p \leqslant 0,05$ ), quando a comção é feita na linha.

As quantidades totais de nutrientes estão representadas em $\mathrm{mg}$. 
a eficiência relativa de cada fungo na absorção de nutrientes. No entanto A. scrobiculata aumentou a concentração e a quantidade total na parte aérea de praticamente todos os nutrientes, em relação a G. margarita e G. macrocarpum.

Nos solos com adição de $P$, as plantas inocula das com G. margarita apresentaram uma concentração de $K 15,68 \%$ superiores (Tabela 24) ao controle não micorrizado. G. margari ta mostrou uma tendência de diminuir tanto a concentração quan to a quantidade total absorvida de $A I$, porém esta diferença não foi significativa. A absorção de $P$ não foi estatisticamente di ferente das plantas não micorrizadas.

$\mathrm{Na}$ Tabela 24, verificamos ainda que as plantas micorrizadas com G. macrocarpum tiveram aumentos significati vos tanto das concentrações quanto dasquantidades totais de $P$, $S$ e Fe. As plantas micorrizadas com A. scrobiculata apresenta ram incrementos significativos nas concentrações e quantidades totais de $P, M g, S, C u, Z n$ e $A l$, havendo uma tendência de dimi nuição da absorção. de $M n$, não significativa estatisticamente.

Na presença de G. margarita e G. macrocarpum hou ve uma tendência de aumento da concentração e quantidade total de Cu absorvido. G. margarita causou um ligeiro decremento na concentração e quantidade total de $Z n$, e G. macrocarpum um ligeiro incremento, os quais não diferiram eln relação ao controle.

Assim, a presença de MVA, de uma maneira geral tende a aumentar a absorção de elementos pouco móveis no solo, como $P$, Cu e $Z n$, provavelmente devido ao fato das hifas se estenderem além da zona de depleção das raizes, explorando um vo lume maior de solo. 
Tabela 24 - Variação percentual da concentração e quantidade to tal de nutrientes na parte aérea de $S$. guianensis com diferentes associações MVA, em relação ao controle não inoculado, nos solos com adição de fósfoIo.

\begin{tabular}{|c|c|c|c|}
\hline \multirow{2}{*}{$\begin{array}{l}\text { Variação } \\
\text { percentual } \\
(\%)\end{array}$} & \multicolumn{3}{|c|}{ Fungo MVA } \\
\hline & G. margarita & G.macrocarpum & A. scrobiculata \\
\hline$P \%$ & 25,17 & $46,15 *$ & $107,69 *$ \\
\hline$P$ total & 9,23 & $60,71 *$ & $132,27^{*}$ \\
\hline K \% & $15,68 *$ & $-1,76$ & 5,50 \\
\hline$k$ total & 5,25 & 8,81 & 20,77 \\
\hline $\mathrm{Ca} \%$ & 6,53 & 5,59 & 5,47 \\
\hline Ca total & $-6,87$ & 14,81 & 14,65 \\
\hline $\mathrm{Mg} \mathrm{\%}$ & 5,12 & 8,10 & $13,88 *$ \\
\hline Mg total & $-3,50$ & 15,22 & $26,32 *$ \\
\hline S \% & 12,03 & $33,83 *$ & $69,55 *$ \\
\hline S total & $-0,01$ & $49,83 *$ & $86,88 *$ \\
\hline Fe ppm & $-11,22$ & $41,57^{*}$ & 33,06 \\
\hline Fe total & $-22,39$ & $67,27 *$ & 40,96 \\
\hline Cu ppm & 36,52 & 36,23 & $72,17^{*}$ \\
\hline Cu total & 21,72 & 41,37 & $90,39 *$ \\
\hline$M n p p m$ & 1,86 & 7,14 & $-11,80$ \\
\hline Mn total & 0,88 & 10,43 & $-10,76$ \\
\hline $\mathrm{Zn} \mathrm{ppm}$ & $-6,37$ & 2,38 & $22,85 *$ \\
\hline Zn total & $-10,67$ & 11,16 & $35,58 *$ \\
\hline B ppm & 10,77 & 7,58 & 12,54 \\
\hline B total & 1,81 & 18,44 & 21,69 \\
\hline $\mathrm{Na} p \mathrm{pm}$ & $-12,11$ & $-14,91$ & $-5,90$ \\
\hline $\mathrm{Na}$ total & $-19,84$ & $-10,00$ & $-5,72$ \\
\hline Al ppm & $-9,32$ & 17,41 & $57,08 *$ \\
\hline Al total & $-19,27$ & 40,33 & $66,35 *$ \\
\hline
\end{tabular}

* Difere estatisticamente do controle sell inoculação (Tuckey $p \leqslant 0,05)$. 
- aumento da absorção de $P$ em plantas micorriza das já foi verificado em praticamente todos os trabalhos com MVA (CARDOSO, 1984).

A maior absorção de $C u$ e $Z n$ por diferentes micorrizas também já foi observada por vários autores (PACKOVSKY, 1986; CARDOSO, 1984; LAMBERT et alii, 1979; GILMORE, 1971; TIM MER e LEYDEN, 1978).

Normalmente, o aumento da absorção de $P$ tem um efeito negativo na absorção de $C u$ e $Z n$. Mas nos experimentos com MVA, o que ocorre com frequência é um aumento na absorção desses três nutrientes.

Nos solos com adição de $P$ verificamos que $a$ absorção de $Z n$, ap̀esar de ser maior nas plantas micorrizadas, di minui em relação à absorção de $P$ (Tabela 25). Um comportamento semelhante foi observado para o Cu. Desta forma, a presença de MVA causou uma diminuição da absorção de Cu e Zn em rela ção à absorção de $P$, nos solos com adição de $P$.

Nos solos sem adição de $P$, notamos que a absorção de $C u$ e $Z n$ nas plantas inoculadas com A. scrobiculata e G. macrocarpum foi maior, proporcionalmente a absorção de $P$, do que nas plantas inoculadas com G. margarita (Tabela 25). A variação da absorção de $C u$ e $Z n$ em relação ao controle não micor rizado não foi possivel avaliar.

A absorção de $A 1$, com excessão das plantas micorrizadas por G. margarita, aumentou. No entanto, a absorção de Al em relação à de $P$ diminuiu nas plantas micorrizadas ( Tabela 25). 
86.

Isto sugere que, provavelmente a maior tolerância de plantas micorrizadas a níveis tóxicos de $A l$ se dá não por diminuição na quantidade de $A l$ absorvido, e sim por uma maior absorção de $P$ em relação ao $A l$,já que a toxidez de Al está di retamente relacionada com a deficiência de $P$.

Quanto ao $\mathrm{Fe}$, sua absorção foi maior em dois ca sos, concordando com CARDOSO (1984) e LAMBERT et alii (1979), e menor em um caso, concordando com PACKOVSKY (1986).

A relação $P / F e$ seguiu o mesmo comportamento da relação P/Al. Houve também uma maior absorção de Fe em rela ção ao Mn na maioria dos casos (Tabela 25) sugerindo que prova velmente a maior tolerância de plantas micorrizadas a niveis tó xicos de Mn se dá por uma maior absorção de fe em relação à de Mn, e não por uma redução na absorção de $M n$ somente.

A absorção de macro e micronutrientes e suas in terrelações é uma área de estudo pouco explorada e de grande im partância na pesquisa com MVA, havendo necessidade de muitos es tudos para se poder afirmar algo relativo a maior tolerância de plantas micorrizadas a niveis tóxicos de Al e Mn, principalmen te.

Esses estudos são dificultados pela variação da eficiência das diferentes micorrizas em absorverem os nutrientes do solo, pelos diferentes tipos de solo onde se desenvol vell as micorrizas, e pelas diferentes condições ambientais que as afetam, mostrando mais uma vez a grande necessidade de se conseguir o cultivo das MVA in vitro. 
De qualquer forma as MVA alteram as relações en tre nutrientes na parte aérea das plantas, mostrando que é mui to provável que as necessidades nutricionais das plantas micorrizadas sejam diferentes das plantas não micorrizadas, havendo uma necessidade da reavaliação dos ensaios de exigências nu tricionais conduzidos em substratos isentos de fungos micorrizicos-VA.

Tabela 25 - Relação entre a concentração de nutrientes na parte aérea de S. guianensis.

\begin{tabular}{|c|c|c|c|c|c|c|c|}
\hline \multirow{2}{*}{ Fungo } & \multirow{2}{*}{$\begin{array}{l}\text { Nivel } \\
\text { de } \\
\text { Fósforo }\end{array}$} & \multicolumn{2}{|c|}{ Relação } & itre os & \multicolumn{2}{|c|}{ nutrientes } & $(\% / \%)$ \\
\hline & & $P / Z n$ & $\mathrm{P} / \mathrm{Cu}$ & $P / M n$ & $P / A I$ & $\mathrm{P} / \mathrm{Fe}$ & $\mathrm{Mn} / \mathrm{Fe}$ \\
\hline \multirow[t]{2}{*}{ Controle } & PO & - & - & - & - & - & - \\
\hline & P1 & 10,92 & 34,76 & 1,13 & 1,85 & 2,96 & 2,63 \\
\hline \multirow[t]{2}{*}{ G.margarita } & PO & 16,25 & 57,46 & 1,71 & 2,86 & 3,74 & 2,19 \\
\hline & $P 1$ & 14,68 & 32,00 & 1,39 & 2,57 & 4,20 & 3,02 \\
\hline \multirow[t]{2}{*}{ G.macrocarpum } & PO & 6,95 & 21,52 & 0,81 & 0,42 & 0,80 & 0,98 \\
\hline & $P 1$ & 15,71 & 37,54 & 1,55 & 2,32 & 3,28 & 2,12 \\
\hline \multirow[t]{2}{*}{ A.scrobiculata } & PO & 8,89 & 22,79 & 1,21 & 1,01 & 2,00 & 1,64 \\
\hline & P1 & 18,58 & 42,08 & 2,67 & 2,46 & 4,38 & 1,63 \\
\hline
\end{tabular}




\section{CONCLUSÕES}

- Stylosanthes guianensis apesar de ser uma plan ta que ocorre naturalmente em solos com até 1 ppm de fósforo mostrou-se altamente dependente deste nutriente.

Em solos ácidos com baixos níveis de fósforo o S. guianensis apresentou um microtrofismo muito elevado, havendo uma correlação positiva entre seu desenvolvimento vegetativo e a colonização das raizes pelos fungos MVA.

As diferentes condições edáficas podem afetar tan to a taxa de germinação dos esporos quanto a taxa de coloniza ção das raizes, bem como a eficiência da micorriza formada em absorver nutrientes do solo e translocá-los para a parte aérea da planta, dependendo da adaptabilidade do fungo e/ou da micorriza a essas condições.

As micorrizas podem alterar as exigências nutricionais da planta, além de alterar as relações entre os nutrien tes.

- aumento da relação P/Al e a diminuição da rela Ção $\mathrm{Mn} / \mathrm{Fe}$ pelas micorrizas, sugerem seu envolvimento em processos que aumentam a tolerância de $S$. guianensis a niveis tóxicos de Al e Mn no solo. 


\section{LITERATURA CITADA}

ABBOTT, L.K. e A.D. ROBSON, 1984. The effect of VA mycorrhizae on plant growth. In: POWELL, C.L.e BAGYARAJ, D.J. (eds.) VA Mycorrhiza. CRC Press, Boca Raton. pp. 113-130.

AZCON-AGUILAR, C.; J.M. BAREA; R. AZCON e J. OLIVARES, 1982. Effectiviness of Rhizobium and VA Mycorrhiza in the introduction of Hedysarum coronarium in a new habitat. Agric.Environ., 7: $199-206$.

AZCON, R.; J.M. BAREA; C. AZCON-AGUILAR E R.M. DIAZ-RODRIGUEZ, 1986. Effects of mycorrhizal inoculation on $N$-fixation by a forage legume under field conditions as evaluated by using a 15-N technique. In: Mycorrhizae: physiology and genetics. 1st ESM, Dijon. pp. 457-460.

AZCON, R. e J.A. OCAMPO, 1981. Factors affecting the vesiculararbuscular infection and mycorrhizal dependency of thirteen wheat cultivars. New Phytol., 87: 677-685.

BAREA, J.M. e C. AZCON-AGUILAR, 1982. Interactions between mycor rhizal fungi and soil microorganisms. In: Les Micorhizes:biologie et utilisation. INRA, no 13. 
BAREA, J.M.; R. AZCON e C. AZCON-AGUILAR, 1987. Estimation of $\mathrm{N}_{2}$-fixation by clover and $\mathrm{N}$-transfer from clover to ryegrass by using ${ }^{15} \mathrm{~N}$ in a time-course experiment under field condi tions and study of some related mycorrhizal implications. Não publicado. (Enviado a New Phytol.).

BAYLIS, G.T.S., 1975. The magnolioid mycorrhiza and mycotro phy in root systems derived from it. In: SANDERS, F.E.; MOS SE, B. \& TINKER, P.B. (eds.). Endomycorrhizas. Academic Press, London. pp. 373-389.

BOWEN, G.D., 1980. Mycorrhizal roles in tropical plants and ecosystems. In: MIKOLA, P. (ed.). Tropical mycorrhiza research. Oxford University Press, Oxford. p. 165-190.

BURNQUIST, W.L., 1984. Avaliação de tolerância ao alumínio em diferentes populações de Stylosanthes guianensis (Aubl.) SW. Dissertação de Mestrado. ESALQ/USP, Piracicaba, p. 73.

CABALA-ROSAND, P. e R. DIAS, 1987. Associações micorrízicas e a nutrição mineral das plantas. In: Anais da I Reunião Brasileira Sobre Micorrizas. Lavras, MG. pp. 33-59.

CARDOSO, E.J.B.N., 1984. Efeito de micorriza vesiculo-arbuscu lar e de fosfato-de-rocha nas culturas de soja e feijão. Te se de Livre-Docência. ESALQ/USP, Piracicaba. p. 220.

CARDOSO, E.J.B.N., 1985. Efeito da micorriza vesículo-arbuscu lar e fosfato-de-rocha na simbiose soja-Rhizobium. R. bras. Ci. Solo, 2: 125-130.

CARDOSO, E.J.B.N., 1986. Interação micorrizas microorganismos não fitopatogênicos. In: Anais da I Reunião Brasileira So bre Micorrizas. Lavras, MG. pp. 60-75. 
CARDOSO, E.J.B.N.; V. ANTUNES; A.P.D. SILVEIRA E M.H.A. OLIVEIRA, 1986. Eficiência de fungos micorrízicos vesiculo-arbus culares em porta-enxertos de citros. R. bras. Ci. Solo, 10: $25-30$.

CARVALHO, M.M. de; D.G. EDWARDS; C.S. ANDREW e C.J. ASHER, 1981. Aluminium toxicity, nodulation, and growth of Stylosanthes species. Agron. J., 73: 261-265.

CARVALHO, M.M. de; D.G. EDWARDS; C.J. ASHER e C.S. ANDREW, 1982. Effects of aluminium on nodulation of two Stylosanthes spe cies grown in nutrient solution. Plant and Soil, 64: 141152 .

CHAMBERS, C.A.; S.E. SMITH E F.A. SMITH, 1980. Effects of ammonium and nitrate ions on mycorrhizal infection, nodula tion and growth of Trifolium subterraneum. New Phytol., 85: $47-62$.

CIAT, 1980. Tropical Pastures Program Annual Report. 1979. pp. 156.

COLOZZI FILHO, A.; J.0. SIQUEIRA e E. OLIVEIRA, 1986. OCOrrência de micorriza vesiculo-arbusculares em alguns eco e agrossitemas do Estado de Minas Gerais. In: Anais da I Reunião Brasileira Sobre Micorrizas, Lavras, MG. pp. 146.

COOPER, K.M., 1975. Growth responses to the formation of endo trophic mycorrhizas in Solanum, Leptospermum and New Zealands ferns. In: SANDRES, F.E.; MOSSE, B. \& TINKER, P.B. (eds). Endomycorrhizas. Academic Press, London. pp. 391-407. 
CORDEIRO, A.T.; P.R. MOSQUIM; L.ZAMBOLIM E J.C.L.NEVES, 1986. Influência do aluminio sobre o crescimento e a micorrizaçãodo Stylosanthes. In: Anais da I Reunião Brasileira Sobre Micorrizas, Lavras, MG. pp. 145.

DAFT, M.J. e A.A. EL-GIAHMI, 1975. Effects of Glomus infec tions on three legumes. In: SANDERS, F.E.; MOSSE, B \& TINKER, P.B. (eds.). Endomycorrhizas. Academic Press, London. p. $470-484$.

DAFT, M.J. e T.H. NICOLSON, 1974. Arbuscular mycorrhizas in plants colonizing coal wastes in Scotland. New Phytol., 73: $1129-1138$.

DANIELS, B.A. E J.M. TRAPPE, 1980. Factors affeting spore ger mination of the vesicular-arbuscular mycorrhizal fungus, Glo mus epigaeus. Mycologia, 72(3): 457-471.

DEAL, D.R.; C.W. BOOTHROYD e W.F. MAI, 1972. Replanting of vineyards and its relationship to vesicular-arbuscular mycor rhiza. Phytopathol., 62: 172-175.

FAQUIN, V.; E. MALAVOLTA e T. MURAOKA, 1987. Efeito da micorriza vesiculo-arbuscular na cinética de absorção de fósforo pela soja. In: Programa e Resumos da II Reunião Brasileira Sobre Micorrizas. São Paulo, SP. pp. 23.

FERNANDES, A.B.; J.V. e N.C. SCHENCK, 1987. Relação entre a ocorrência de MVA e caracteristicas de solo, planta e manejo de lavouras cafeeiras do sul do Estado de Minas Gerais. In: Programa e Resumos da II Reunião Brasileira Sobre Micorrizas, São Paulo, SP. pp. 5. 
FURLAN, V. e J.A. FORTIN, 1973. Formation of endomycorrhizae by Endogone calospora on Allium cepa under three temperatures regimes. Naturaliste Canadien, 100: 467-477.

GERDEMANN, J.W., 1964. The effect of mycorrhiza on the growth of maize. Mycologia, 56: 342-349.

GERDEMANN, J.W., 1968. Vesicular-arbuscular mycorrhiza and plant growth. Ann. Rev. Phytopath., 6: 397-418.

GERDEMANN, J.W. e T.H. NICOLSON, 1963. Spores of mycorrhizal Endogene species extracted from soil by wet sieving and decanting. Trans. Brit. Mycol. Soc., 46: 235-244.

GERDEMANN, J.W. e J.M. TRAPPE, 1974. The endogonaceae in the Pacific North-west. Mycol. Mem. no 5. New York Botanical Garden and the Mycological Society of America, New York, p. 76.

GILMORE, A.E., 1971. The influence of endotrophic mycorrhizae on the growth of peach seedlings. J.Am. Soc. Hort. Sci., 96: $35-38$.

GRAHAM, J.A.; R.T. LEONARD E J.A. MENGE, 1981. Membrane-me diated decrease in root exudation responsible for phospho rus inhibition of vesicular-arbuscular mycorrhize formation. Plant Physiol., 68: 548-552.

GREEN, N.E.; S.O. GRAHAM E N.C. SCHENCK, 1976. The influence of $\mathrm{pH}$ on the germination of vesicular-arbuscular mycorrhizal spores. Mycologia, 68: 929-934.

HALL, I.R., 1977. Species and mycorrhizal infection of New Zealand Endogonaceae. Trans. BI. Mycol. Soc. , 68: 341-356. 
HARLEY, J.L e S.E. SMITH, 1983. Mycorrhizal symbiosis. Academic Press, London. $483 \mathrm{p}$.

HAYMAN, D.S., 1970. Endogone spore numbers in soil and vesicular-arbuscular mycorrhiza in wheat as influenced by sea son and soil treatment. Trans. Br. Mycol. Soc., 54: 53-63.

HAYMAN, D.S., 1974. Plant growth responses to vesicular-ar buscular mycorrhiza. IV. Effect of light and temperature. New Phytal., 73: 71-80.

HAYMAN, D.S., 1982. Influence of soils fertility on activity and survival of vesicular-arbuscular mycorrhizal fungi. Phytopathology, 72(8): 1119-1125.

HAYMAN, D.S. e B. MOSSE, 1971. Plant growth responses to vesicular-arbuscular mycorrhiza. I. Growth of Endogone inoculated plants in phosphate deficient soils. New Phytol., 70: 19-27.

HEPPER, C.M., 1979. Germination and growth of Glomus caledonium spores: the effects of inhibitions and nutrients. Soil Biol. Biochem., 11: 269-277.

HEPPER, C.M. e G.A. SMITH, 1976. Observation's on the germinanation of Endogone spores. Trans. Br. Mycol. Soc., 66 (2): 189-194.

HOLLEY, J.D. e R.L. PETERSON, 1979. Development of vesiculararbuscular mycorrhiza in bean roots. Can J. Bot., 57: 19601978.

HOWELER, R.H., 1981. The effect of mycorrhizal inoculation on the phosphorus nutrition of cassava. In: RUSSEL, R.S.; IGUE, K \& MEHTA, Y.R. (eds.). The soil/root system relation to brazilian agriculture. Instituto Agronômico do Paraná, Londrina. p. 243-258. 
JEHNE, W., 1984. Mycorrhizas and Stylosanthes. In: STACE, H. M. \& EDYE, L.A. (eds). The Biology and Agronomy of Stylosanthes. Academic Press, Sidney. pp. 227-241.

KOSKE, R.E. 1981. Gigaspora gigantea: observations on spore germination of a VA-mycorrhizal fungus: Mycologia, 73:288300 .

KRUCKELMANN, H.W., 1975. Effects of fertilizers, soils, soil tillage, and plant species on the frequency of Endogone chlamydospores and mycorrhizal infection in arable soils. In: SANDERS, F.E.; MOSSE, B. \& TINKER, P.B. (eds). Endomy corrhizas. Academic Press, London. p. 511-525.

LAMBERT, D.H.; D.E. BAKER e H. COLE Jr., 1979. The role of mycorrhizae in the interactions of phosphorus with zinc, cop per, and other elements. Soil Sci. Soc. Am. J., 43: 976980 .

LAMBERT, D.H. e H. COLE Jr., 1980. Effects of mycorrhizae on establishment and performance of forage species in mine spoil. Agron. J., 72: 257-260.

LAMBERT, D.H.; H. COLE Jr. e D.E. BAKER, 1980. Adaptation of vesicular-arbuscular mycorrhizae to edaphic factors. New Phytol., 85: 513-520.

LOPES, A.S., 1983. Solos sob "cerrado": caracteristicas, propriedades e manejo. Instituto Internacional da Potassa, Piracicaba, pp. 162. 
MALUF, A.M.; A.P.D. SILVEIRA e I.S. MELO, 1987. Influência do $\mathrm{pH}$ e da micorriza vesículo-arbuscular no desenvolvimento de cultivares de Leucaena leucocephala (LAM.) DE WIT tolerante e intolerante ao aluminio. In: Programa e Resumos da II Reunião Brasileira sobre Micorrizas, são Paulo, SP, pp. 38.

MENGE, J.A., 1978. Commercial production of mycorrhizal inoculum may benefit citrus growers. Citrograph, 15: 139-143.

MENGE, J.A.; D. STEIRLE; D.J. BAGYARAJ; E.L.V. JOHNSON e R.T. LEONARD, 1978. Phosphorus concentrations in plants responsible for inhibition of mycorrhizal infection. New Phytol., 80:575-578.

MOSQUIM, P.R.; A.T. CORDEIRO; L. ZAMBOLIM; M.M. BELLEI E J.C.L. NEVES, 1986. Influência do alumínio sobre o crescimento e a micorrização de Stylosanthes guianensis associado a Rhizo bium. In: Anais da I Reunião Brasileira sobre Micorrizas, Lavias, MG, Pp. 160.

MOSSE, B., 1957. Growth and chemical composition of mycorrhi zal and non-mycorrhizal apples. Nature, 179: 922-924.

MOSSE, B., 1962. The establishment of vesicular-arbuscular mycorrhiza under aseptic conditions. J. Gen. Microbiol., 27: $509-520$.

MOSSE, B., 1970. Honey-coloured sessile Endogne spores. I. Life history. Archiv fur mikrobiologie, 70: 167-175.

MOSSE, B., 1972. Effects of different Endogone strains on the growth of Paspalum notatum. Nature, 239: 221-223.

MOSSE, B., 1973. Advances in the study of vesicular-arbuscular mycorrhiza. Ann. Rev. Phytopath., 11: 171-196. 
MOSSE, B., 1975. Specificity in VA mycorrhizas. In: SANDERS, F.G.; MOSSE, B. \& TINKER, P.B. (eds.). Endomycorrhizas. Aca demic Press, London. p. 470-484.

MOSSE, B., 1977. Plant growth responses to vesicular-arbuscular mycorrhiza. $X$. Responses of Stylosanthes and maize to inoculation in unsterile soils. New Phytol., 78: 277-288.

MOSSE, B., 1981. Vesicular-arbuscular mycorrhiza research for tropical agriculture. Res. Bull. (Hawaii Institute of Tropi cal Agriculture and Human Resources), 194, p. 81.

MOSSE, B.; C.L. POWELL e D.S. HAYMANS, 1976. Plant growth responses to vesicular-arbuscular mycorrhizas. IX. Interactions between VA mycorrhiza, rock phosphate and symbiotic ni trogen fixation. New Phytol., 76: 331-342.

NAVARRO, R.B.; I.C. PIMENTEL. I.C. REGO E S.M.T. SAITO, 1987. Efeito do pH na germinação de esporos de fungos em solo da Amazônia. In: Programa e Resumos da II Reunião Brasileira Sobre Micorrizas, São Paulo, SP. pp. 102.

NEMEC, S., 1978. Response of six citrus root stocks to three species of Glomus, a mycorrhizal fungus. Proc. Fla. State Hort. Soc., 91: 10-14.

OLIVEIRA, E., 1986. Taxonomia da Endogonaceae. In: Anais da I Reunião Brasileira Sobre Micorrizas. Lavras, MG. pp. 100119 .

OLIVEIRA, M.H.A. e E.J.B.N. CARDOSO, 1986. Efeito de fosfato de rocha e micorriza na simbiose soja $\times$ Rhizobium japonicum. In: Anais da I Reunião Brasileira Sobre Micorrizas, Lavras, MG, pp. 161 . 
PACKOVISKY, R.S., 1986. Micronutrient uptake and distribution in mycorrhizal or phosphorus-fertilized soybeans. Plant and Soil, 95: 379-388.

PROBERT, M.E., 1984. The mineral nutrition of Stylosanthes. In: STACE, H.M. \& EDYE, L.A. (eds). The Biology and Agronomy of Stylosanthes. Academic Press, Sydney. pp. 203-226.

RATNAYAKE, M.; R.T. LEONARD e J.A. MENGE, 1978. Root exudation in relation to supply of phosphorus and its possible relevance to mycorrhizal formation. New Phytol., 81: 543-552.

REEVES, F.B.; D. WAGNER; T. MOORAN E J. KIEL, 1979. The role of endomycorrhizae in revegetation practices in the semi-arid West. I. A comparison of incidence of mycorrhizae in severely disturbed natural environments. Am. J. Bot., 66: 66-73.

REID, C.P. E G.D. BOWEN, 1979. Effect of soil moisture on VA mycorrhiza formation and root development in Medicago. In: HARLEY, J.L. \& RUSSELL, R.S. (eds). The soil-root interface. Academic Press, London. p. 211-219.

RHODES, L.H. e J.W. GERDEMANN, 1975. Phosphate uptake zones of mycorrhizal and non-mycorrhizal onions. New Phytol., 75: 555561 .

ROSS, J.P. E J.A. HARPER, 1970. Effect of Endogone mycorrhiza on soybean-yields. Phytopathol., 60: 1552-1556.

SAFIR, G.R. e J.M. DUNIMAY, 1982. Evaluation of plant response to colonization by vesicular-arbuscular mycorrhizal fungi. $B$. Environmental variables. In: SCHENCK, N.C. (ed.). Methods and principles of micorrhizal research. The Amer. Phytopath. Soc. St. Paul. p. 77-80. 
SAIF, S.R., 1981. The influence of soil aeration on the efficiency of vesicular-arbuscular mycorrhizae. I. Effect of soil oxygen on the growth and mineral uptake of Eupatorium odoratum $L$. inoculated with Glomus macrocarpus. New Phytol. 88: $649-659$.

SAIF, S.R.; SHEIKH, N.A. e A.G. KHAN, 1975. Ecology of Endogone. I - Relationship of Endogone spore population with physical soil factors. Islamabad J. Sci., $2(1): 1-5$.

SANDERS, F.E., 1975. The effect of foliar-applied phosphate on mycorrhizal infections of onion roots. In: SANDERS, F.E,; MOSSE, B. \& TINKER, P.B. (eds.). Endomycorrhizas. Academic Press, London. pp. 261-276.

SCHENCK, N.C.; S.O. GRAHAM e N.E. GRENN, 1975. Temperature and light effect on contamination and spore germination of vesicu lar-arbuscular mycorrhizal fungi. Mycologia, 67: 1189-192.

SCHENCK, N.C. E V.N. SCHORODER, 1974. Temperature response of Endogone mycorrhiza on soybean roots. Mycologia, 66: 600-605.

SILVEIRA, A.P.D. e E.J.B.N. CARDOSO, 1987. Efeito do fósforo e da micorriza vesiculo-arbuscular na simbiose Rhizobium-feijoei ro. R. bras. Ci. Solo, 11: $31-36$.

SILVEIRA, A.P.D.; E.J.B.N. CARDOSO e V. FAQUIN, 1987. Influência da micorriza VA no desenvolvimento do feijoeiro e nos parâmetros cinéticos de absorção radicular de fósforo. In: Pro grama e Resumos da II Reunião Brasileira Sobre Micorrizas.São paulo, SP. pp. 26. 
SIQUEIRA, J.0., 1986. Micorrizas: forma e função. In: Anais da I Reunião Brasileira Sobre Micorrizas. Lavras, MG. pp. 5-32.

SIQUEIRA, J.P., 1987. Cultura axênica e monoxênicas dos fungos micorrizicos vesiculo-arbusculares. In: Programa e Resumos da I Reunião Brasileira Sobre Micorrizas. São Paulo, SP. pp. $44-70$.

SIQUEIRA, J.0.; D.H.HUBBELL e A.W. MAHMUD, 1984. Effect of liming on spore germination, germ tube growth and root colo nization by vesicular-arbuscular mycorrhizal fungi. Plant and Soil, 76 : $115-124$.

SIQUEIRA, J.O.; D.H.HUBBELL e N.C. SCHENCK, 1982. Spore germination and germ tube growth of a vesicular-arbuscular my corrhizal fungus in vitro. Mycologia, 74: 952-959.

SIQUEIRA, J.0.; D.H. HUBBELL e R.R. VALLE, 1984. Effects of phosphorus on formation of the vesicular-arbuscular mycorrhizal symbiosis. Pesq. agropec. bras., 19: 1465-1474.

SIQUEIRA, J.O.; D.M. SYLVIA; J. GIBSON E D.H. HUBBELL, 1985. Spores, germination and germ tubes of vesicular-arbuscular mycorrhizal fungi. Can. J. Microbiol., 31: 965-972.

St. JOHN, T.V. E D.C. COLEMAN, 1981. The role of mycorrhizae in plant ecology. Proc. of the $5^{\text {th }}$ North American Conference on Mycorrhizae, Universite Laval, Quebec. snt.

SWARD, R.J., 1981. The structure of the spores of Gigaspora margarita. III. Germ-tube emergence and growth. New Phytol. 88: $667-673$. 
SWARD, R.J.; N.D. HALLAM e A.A. HOLLAND, 1978. Endogone spo res in a heathland area of south-eastern Australia. Aust. J. Bot., 26: 20-43.

TIMMER, L.W.e R.F.LEYDEN, 1978. Stunting of citrus seedlings in fu migated soils in texas and its correction by phosphorus fer tilization and inoculation with mycorrhizal fungi. J. Am. Soc. Hort. Sci., 103: 533-537.

THOMAS, D., 1984. Global ventures in Stylosanthes. I. South America. In: STACE, H.M. \& EDYE, L.A. (eds.). The biology and Agronomy of Stylosathes. Academic Press, Sydney. pp. $451-466$.

TRAPPE, J.M., 1981. Mycorrhizae and productivity of arid and semiarid rangelands. In: USDA Forest Service, (ed.). Advances in food producing systems for arid and semiarid lands. Academic Press, New York. pp. 581-599.

WAIDYANATHA, S.; N. YOGARATNAM E W.A. ARIYARATNE, 1979. Mycorrhizal infection on growth and nitrogen of Pueraria and Stylosanthes and uptake of phosphorus from two rock phospha tes. New Phytol., 82: 147-152.

WANG, G.; S. WANG; D.P. STRIBLEY E P.B. TINKER, 1986. Efeito do $\mathrm{pH}$ do solo sobre micorriza vesicular-arbuscular (VA). In: Anais da I Reunião Brasileira Sobre Micorrizas. Lavras, MG. pp. 194 . 
WILCOX, H.E., 1983. Fungal parasitism of woody plants roots from mycorrhizal relationship to plant disease. Ann. Rev. Phytopathol., 21: 221-242.

WOOLHOUSE, H.W., 1975. Membrane structure and transport problems considered in relation to phosphorus and carbohydrate movements and the regulation of endotrophic mycorrhizal associations. In: SANDERS, F.E.; MOSSE, B. \& TINKER, P.B. (eds.). Endomycorrhizas. Academic Press, London. pp. 209239. 